\title{
Navigating the seascape of ocean management: waypoints on the voyage toward sustainable use
}

\author{
Steven Katona ${ }^{1}$, Johanna Polsenberg ${ }^{1}$, Julia S. Lowndes ${ }^{2}$, Benjamin S. Halpern ${ }^{2,3,4}$, Erich \\ Pacheco $^{1}$, Lindsay Mosher ${ }^{1}$, Anna Kilponen ${ }^{1}$, Katherine Papacostas ${ }^{1,5}$, Ana Gloria Guzmán- \\ Mora $^{1}$, Ginny Farmer ${ }^{1}$, Luca Mori ${ }^{6}$, Olive Andrews ${ }^{6}$, Sue Taei ${ }^{6}$ and Sarah Carr ${ }^{7}$
}

${ }^{1}$ Conservation International (CI), 2011 Crystal Drive, Suite 500, Arlington, VA 22202; ${ }^{2}$ National Center for Ecological Analysis and Synthesis, University of California at Santa Barbara, Santa Barbara, CA, USA; ${ }^{3}$ Bren School of Environmental Science and Management, university of California at Santa Barbara, Santa Barbara, CA, USA; ${ }^{4}$ Department of Life Sciences, Imperial College London, Silwood Park, U.K.; ${ }^{5}$ Current address, NOAA-NMFS, Silver Spring, MD, USA and ECS Federal LLC, Fairfax, VA, USA; ${ }^{6}$ Conservation International New Zealand Ltd., University of Auckland School of Biological Sciences, Private Bag 92019, Auckland, NZ 1142; ${ }^{7}$ Network Coordinator, Coastal-Marine EBM Tools Network, co-coordinated by NatureServe and OpenChannels.

March 23,2017_Corresponding author Steven Katona: skatona@conservation.org or steven.katona1@gmail.com.

\begin{abstract}
Some societies have sustainably managed their local marine resources for centuries using traditional methods, but we are only beginning to learn how to do it at larger scales, including globally. A broad, deep and constantly growing body of ocean knowledge has developed, adding many new concepts, perspectives, management models and analytical tools into the knowledge base in a relatively short period. Such rapid growth has created a potentially confusing mash-up of ideas, acronyms, techniques, tools and regulations, demonstrated by recent titles such as, 'Marine planning: tragedy of the acronyms' (Ardron 2010), 'Integrated marine science and management: wading through the morass' (Elliott 2014), 'Beyond rhetoric: navigating the conceptual tangle towards effective implementation of the ecosystem approach to oceans management ' (Engler 2015) and 'Marine legislation - the ultimate "horrendogram" (Boyes and Elliott 2014, undated and 2016).
\end{abstract}

The purpose of this paper is to assist policy makers, marine managers and those considering careers in this area by providing a short history of ocean management, its conceptual foundation, frameworks for modern management and examples of its application at different scales. Extensive literature exists to supplement the summarized information we present.

We highlight the following terms as navigational markers through the 'seascape' ${ }^{\text {'1 }}$ of marine management rhetoric: sustainability, ecosystem approach, ecosystem-based management, natural capital, ecosystem services, integrated ecosystem assessment, the causal framework DPSIR (Drivers, Pressures, States, Impacts, Responses) and its variants, indicators and reference points, marine area planning, marine spatial management (including decision support tools), adaptive ocean management and dynamic ocean management. We also point out the important roles of marine initiatives such as Blue Economy, the Ocean Health Index, Large Marine Ecosystems, Seascapes, Protected Areas and others. Understanding the similarities, differences, relationships and synergies among these activities increases the likelihood of achieving successful management processes or solutions.

1 We use 'seascape' (lower case) to describe the panorama of concepts, acronyms, techniques, tools and regulations germane to marine management. 'Seascape' and 'Oceanscape' (upper case) signify specific programs for integrated management at large-scales. 
Further knowledge and additional methods are still needed to safeguard the human-ocean system and the benefits it provides to people particularly with continued global population growth, but better awareness of what we already know will speed collective progress toward healthier oceans and coastlines. Working toward that goal can also be a uniting force in an increasingly divisive world, because it must necessarily breach political, geographic, economic and other differences.

\section{THE BIRTH OF OCEAN MANAGEMENT}

Many cultures with intimate relationships to the sea and high dependence on it have managed marine resources effectively for centuries using traditional methods. Hawaiians, for example, practiced extraordinarily sophisticated customary management systems based on traditional ecological knowledge (TEK) of habits, spawning periods and locations for each target species and socially assigned rights to use, access or own specified areas (customary marine tenure, CMT) (Friedlander, Schakeroff and Kittinger 2013). TEK, CMT and other traditional methods continue to be used by hundreds of villages and communities in the Indo-Pacific, Indian Ocean and elsewhere, including those that employ Locally Managed Marine Areas (LMMA) to manage fisheries or access to other marine products in traditional ways, supporting families, communities, coastal economies and broader scale food security for their nations (Rocliffe et al. 2014). These systems are characterized by strong community-based participation; use of local and traditional customs in making decisions about fishing practices, resource status and responses to environmental degradation; and use of techniques such as establishing marine reserves, enacting periodic closures of areas or fisheries, establishing communitybased aquaculture and others.

Because the human population grew, colonized, industrialized, urbanized and globalized, additional management systems were needed to address increasingly complex situations and broader geographic scales. Here we trace the origins of these newer systems while acknowledging that the demonstrated success of traditional governance and management still has much to teach anyone working in the marine policy and management area and vice versa. $^{2}$

The anchor line for modern ocean management is braided from strands of thought that emerged sequentially, gaining strength as one joined another to form the environmental movement, eventually extending into the ocean the attention and concerns originally focused on land. Below we mention 5 key strands.

First strand to emerge was awareness of pressures and human impacts, spurred by Rachel Carson's warnings about the effects of widespread pollution from chemical pesticides (Carson, 1962). Silent Spring transformed the way humans viewed our role in the world and began a half-century of awakening that created the environmental movement and underlies modern marine and terrestrial management. The human population then was 3.14 billion, about $42 \%$ of today's 7.4 billion, but we were already beginning to collide with the natural world in new ways.

Second was growing concern about limits to resources. In 1966, American economist Kenneth Bolding stated, "Los Angeles has run out of air, Lake Erie has become a cesspool, the oceans are getting full of lead and DDT, and the atmosphere may become man's major problem in another generation, at the rate at which we are filling it up with gunk," and presented the metaphor of Earth as a spaceship with limited resources that could not withstand the pressures of overproduction, overconsumption, and pollution (Bolding 1966).

2 Equally important, incorporation of scientific methods into traditionally-based management systems, as Kittinger et al. (2015) discussed for sites in the Marquesas Islands, Philippines, Indonesia and Hawai'i and Schemmel et al. (in press) detailed in Hawai'i, indicates that the resulting 'hybrid' management, if properly done, improves the potential for conserving not only target species, but also biodiversity, species richness and overall biomass (Kittinger et al. 2015). 
Bolding's spaceship metaphor gained strength with Buckminster Fuller's (1968) statement, 'Now there is one outstandingly important fact regarding Spaceship Earth, and that is that no instruction book came with it." Also that year, publication of The Population Bomb (Ehrlich 1968) dramatically illustrated that the ship was becoming dangerously overcrowded. Just in the 6 years since publication of Carson's book, the human population had increased by 401 million, nearly $13 \%$.

With a steadily growing movement calling for management of theselooming problems at the planetary scale, global concern peaked in 1972 to produce one of the most significant years in environmental history, dramatically recognizing Earth's finite resources and inserting human well-being into environmental discussions.

In April, Limits to Growth (Meadows et al. 1972) used computer-simulations to warn that industrialization, pollution, resource depletion and food shortage associated with excessive growth of the human population would destabilize global systems by approximately 2050 or slightly later.

In June, the first United Nations Conference on the Human Environment, held in Stockholm, Sweden, laid the groundwork for nearly all future global environmental actions by adopting the Declaration of the United Nations Conference on the Human Environment. The Declaration listed principles to inspire and guide preservation and enhancement of the human environment. An equally significant product was creation of the United Nations Environment Programme (UNEP). The book Only One Earth: The Care and Maintenance of a Small Planet (Ward and Dubos, 1972), prepared for the conference, was influential in popularizing concepts that later became known as sustainable ${ }^{3}$ development.

In December, NASA's 'blue marble' photograph taken by the Apollo 17 crew from 28,000 miles skyward gave Earthlings the first view of our ocean-dominated planet and its weather patterns. Said to be the most viewed image in human history, this photo of our dynamic, vibrant and colorful planet surrounded by endless black space instantly became the symbol of the growing environmental movement.

Biological diversity emerged as a third strand of thought, as public alarm about impending extinctions of whales, pelicans, peregrine falcons and others led the newly created United Nations Environmental Program (UNEP) to conclude the Convention on International Trade in Endangered Species (CITES 1973).

Concerns about whales brought oceans into the new environmental agenda. Millions joined the environmental movement, motivating passage of the U.S. Marine Mammal Protection Act of 1972 and the International Whaling Commission's 1982 moratorium on commercial whale hunting, which took effect in 1986 and continues today. Also in 1982, the UN Convention on the Law of the Sea (UNCLOS 1982), which entered into force in 1994, defined the geographic framework for ocean management and specified the rights of nations for different uses of ocean zones out to 200 miles seaward from their coastlines.

Elimination of the boundary between people and
nature formed a fourth strand. In 1983 the UN
established the World Commission on Environment

3 The central precept of sustainability is that development promoting human well-being today must not compromise opportunities available to future generations. The services and benefits supporting people and all life on earth flow from stocks of living and non-living resources that form Earth's natural capital (discussed below). Benefits will only be available to future generations if each generation at least maintains, but where possible increases the natural capital it inherited. Sustainably delivering a range of benefits now and in the future can only be done by people in partnership with nature, because people need nature to thrive. 'Sustainability' though not an exciting word, nevertheless encapsulates that partnership and serves as a pole star guiding us toward living within planetary limits, working toward a more enlightened and beneficial future for ourselves and treating species and living systems responsibly and respectfully. See World Ocean Review (2015) for additional history and perspective on the concept of sustainability. 
and Development whose 1987 report, Our Common Future ('Gruntland Report') marked a turning point in ecological thought by collapsing any differences between 'natural ecology' and 'human ecology'. Organized around the interrelationships between poverty, hunger, conflict, economic growth, resources, pollution, health, biodiversity and energy, and highlighting examples of promising solutions, the report laid the foundation for all future progress toward planetary scale management. It also codified a fifth strand of thought, the need for sustainability and sustainable development.

Our Common Future formed the basis for the 1992 U.N. Conference on Environment and Development ("Earth Summit"), its Rio Declaration on Environment and Development and world recognition of "the integral and interdependent nature of the Earth, our home, and the necessity of working towards international agreements which respect the interests of all and protect the integrity of the global environmental and developmental system." A global work plan, Agenda 21 , was adopted by vote of 178 governments to address all those issues and improve social justice and equity while doing so. Its Chapter 17, "Protection of the oceans, all kinds of seas, including enclosed and semienclosed seas, and coastal areas and the protection, rational use and development of their living resources," was a significant advance for oceans. Whereas ownership and resource use on land and freshwater had long been regulated and managed, the ocean's vast size suggested that its resources were boundless and inexhaustible,${ }^{4}$ a belief that retarded development of marine management for centuries.

Also introduced for signature at the 1992 Earth Summit was the Convention on Biological Diversity (CBD) which came into force the next year with the goals of conserving biological diversity, using its components sustainably and sharing benefits derived from genetic resources fairly and equitably. By reinforcing the key role of biodiversity to human well-being, CBD became the foundation for global goals to establish protected areas on land and at sea.

Agenda 21 was reaffirmed in 2002 at the U.N. Conference on Sustainable Development in Johannesburg ('Earth Summit 2002' also called 'Rio+10'), where the Millennium Development Goals (MDG) were unveiled to eliminate extreme hunger and poverty, achieve universal primary education, promote gender equality and empower women, reduce child mortality, improve maternal health, combat HIV/AIDS, malaria and other diseases, ensure environmental sustainability and develop a global partnership for development.

Agenda 21 was again reaffirmed in 2012 at the 'Rio+20' conference in Rio de Janeiro ('Earth Summit 2012'). Shortly afterwards, the UN General Assembly Outcome Document, The Future We Want amplified many of Agenda 21's themes, including Oceans and Seas (Items 158-180), while calling for holistic and integrated approaches to sustainable development that will guide humanity to live in harmony with nature and lead to efforts to restore the health and integrity of the Earth's ecosystem."

Rio+20 and The Future We Want also developed the 'Green Economy' concept for building economic development that contributes to eradicating poverty, increasing social inclusion, creating opportunities for employment and improving human welfare while maintaining the healthy functioning of Earth's ecosystems. The concept of "Blue Economy" was subsequently developed to recognize the potential of oceans to contribute to the same goals, particularly for small island developing nations (SIDs), but also for sustainable use of resources in areas beyond national jurisdiction (the High Seas). Blue Economy (or synonyms used in various regions (e.g. Blue Agenda, Blue Frontier) all attempt to include corporations,

4 "There is the sea. Who will drain it dry? It gives us crimson dye in huge amounts, as valuable as silver, inexhaustible. With that we dye our garments. And of these our house has a full store, thanks to the gods. We are rich. We have no sense of poverty," (Clytemnestra after speaking with Agamemnon (Aeschylus (400 B.C.). More than two millennia later: "It is obvious that the resources of the sea are vast and inexhaustible as itself, and that the extent to which those fisheries could be profitably worked would be bounded only by the amount of capital embarked in them," quoted in Royal Commission on Irish Oyster Fisheries (1870); and "I believe, then, that the cod fishery, the herring fishery, the pilchard fishery, the mackerel fishery, and probably all the great sea fisheries, are inexhaustible; that is to say, that nothing we do seriously affects the number of the fish. And any attempt to regulate these fisheries seems consequently, from the nature of the case, to be useless," (Huxley 1883). 
industries and economies within the larger goal of building sustainable economic development consistent with maintaining marine environmental health.

Eleven (11) countries also signed the Global Ocean Commission's 'Because the Ocean' declaration, calling for the Intergovernmental Panel on Climate Change (IPCC) to complete a Special Report on the relationship between ocean and climate as well as a UN Conference on Oceans and Seas in June 2017 in Fiji to promote the ocean's importance of oceans for climate regulation.

Capping four decades of deliberations were two remarkable global agreements, slow in coming perhaps, but hugely important for the future.

First, on September 25, 2015, more than 150 world leaders at the United Nations Sustainable Development Summit adopted the 2030 Agenda for Sustainable Development, which includes 17 Sustainable Development Goals (SDG) and 169 associated targets to end poverty, increase equality and justice, and protect the environment and climate by 2030. The SDGs build on MDG accomplishments, but go farther to deal with root causes of poverty and the need for kinds of development that are broadly appropriate. Indicators ${ }^{5}$ to use in evaluating progress are still in development.

SDG Target 14 is specifically devoted to conserving and sustainably using the oceans, seas and marine resources for sustainable development. Its broadlyframed objectives include reducing pollution, protecting and restoring marine and coastal ecosystems, strengthening resilience, reducing ocean acidification, ending harmful fishing practices and conserving $10 \%$ of coastal and marine areas. Meeting those objectives will not only achieve Target 14, but also enable progress toward other goals, since the SDGs reinforce each other in many direct or indirect ways.
Then in December, 2015, 195 nation signed the UN Framework Agreement on Climate Change at the 21st Conference of Parties (Paris COP21) obligating their countries to act in ways that keep global warming well below $2 \mathrm{C}^{\circ}$ and to try to limit it to $1.5 \mathrm{C}^{\circ}$. It was the first such agreement to include the ocean.

Thus by 2015's end, spaceship earth had at last developed an agreed-upon outline for its operating manual. Just as the "blue marble" photograph portrayed major patterns of global structure and atmospheric circulation, five decades of actions had codified the major objectives for managing Earth's future: reducing anthropogenic pressures, recognizing limits to resources, preserving biodiversity and improving of all aspects of human well-being. Most important, all would be approached with acknowledgement of the connectedness between people, nature and all aspects of the planetary system, in which oceans play a central role.

\section{DEVELOPMENT OF MODERN MARINE MANAGEMENT}

Modern marine management is young, changing rapidly and adapting to meet rising challenges: human population growth, accelerated migration to the coasts, increased competition for shore land and access to coastal waters, amplified pressures-including climate change-on coastal and marine habitats and the activities they support. Maximizing ocean value will require alleviating pressures; allocating scarce resources in ways that are strategic, equitable and sustainable; balancing private property rights with social interests; and honoring jurisdictional rights of communities, municipalities, states and nations.

Two fundamental concepts-Ecosystems and Ecosystem-based Management (EBM)-undergird management approaches to meet those challenges at sea as well as on land.

$5 \quad$ Socioecological systems are too large and complex to permit holistic assessment, so selected indicators are used to represent aspects of the system. Where possible, indicators are directly related to the aspect they represent, e.g. amount of carbon dioxide in the atmosphere as a measure of climate change. When direct measurements are not feasible, measurement of a different but functionallyrelated factor ('proxy indicator') must serve, e.g. per capita gross domestic product as an indicator of human well-being. A reference point (often called 'target') that represents the desired condition is selected for each indicator or proxy indicator. The value of each indicator is either obtained by objective measurement, estimated using a mathematical model or estimated subjectively using available expertise as possible. The status of each indicator is expressed as a ratio or other relationship between its measured and reference values. The suite of such measurements forms the empirical basis for assessing overall ecosystem status. 
The term 'ecosystem' was introduced in the 1930s, though the concept has much earlier roots (Willis 1997), to describe interactions between living and nonliving components of the natural environment. Strict delineation of ecosystems is somewhat arbitrary, since few such assemblages are sufficiently bounded to eliminate all interactions with others. Nevertheless, Earth is usefully described as a nested distribution of biophysical systems, using 'ecosystem' to describe groupings that are long-lived and closely intra-related historically, functionally and structurally.

An ecosystem is a dynamic complex of plants, animals, microbes and physical environmental features that interact with one another. Humans are an integral part of ecosystems, marine and terrestrial. Interconnectedness within and among ecosystems is provided by the physical environment (e.g. water currents transporting larvae or nutrients), biological interactions (predation, migration, species invasions) and stressors produced by human activities (e.g. climate change, pollution) (MEA 2005, McLeod et al. 2005, Halpern et al. 2008).

Examples of marine ecosystems range in size from microbiomes of bacteria, viruses and other tiny organisms through seagrass beds or mangrove forests to the 232 Ecoregions $^{6}$ described for marine coastlines and nearshore waters (Spalding et al. 2007) and the 64 Large Marine Ecosystems (LEM) (Sherman et al. 2005) that are generally $200,000 \mathrm{~km}^{2}$ or greater and overly the continental shelves out to about $200 \mathrm{~nm}$. Newly described Ecological Marine Units (EMUs) ${ }^{7}$ may be another way to characterize marine ecosystems, because their distinctive physical and chemical compositions suggest that each may be a relatively closed system.

But today no area of the oceans is unaffected by human influence and nearly all of it is affected by multiple pressures (Halpern et al. 2008, 2015). Humans are now a dominant force altering climate worldwide, probably affecting large-scale atmospheric movements such as monsoons (Looya et al.2015), large scale oceanographic currents such as the Atlantic Meridional Overturning Circulation (AMOC) (Cheng et al. 2013, Haine 2016, Hand 2016), perhaps influencing local earthquakes (US Geological Service), and leaving ubiquitous chemical signatures of our activities (Zalasiewicz et al. 2010). Additionally, human influence is in part responsible for altering wild populations by invasions and extinctions (Zalasiewicz et al. 2016), such that the geological period beginning about 1950 (but much earlier in some views) is termed the 'Anthropocene Age' (Zalasiewicz et al. 2010; Williams et al. 2016, Voosen 2016).

Acknowledging that allecosystemsnowincludehumans directly and/or indirectly, policy and management have shifted away from focus on one species, sector, pressure or type of activity, to consideration of the ecosystem as a whole, including connections between its component species, connectedness to other systems (land, water and air) and explicit accounting of all the ways that humans affect, modify and benefit from it (Ehler and Douvere 2009, Kelble et al. 2013). This inclusive perspective, known as ecosystem-based management (EBM) is equally applicable on land or at sea.

The concept of 'ecosystem management' was pioneered in the early 1990s by the U.S. Forest Service as a comprehensive method to "blend the needs of people and environmental values in such a way that

6 'Ecoregions' are the smallest areas within the Marine Ecoregions of the World (MEOW) framework (Spalding et al. 2007) of biogeographically defined units. Largest are 12 'Realms' with distinctive evolutionary histories, coherent biota and many endemic genera or families. The realms contain 62 'Provinces' usually bounded by currents, upwelling, ice, nutrient regimes or geological isolation that contain distinct biotas and many endemic species. The 232 smaller 'Ecoregions' are frequently bounded by factors similar to those that separate provinces, but also by complexity of the coast or bottom, temperature, freshwater influx or other biogeographic factors. Endemism is less notable than in realms or provinces.

$7 \quad$ Ecological Marine Units (EMUs) are a newly defined set of ocean volumes identified by statistical clustering of chemical and physical data for all areas of the world ocean from surface to bottom. Analysis revealed 37 distinct, 3-dimensional EMUs within which chemical properties of the water are most likely to drive ecosystem response. Biological data remain to be added to EMU profiles, but perhaps they might be useful as management units in the future. You can explore EMUs here. 
the National Forests and Grasslands represent diverse, healthy, productive, and sustainable ecosystems" (Robbins 2013). Early attempts at implementation failed or met with public resistance and resentment because they were top-down, government-mandated, expert driven and did not include stakeholder participation (Meffe et al. 2015). Transitioning from solutions imposed by government to processes that encourage shared decision making, cooperation with the private sector and local communities, and focus on large, ecologically meaningful natural systems (e.g. watersheds) rather than artificially designated areasthough never easy-has produced many successes, as Meffe et al. (2015) and Robbins (2013) discuss. Those efforts, variously called 'ecosystem management', 'community-based conservation', 'adaptive management' or 'landscape-level conservation' have come to be known as 'ecosystem based management' (McLeod and Leslie (2009).

\section{Ecosystem-based management (EBM) (1)}

Protects ecosystem structure, functioning, and processes; (2) Recognizes interconnectedness within and among systems; (3) Integrates ecological, social, economic, and institutional perspectives; and (4) Is place-based or area-based (Ehler and Douvere 2007, adapted from COMPASS, 2005).

EBM shifts away from the traditional single-goal management approach (e.g. timber production, fisheries or shipping). In contrast, EBM aims to maintain ecosystems in healthy, productive and resilient states that can sustainably provide the maximal amount of a portfolio of services and benefits wanted by people (e.g. seafood, natural products, protection from storms, opportunities for tourism and recreation, jobs, revenue and intangible benefits such as sense of place) and also needed by the systems' non-human components (e.g. clean water, biodiversity) (Halpern

\section{BOX 1. Names used for approaches to integrated management of marine areas (listed alphabetically).}

Adaptive Ocean Management. Adaptive management is a systematic process for continually improving management policies and practices toward defined goals by learning from the outcomes of previous policies and practices (Pomeroy et al. 2013). Management planning must recognize the variability inherent in the biophysical, social and economic sectors of socioecological systems and the scientific uncertainty that resides in assessment of a system. Adaptive ocean management acknowledges the changes in conditions and knowledge that are likely to occur during the life of a plan by incorporating a schedule for periodic review and updating, as well as ad hoc opportunities for response to unanticipated events. Adaptive ocean management is thus an iterative process. Dynamic ocean management (see below) is a special case of adaptive ocean management that is particularly useful for managing species or processes that are predictably variable in time and space.

Coastal and Marine Spatial Planning (CMSP). CMSP is defined as "A public process of analyzing and allocating the spatial and temporal distribution of human activities in coastal and marine areas to achieve ecological, economic, and social objectives that are usually specified through a political process. Sometimes used inter changeably with marine spatial planning (MSP)" (Ehler and Douvere 2009).

Coastal Zone Management (CZM). CZM is the term used in the United States for managing coastal areas to balance environmental, economic, human health, and human activities according to the U.S. Coastal Zone Management Act of 1972, as

5 Long et al. (2015) discussed the history of EBM, identified 15 key principles and offered this more detailed definition: "Ecosystembased management is an interdisciplinary approach that balances ecological, social and governance principles at appropriate temporal and spatial scales in a distinct geographical area to achieve sustainable resource use. Scientific knowledge and effective monitoring are used to acknowledge the connections, integrity and biodiversity within an ecosystem along with its dynamic nature and associated uncertainties. EBM recognizes coupled social-ecological systems with stakeholders involved in an integrated and adaptive management process where decisions reflect societal choice." 
amended through Pub. L. No. 109-58, the Energy Policy Act of 2005. The marine "coastal zone" includes the waters, bottom, islands, intertidal, wetland, salt marsh and beach areas seaward to the outer limit of State title and ownership as elsewhere defined in various US laws; and inland to the extent necessary to control shorelands whose uses impact coastal waters or which are likely to be affected by or vulnerable to sea level rise.

Dynamic Ocean Management (DOM). Because the human-ocean system is dynamic, DOM is a management system that changes in space and time that responds to the shifting nature of the ocean and its users based on the integration of current biological, oceanographic, social, and/ or economic data. It can be particularly useful for managing species or oceanographic areas (feeding or breeding areas) that migrate or move in time. DOM can reduce conflicts by limiting restrictions to a sequence of small spatial areas rather than a large fixed-scale area Hobday et al. 2014).

Ecosystem Approach. This term describes a management strategy that integrates water, land, and all living resources and which promotes "conservation and sustainable use in an equitable way" (Convention on Biological Diversity). Ecosystem Approach is also used in the Regional Seas Conventions of OSPAR and HELCOM and by the European Commission 2009, Government of Ontario, Canada, and elsewhere.

Ecosystem-Based Approach. This term is used by the European Commission and the European Marine Strategy Framework Directive (MSFD).

Ecosystem-Based Management (EBM). EBM is the leading term used in the U.S. (COMPASS, 2005). Farmer et al. (2012) found no fundamental differences between EBM and Ecosystem Approach or Ecosystem-Based Approach, terms used more frequently in the EU and elsewhere.

Ecosystem-Based Fisheries Management
(EBFM). The U.S. National Oceanic and

Atmospheric Administration's National Marine Fisheries Service (NOAA-NMFS) uses this term to describe its ecosystem-based approach to fisheries management in the U.S.

\section{Ecosystem-Based Marine Spatial Management} (EB-MSM). EB-MSM, is defined by Katsanevakisa et al. (2011) as an approach that recognizes the full array of interactions in an ecosystem, including human uses, rather than considering single issues, species, or ecosystem services in isolation, and is supported by processes such as marine spatial planning, ocean zoning and marine protected areas (MPA) establishment, among others. EBMSM appears to be synonymous with the three previous entries.

Ecosystem stewardship. Although this term, defined by Chapin et al. (2016) as a 'framework for actively shaping trajectories of ecological and social change to foster a more sustainable future for species, ecosystems, and society" does not differ significantly from EBM, it is rooted in a more spiritual tradition of involvement with nature and may be carried out in a much less formal manner than, for example, marine spatial planning. The authors emphasize the key role of traditional knowledge and indigenous cultures for ecosystem stewardship of the Arctic.

\section{Integrated Coastal Zone Management} (ICZM). ICZM (also called Integrated Coastal Management $[\mathrm{ICM}])$ is the process of managing the coast and nearshore waters in an integrated and comprehensive manner with the goal of achieving conservation and sustainable use. ICZM was advocated at the 1992 Earth Summit in Rio de Janeiro, described in detail as part of Agenda 21 and defined by the European Commission as "...a dynamic, multidisciplinary and iterative process to promote sustainable management of coastal zones. It covers the full cycle of information collection, planning (in its broadest sense), decision making, management and monitoring of implementation. ICZM uses the informed participation and cooperation of all stakeholders to assess the societal goals in a given coastal area, and to take actions towards 
meeting these objectives. ICZM seeks, over the long-term, to balance environmental, economic, social, cultural and recreational objectives, all within the limits set by natural dynamics. 'Integrated' in ICZM refers to the integration of objectives and also to the integration of the many instruments needed to meet these objectives. It means integration of all relevant policy areas, sectors, and levels of administration. It means integration of the terrestrial and marine components of the target territory, in both time and space." ICZM appears to be synonymous with all terms listed save for Ocean Zoning and Adaptive Management.

Integrated Marine and Coastal Area Management (IMCAM). IMCAM, adopted and used by the Convention on Biological Diversity is defined as "a participatory process for decisionmaking to prevent, control, or mitigate adverse impacts from human activities in the marine and coastal environment, and to contribute to the restoration of degraded coastal areas. It involves all stakeholders, including: decisionmakers in the public and private sectors; resource owners, managers and users; non-governmental organizations; and the general public."

Marine Spatial Planning (MSP). MSP is the most widely used process for setting targets and implementing marine EBM in the U.S (National Ocean Council 2013), EU (Douvere et al. 2007), Australia, China and elsewhere.

Ocean Zoning. An important regulatory measure to implement comprehensive marine spatial management plans usually through a zoning map or maps and regulations for some or all areas of a marine region. Ocean zoning is one of the many tools available to MSP (Ehler and Douvere 2009).

Sea Use Management. Analogous to land use management in terrestrial areas, sea use management as defined by Ehlers and Douvere (2007):(1)Workstowardsustainabledevelopment, rather than simply conservation or environmental protection, and in doing so contributes to more general social and governmental objectives; (2)
Provides a strategic, integrated and forwardlooking framework for all uses of the sea to help achieve sustainable development, taking account of environmental as well as social and economic goals and objectives; (3) Applies an ecosystem approach to the regulation and management of development and activities in the marine environment by safeguarding ecological processes and overall resilience to ensure the environment has the capacity to support social and economic benefits (including those benefits derived directly from ecosystems); (4) Identifies, safeguards, or where necessary and appropriate, recovers or restores important components of marine ecosystems including natural heritage and nature conservation resources; and (5) Allocates space in a rational manner that minimizes conflicts of interest and, where possible, maximizes synergy among sectors. These authors consider sea use management to be an element of ecosystembased management and marine spatial planning (MSP) to be an element of sea use management.

Whole domain management. Conservation International uses "whole domain management" to describe integrated management both spatially and within the management agencies context, such that all key agencies coordinate to plan and manage a State's entire marine jurisdiction including islands, its territorial waters ${ }^{9}$, Exclusive Economic Zone ${ }^{10}$, seabed and terrestrial and watershed areas with significant connections to marine resources.

et al. 2010, 2012; McLeod et al. 2005, Rosenberg and McLeod 2005).

The rise of $\mathrm{EBM}^{8}$ has been accompanied by development of other similar names or processes, some largely synonymous (as was the case with ecosystem management), but others differing in one or more important ways (Box 1). Decreasing the number of terms in use could reduce confusion, but codification of some terms within national legislation or international agreements ensures their continued usage. 
Since it is not possible to manage marine ecosystems directly, but only how people use and behave toward them, Ehler and Douvere (2007) recommend 'sea use management' rather than 'ecosystem management' as the overarching term for such activities. However, the term 'ecosystem-based management' satisfactorily describes what needs to be done.

Regardless, all of the terms in use are frameworks for considering in an integrated manner whether and how to use and manage coastal habitat and marine waters. All depend on an inclusive process to identify a community's social and economic needs and goals as well as the likely or potential benefits and impacts of human use(s) on natural communities. All attempt to maximize social value, minimize conflicts between existing or proposed uses and minimize impacts on the natural environment. Those including the term 'coastal' generally refer to land and waters very near to the shore; those including 'sea' or 'ocean' may refer to waters further offshore.

The EBM concept implies a thoughtful and inclusive process, but does not prescribe a one-size-fits-all method. Instead, information and suggestions drawn from many examples describing what worked or didn't (lessons learned) and what worked best (best practices) help others shape their own processes (e.g. McLeod and Leslie 2009).
Because EBM attempts to maximize a portfolio of benefits and reduce or eliminate many kinds of pressures, many types of actions may be utilized. No single action can substitute for EBM or accomplish its goals. For example, establishing marine protected areas (MPA) will almost always be a necessary component of EBM, and will especially improve ocean health in areas where fishing is the dominant impact, but MPAs alone cannot restore fisheries (Hilborn 2016) or address the cumulative impacts and tradeoffs among all the benefits people want and need from ocean ecosystems (Halpern, Lester and McLeod 2010).

Conflicts are inherent in any system being evaluated or managed using EBM, including competition among public, private or corporate entities for access, space and economic benefits. Adjudicating conflicts involving money, land, access, environmental services and values, as well as environmental costs, requires detailed information from stakeholders as well as clear laws that specify the limits of what can be done and how.

Österblom et al. (2013) proposed a model for including social-ecological factors and scenarios into marine planning in a more powerful and integrated manner, including advocating equal value within the models for social and ecological factors. However, as Foley et al. (2010) caution, management must be based

8 Long et al. (2015) discussed the history of EBM, identified 15 key principles and offered this more detailed definition: "Ecosystembased management is an interdisciplinary approach that balances ecological, social and governance principles at appropriate temporal and spatial scales in a distinct geographical area to achieve sustainable resource use. Scientific knowledge and effective monitoring are used to acknowledge the connections, integrity and biodiversity within an ecosystem along with its dynamic nature and associated uncertainties. EBM recognizes coupled social-ecological systems with stakeholders involved in an integrated and adaptive management process where decisions reflect societal choice."

9 'Territorial waters' (also called 'territorial seas') refers to the band of water extending 12 nm seaward from the coast, over which nations have specific rights to regulate, police, and adjudicate issues and exclusive rights to control and exploit natural resources. See footnote 24 for further information.

10 The exclusive economic zone (EEZ) refers to waters beyond a state's territorial waters out to $200 \mathrm{~nm}(370.4 \mathrm{~km})$ from its coast. Within the EEZ, the coastal state has sovereign rights to explore, exploit, conserve and manage living and non-living natural resources of the seabed and waters, as well as to produce energy from the water, currents and winds. It can also establish and use artificial islands or other structures for economic or marine scientific purposes or to preserve the marine environment. However, within one country's EEZ, other states still maintain the traditional high seas freedoms, such as freedom of navigation and overflight and the freedom to conduct military exercises.

11 The target area for an EBM initiative may or may not correspond exactly with a complete 'ecosystem.' For example, small areas selected for study do not represent whole ecosystems; and even large areas described as ecosystems do not have sharp edges and therefore share some unmeasured (or unmeasurable) inputs and outputs with other systems. Regardless, the EBM approach studies an area as if it were an ecosystem, with consideration for its abiotic, biotic, non-human and human components and interactions. 
on ecological principles, because social and political goals cannot be accomplished without the support of a healthy, sustainable ecological foundation.

EBM always derives from a mandate that targets a specific geographic area whose scale may range from international or national (e.g. EU Marine Strategy Framework Directive; U.S. National Ocean Policy) to sub-national (e.g. Great Barrier Reef Plans of Management, Massachusetts Ocean Management Plan), or even more local (e.g. Pacific communities). There is often a mismatch between the scale of the area requiring management and the scale at which existing jurisdictions, governance structures, agreements, and key ecological, social and economic processes operate (Agardy 2005, Crowder et al. 2006, Leslie and McLeod 2007). Consequently each EBM process must be tailor-made for its particular environment. Finding better ways to address these mismatches is becoming increasingly important as marine area management becomes increasingly urgent ${ }^{11}$. As a rule of thumb, Halpern et al. (2014) recommend matching the scale of management to the scale where decisions are made, to ensure the inclusion of the processes into recurring fiscal cycles (for funding) as well as into discussions on resource management of larger scope.

EBM initiatives include three related activities: assessment, planning and management.

- Assessment measures ecosystem status, hopefully in relation to defined reference points (Samhouri et al. 2012), to serve as a baseline against which to measure future progress.

- Planning develops the rationale and broad social, political and environmental ideas about what needs to be done, why and where.

- Management entails taking specific actions-including monitoring and evaluation--to achieve changes in ecosystem status explicitly stated in the plan(s). Ideally, information from assessments is used to inform the management plan; and later to test whether the actions taken improved overall performance of the system.

Planning, assessments and management all explicitly recognize the system's human components by using the term 'integrated' as in 'Integrated Marine Planning'
(Dickinson et al. 2010) and 'Integrated Ecosystem Assessment (IEA)' (Levin et al. 2008, 2009). 'Integrated' eliminates the conceptual separation of 'humans' and 'nature' that prevailed prior to the 1960s. It identifies us as participants in the system not only through our negative impacts, but also by seeking and receiving benefits to human well-being in the same ways that other organisms do. It recognizes that human impacts harm not only wild species (e.g. bird populations [Carson 1962] or habitats (e.g. coral reefs [Burke et al. 2015]), but also the benefits that nature provides to people (e.g. UNEP 2014b).

Since ecosystems (including human needs and values) are dynamic, ecosystem-based management entails long-term commitment and a continual process that includes formal assessments repeated at regular intervals along with scheduled cycles of monitoring and evaluation (M\&E) (Kusek and Rist 2004).

\section{EBM AT SEA: MARINE SPATIAL PLANNING (MSP)}

Marine spatial planning (MSP) was pioneered in Western Europe by the United Kingdom, Belgium, Netherlands and Germany and has spread to at least 40 countries worldwide (Ehler 2014) to become the most commonly endorsed method for doing EBM in the ocean (Katsanevakisa et al. 2011, Flannery et al. 2016, Flannery and Ellis 2016). MSP is the public process of analyzing, organizing and allocating the spatial and temporal distribution of human activities in marine areas, often at fine spatial scales, to achieve ecological, economic and social objectives that are usually specified through a political process (Ehler and Douvere 2009, Fairgrieve 2016). Scales of application are usually chosen for geographic and socio-political reasons and are frequently too small to qualify as biological ecosystems, but the process typically honors EBM principles.

Assessing a marine ecosystem in an integrated manner is difficult, but managing it is harder still, because it entails balancing economic and ecological goals (Frank and Schlenker 2016), allocating limited space and resources and making decisions about who, how, where and when those resources can be used. Consequently, MSP is often contentious, since in most cases the 
combination of all individual production objectives is incompatible with the ecosystems' capacity to deliver the goods and services needed. As such, MSP requires achieving an optimal (sustainable) mix of outputs, taking into consideration different proposed uses, and the fact that the supply of marine and coastal space is fixed.

Guaranteeing an inclusive process with meaningful participation by as broad a representation of stakeholders as possible improves the likelihood of achieving binding agreements that accomplish desired goals, balance private rights and honor public interests. Indigenous people and others who have not always been consulted need to be included not only by being informed about the process, but also in producing maps, local and traditional information that will enrich the knowledge base that will inform the plan's foundation (Knol and Jentoft 2016, Brondizio and Le Tourneau 2016, Chapin et al. 2015).

The MSP process may draw upon a variety of spatial or temporal management tools ${ }^{12}$ in different circumstances, including establishing marine protected areas (MPAs), zoning, permitting of specific activities tied to specific times or areas within zones, dynamic management of geographic and/or temporal restrictions and others (Ehler and Agardy online discussion). UNESCO's worldwide list of MSP implementation provides links to dozens of initiatives on every continent.

Because MSP is an integrated, inclusive process that aims to balance the often-divergent needs of many stakeholders, including those of marine species, populations and habitats, it deserves time, patience, financial resources and effective leadership. Useful to any team contemplating an MSP initiative will be Ehler and Douvere's (2009) step-by-step guide to the MSP process and Ehler's (2014) manual on evaluating marine spatial plans.

The choice of spatial area to assess and manage usually derives from a particular mandate (e.g. MSFD requirements for EU Member states) or issue facing a nation, sub-national state, municipality or local community. Issues are often too local or restricted to garner attention or specific guidance from international groups or agreements; and large-scale (global, international, national) policy initiatives are usually not sufficiently granular to help those smaller constituencies. Finding better ways to address that mismatch (Agardy 2005) is becoming increasingly important as marine area management becomes more common or urgent. Even if the site to be studied does not strictly qualify as an ecosystem, the ecosystembased perspective can still guide the process and will often produce results of broader and greater value than less inclusive methods could achieve. White et al. (2011) noted that MSP creates its greatest benefits when done at large scale, but successes at much smaller scales that have been achieved using highly

\section{BOX 2. EBM, MSP and Blue Economy}

Nations frequently use the term 'Blue Economy' to represent their goals to increase economic benefits from the ocean, but what is it and how does it relate to EBM and MSP? Blue Economy began as a developing world initiative by Small Island Developing States (SIDS), but has extended beyond ocean-dependent economies to encompass a sustainable development framework that integrates conservation, subsistence use, and ocean-based sustainable production systems, including fisheries, tourism, oil and mineral wealth extraction, bioprospecting, sustainable energy production, and marine transport (UN 2012).

Because Blue Economy does not stipulate specific methods to evaluate status or sustainability, its success must be evaluated within the integrated management frameworks that have become the cornerstones of marine managementecosystem-based management (EBM) and

12 Use of the word tool can be confusing. Tools are created for specific purposes. Just as a carpenters need different tools for different tasks, e.g. pliers for grasping objects, hammers for pounding them, screwdrivers for fastening objects together with screws, etc., so marine managers require tools for monitoring indicators, analyzing data, assessing environmental status and formulating decisions and actions to improve ecosystem status and evaluating their success. Specifying the general purpose for each tool can reduce confusion. 
marine spatial planning (MSP). EBM is typically associated with concepts such as adaptive and integrated management, stakeholder involvement, and cross-sectoral collaboration (Long et al. 2015), and depending on the principles applied, the implementation of EBM framework can take many forms (e.g., EU Marine Strategy Framework Directive, Seascapes; refer to the 'Examples of EMB at various scales' section below). MSP is an instrument that balances different human activities in specified marine areas, e.g., areas within countries' Exclusive Economic Zones (EEZ), the borders between EEZ's and offshore regions, and it is often considered to be a mechanism to implement EBM to marine management (Maes 2008). Both EBM and MSP are cross-sectoral approaches which aim to balance ecological, economic, social and political goals. Thus EBM and MSP both support the emerging Blue Economy framework that promotes the sustainable development of ocean resources and the crucial role of integrated and multi-level approaches in marine economy and management. Efforts to stimulate Blue Economy development will provide opportunities for implementing or augmenting a variety of EBM and MSP projects by bringing together all the stakeholders from conservationists and other sectors to discuss long-term objectives and planning underpinned by best available science. Conversely, future expansion of many oceanrelated economic activities (e.g., aquaculture, shipping, energy extraction) is likely to increase the potential for conflict both between different economic sectors and between economic and nature conservation efforts. In this context, EBM and MSP approaches have the potential to facilitate the transition to Blue Economy by reducing conflict between different entities, and providing an operational framework to balance different ocean uses, development and marine protection.

Blue Economy as a label for sustainable marine sector development should not be confused with the book, The Blue Economy: 10 years - 100 innovations - 100 million jobs (Pauli 2010) which identifies the best nature-inspired technologies that could enhance economies and sustainably provide for human needs (e.g. jobs, pure water, food, shelter). Though projects accomplished include mangroves regeneration in Indonesia, conversion of islands to energy and water selfsufficiency in Spain, three-dimensional sea farming in Brittany and large scale seaweed farming programs, this valuable project does not focus exclusively on the ocean, instead taking its name from Earth's appearance as 'blue marble' when seen from space (G. Pauli personal communication).

local traditional and community-based management (Rocliffe et al. 2014, Schemmel et al. in press).

MSP processes can deliver substantial economic, ecological and social benefits. For example, Blau and Green's (2015) analysis of MSP results from Australia, Belgium, Norway and the US revealed economic gains averaging $\$ 60$ million per year in value from enabling new industries (primarily offshore wind) and retaining value in existing industries. Planning also increased marine protection, avoided use of sensitive areas, reduced carbon emissions, lessened risks from oil spills, and improved engagement with and trust among stakeholders. Some stakeholders suffered losses, but overall social gains were much larger. Quantitative analysis of tradeoffs can add further value to MSP. In a study of Massachusetts Bay, quantitative analysis of tradeoffs among alternative sites for offshore wind turbines, fisheries for flounder and lobster and whale watching could increase the potential benefits to the wind power sector by more than $\$ 10$ billion and also reduce potential losses to the other sectors by $\$ 1$ million or more (White et al. 2011).

For people to thrive, ecosystems must flourish. Given that each ecosystem contains different abiotic factors, species, habitats and human contexts, are there any common features that could be used to identify whether a system is thriving, and managed to improve its status?

At first glance, pressures might seem to be candidates, but since they do not indicate how the system benefits people, they are not a sufficient descriptor of system health. 
Instead, management now focuses on the two major things that pressures affect: natural capital $^{13}$ and environmental services (ES). Both are defined and examined with reference to people, though it would also be possible to consider them from the perspective of any other species. Together, they form the biophysical foundation for human well-being.

Throughout Earth's 4.5 billion year history, chemical reactions and evolutionary processes created a breathtaking array of physical and biological resources, including air, water, gases, minerals, hydrocarbons, soil and millions of species of living organisms ranging from the tiniest viruses and microbes to immense trees and whales. These stocks ${ }^{14}$ - our planet's 'natural capital' - underlie the success and further evolution of all life on land and in the ocean.

Natural capital includes the stocks of living and non-living resources that provide benefits and services needed by people and all life on Earth.

During recent centuries, technological development, population growth and changes in patterns of consumption accelerated human demand for living space and natural capital to the point that abundance of some stocks, including liquid fresh water, biodiversity, helium, easily accessible hydrocarbons, biodiversity and some habitats are being depleted regionally or globally.

The value and importance assigned to natural capital stocks may vary owing to changes in demand, new development in knowledge and technology or other factors. For example, deposits of rare earths (neodymium, praseodymium and others) were probably not recognized as natural capital until they became essential for developing super-magnets, lasers, super conductors and other technology. Similarly, though living species and habitats were always recognized and appreciated as natural capital, even before the term was coined, advances in understanding, such as the crucial role of blue carbon ${ }^{15}$ for climate regulation or discovery of useful genes or medically important compounds from a species can quickly change perspectives regarding such stocks. The unforeseen potential existing in nearly all of Earth's living and non-living resources calls for a cautious approach to using them and a vigorous emphasis on conserving them.

Time- and place-based stocks of living and non-living matter are not the only source of benefits to human well-being. Dynamic geophysical characteristics also provide essential support for life. Thermal currents in Earth's molten core move crustal plates, building mountains and gouging ocean trenches rich with minerals and chemotrophic life. Earth's rotation, axial tilt, and revolution around the sun generate the large scale winds and ocean currents that power seasonal change, climatic zones, fresh water regimes, and ocean oxygenation and nutrient regeneration, while the Moon's revolution contributes tidal energy and cycles. These and other benefits flowing or drawn from stocks of natural capital are known as ecosystem services (ES).

Nature sustains life and human well-being by providing at no $\operatorname{cost}^{16}$ a range of marketable goods, such as fish, timber and other natural products; services that are less easily marketable or non-marketable such as carbon

13 Other types of 'capital' recognized by economists include real or built capital (machines, factories, infrastructure; cultivated natural capital (commercial forests, fields, vineyards, aquaculture); social capital (political institutions, social communities and strength), human capital (personal skills and education), and knowledge capital (libraries, universities, accumulated knowledge) (World Ocean Review 2015; Costanza et al. 2014).

14 Natural capital may be further categorized as renewable or self-regenerating resources (living organisms), non-renewable resources (minerals such as metal or oil), original (free-flowing rivers, natural habitats such as primary forests), cultivated (shaped by human activity, sources (e.g. minerals from the mountains), sinks (e.g. mangrove habitats or the ocean for long-term storage of carbon dioxide) and stocks (e.g. animal populations) (World Ocean Review 2014), but for present purposes all are described as 'stocks.'

15 Plants retard global warming by capturing and sequestering carbon dioxide from the atmosphere. About $55 \%$ of all biological carbon captured (termed 'green carbon') is captured by marine plants, so it is called 'blue carbon.' Mangrove forests, seagrasses and salt marshes capture nearly all blue carbon (Nelleman et al. 2009; Laffoley and Grimsditch 2009). 
storage, nutrient cycling, and coastal protection; and intangible cultural benefits such as support of aesthetic, traditional or spiritual values. These beneficial goods and services, which flow from an ecosystem's stocks of natural capital, are known as Ecosystem Services (ES).

ES are usually framed in human terms as a flow of goods or services from the environment to people, e.g. 'the benefits people derive from ecosystems' (MEA 2002), but many would still exist even without humans, because they mutually support all life on Earth. Nevertheless, many of their interactions with humans seem unique. For example, many ES do not flow simply from natural capital to individual people (human capital), but also interact in complex ways with our communities (social capital) and our built environment (built capital) (Costanza et al. 2014). In any case, the future status of ecosystems now depends on how well humans understand and analyze ES and use that information to modify our relationships to natural capital and planetary systems appropriately.

The Millennium Ecosystem Assessment raised ES to global attention and categorized them into four general types: provisioning (e.g. goods such as food and water); regulating (e.g. climate regulation); supporting (e.g. pollination, nutrient cycles); and cultural (e.g. spiritual, aesthetic and recreational benefits).

Regardless of that categorization, ES are not delivered individually, but come as interactive bundles such that changes in one may affect many others, increasing or decreasing their flow(s) in a variety of manners (symmetric, asymmetric, linear, synergistic etc.). Even qualitative knowledge about such interactions can inform efforts to manage ES and other socioenvironmental goals (Nilsson et al. 2016).
Just as the flow of interest from a savings account depends on the amount of money in the account and current rate of interest, the flow of one or more ES from a stock of natural capital depends on the stock's size and condition. However, other factors also affect it, including the size, condition and ES flow from other stocks, societal demand (and price) for the ES and often other factors. If sufficiently well understood, these factors can be assembled into an equation termed the 'production function' that links a stock with its ES.

Among the services provided by marine ecosystems are protein, calories and micronutrients (Golden et al. 2016) from seafood (including food from mariculture) and other natural products; opportunities for artisanal fishing, recreation, tourism, shipping and marinerelated jobs; nutrient cycling and waste filtration; long-term carbon storage that slows climate change; protection of coastlines from flooding and erosion; and intangible values to culture, tradition and spirit (Beaumont et al. 2007, Chan and Ruckelshaus 2007, Halpern et al. 2012). Maintaining or restoring sustainable flows of such services and benefits should be a central goal for decision-making (Hancock 2010) including for marine ecosystems (Chan and Ruckelshaus 2010).

\section{MEASURING NATURAL CAPITAL AND ECOSYSTEM SERVICES}

Stocks of natural capital are tangible and separately measurable (in theory at least) using biophysical units native to each one (e.g. numbers of whales, biomass of herring, hectare ${ }^{17}$ of mangrove forest). Some stocks also possess 'existence value' based on intangible (cultural) factors such as iconic importance, ability

16 Nature freely provides ES to people even though using them may entail cost. The natural capital stocks from which they flow may be replenishable or not. ES flow from a non-replenishable stock diminishes its value, but income or products from their use transfers some of that value to stocks of goods, built infrastructure and social capital that may be accounted for more or less easily using normal accounting methods. The transferred gains could equal the natural capital losses in financial terms, but accounting should also consider broader implications of the non-replaceable loss to natural stocks.

18 A Coelocanth (AMS IB,7555) captured off the Comoros Islands was purchased by the Australian Museum in 1965 and exhibited in Sidney. Visitors nicknamed it the 'wishing fish' and dropped coins through a crack in the case of the display tank to make a wish, valuing the fish for intangible, non-economic reasons (e.g. rarity, interest as a "living fossil." The coins discolored the liquid in the tank so the practice was stopped. 
to inspire reverence, awe or aesthetic appreciation, contribution to biodiversity or others. For example the stock(s) of coelacanth (Latimeria chalumnae Smith 1939) has symbolic value as a 'living fossil' rather than for any tangible use. ${ }^{18}$

Until recently nations have not measured natural capital, but instead measured wealth only as the monetary value of all goods and services produced each year (Gross Domestic Product, GDP). GDP does not account for losses associated with depletion of natural capital assets (Barbier 2014) even though resources used in creating such goods and services are generally drawn from those stocks. As a result, depleting a fishery, or destroying a mangrove for timber, is counted as a net economic gain in national accounts (GDP), even though the long-term benefits provided by those intact resources may exceed their immediate monetary value.

Natural Capital Accounting responds to that important omission by treating the biomass or deposits of each resource (e.g. fisheries, minerals, water) as an account and measuring whether its stock is being conserved, depleted or replenished. ${ }^{19}$ Some measurable benefits (e.g. climate amelioration, marine productivity, renewable energy) flow from dynamic geophysical processes (e.g. winds, currents, tides, hydrothermal vents) that are not easily represented as standing stocks of natural capital. Similarly, benefits such as cultural, traditional or spiritual value (e.g. 'sense of place') may not correlate with measurable aspects of natural capital. Nevertheless, natural capital accounting would produce a fuller description of national wealth than GDP, particularly for tangible assets whose value can be expressed in physical or monetary terms.

Unfortunately, the internationally agreed set of standards - the System of National Accounts (SNA)-for how to compile measures of economic activity, including national income and savings, only includes physical processes in which human labor and assets are used to transform inputs of goods and services into outputs of other goods and services that can be sold on markets or traded at no charge. Natural capital can thus appear as an input and cost of production, but since it is not treated as an account(s), countries have no agreed upon way to record or track decreases or increases in its status. The UN Statistical Commission of the System for Environmental-Economic Accounts (SEEA) has developed methods for including marketable natural resources in national wealth accounting; and the Wealth Accounting and Valuation of Ecosystem Services (WAVES 2016) partnership initiated by the World Bank is seeking ways to include natural resources that are not traded or marketed as well as ecosystem services into such accounts. For example, measuring social capital and how equitably the benefits from natural assets are shared could add further value to future descriptions of national wealth. Valuation case studies prepared by TEEB (The Economics of Ecosystems and Biodiversity) (TEEB 2010) are intended to make nature economically visible and show the economic rewards available from responsible stewardship of natural capital. Lu et al. (2016) suggest developing a 'gross marine product' (GMP) index for use by decision makers, the private sector and the public in meeting SDG 14 and other goals. Despite this progress, Colgan (2016) summarizes many technical difficulties that must be overcome before such integration is achieved and cautions that it will not occur quickly.

In most cases, natural capital stocks are measured primarily to value or predict the flow of benefits (ES and others) that they provide (e.g. the amount of fish that can be caught from the existing stocks or the potential tourism opportunities offered by a population of whales). However, several factors complicate measurements of ES and their use for integrated assessment of ecosystem status. Here we highlight four main complications.

First, intangible 'existence' benefits are frequently

19 Current thinking emphasizes 'strong sustainability', i.e. each natural capital stock needs to be conserved, as opposed to 'weak sustainability' where only the sum total of all natural capital stocks needs to be held constant, with any decreases in one stock replaced by services derived from another stock (World Ocean Review 2014). Expressed slightly differently, 'soft' sustainability assumes that losses of natural capital stocks can be compensated by improvements in technology, economic growth or other human contributions; whereas 'hard' sustainability assumes that man-made capital cannot substitute for natural capital, e.g. construction of a swimming pool(s) cannot replace loss of a pond or lake; consequently, growth in man-made capital must not harm natural capital and the ES it provides (Qiu and Jones 2013). Since services are not always replaceable, 'strong' or 'hard' sustainability is a more prudent model. 
omitted from ES valuations owing to the difficulty in measuring them, even though they may sometimes be partially valued with willingness to pay, willingness to accept compensation ${ }^{20}$ or other contingent valuation methods. Their omission precludes full evaluation of ecosystem worth. Moreover, 'existence value' stocks may not enjoy the same attention and protection as stocks yielding ES of high monetary value.

Second, although ES are bundled, the only way to assess their overall benefit is to evaluate the individual components (e.g. Fisheries Performance Indicators (Anderson et al. 2015), Integrated Biodiversity Assessment Tool [IBAT], Coastal Economies [Kildow et al. 2016] and others). However, since individual services are measured in different ways and with different units, their values cannot be directly combined into an integrated assessment without an additional step.

For example, the Ocean Health Index (Halpern et al. $2012,2015 b$ ), which is to date the most comprehensive measure of how sustainably nations are maximizing their sustainable flows of ocean benefits, and other synthetic indices (Fernández-Macho et al. 2015) accomplish this by eliminating the different units of measurement. Values for each data layer are transformed from 0 to 1 with respect to a specific reference point. Units of measurement disappear during this transformation, so that numeric values for the different layers are easily combined into an integrated value that ranges from 0 to 1 (communicated as a 0 to 100 scale), again with reference to a specified reference point.

Third, many factors guarantee that uncertainty will always surround results of integrated ecosystem assessments, with data providing the first challenge. Assessments must often use data gathered opportunistically by individual researchers, laboratories or agencies based upon tradition, interest, proximity, available technology, incentives or other factors. Consequently, data frequently differ in resolution, scale, precision, accuracy and documentation, varying geographically, culturally, temporally and in other ways. Such differences complicate or constrain the creation of databases, especially at the global level.

Further uncertainty accrues from the numerous assumptions, data inputs and sub-models needed to assess each ES, aggregation of ES-each with its own uncertainty -into the integrated assessment, cultural variations in the supply, demand and value assigned to each ES, lack of knowledge about trade-offs between services and other linear or non-linear effects. Finally, the likely, but unpredictable and uncontrollable occurrence of chance events, especially when any system parameters approach thresholds or tipping points (Rockstrom et al. 2009, Hicks et al. 2016) guarantees that future states cannot be predicted exactly regardless of how reliable current estimates appear to be. Frazier et al.s (2016) method for analyzing the contribution of missing data to uncertainty in Ocean Health Index results and Burgass et al.s (2017) review of uncertainty in composite environmental indicators provide valuable insights to this thorny problem.

Fourth, ES may extend well beyond the location of the natural capital stocks that produced them. For example, young fish sheltered along a coral reef or in a seagrass meadow may complete their life cycle far away and contribute to catches in other countries halfway across the world. Carbon dioxide sequestered in soil below a mangrove forest is not dedicated to climate mitigation in its immediate vicinity, but instead contributes to slowing climate change worldwide.

These challenges should not detract from the importance of assessing ES and improving their measurement over time, so that integrated assessment becomes a regular process to be repeated-and improved-at specified intervals.

20 Willingness-to-pay (WTP) estimates the maximum amount of money that people are willing to pay in exchange for a certain state or good for which there is normally no market price (TEEB 2010), such as saving polar bears or protecting a coastal area held to be sacred by a culture. Willingness to accept compensation (WTA) estimates the minimum amount required for an individual to forgo such a benefit or bear some harm. 


\section{VALUING NATURAL CAPITAL AND ECOSYSTEM RESOURCES}

Measurement of the magnitude of a stock of natural capital or the flow(s) of benefits it provides ${ }^{21}$ is important as a benchmark in itself and as a potential indicator of whether the stock is being used sustainably. However, the resulting measurements may not be adequate for policy making and management without some method of common valuation that permits comparison between different benefits as well as expression of aggregated benefits.

As noted earlier, data transformations permit comparisons and aggregation by eliminating the units associated with different types of stocks or flows, but the output can only be expressed in a relative way, as on a scale from 0 to 100 , and policy makers or managers may also desire evaluation in more tangible terms.

In theory any ES could serve as a "common denominator" with all others expressed in terms of its units (Costanza et al. 2014), but only a few have been used, including land area (UNEP 2014a); ecologicallyweighted land area ('ecological footprint' comparing the areas of land or sea needed to balance a region's production and consumption as well as the time needed to produce what it consumes); energy (UNDP 2000) or flow of materials such as carbon, nitrogen and phosphorus (see Rockstrom et al. 2009). Evaluation in those terms reveals whether a system is operating within safe biophysical boundaries, but cannot express the system's economic benefits or costs.

Consequently, expression of ES in monetary terms is the valuation method most frequently attempted, despite the bias that ES with tangible benefits usually dominate such assessments since they are easier to measure and convert to monetary equivalents. Tangible goods measured directly in biophysical units (e.g. tonnes of fish) are easily monetized using market equivalents (usually US\$); and indirect tangible benefits, such as coastal protection or carbon storage, can be converted to monetary values by determining avoided damages or replacement costs associated with each hectare of measured habitat, e.g. how much does each unit of mangrove forest contribute to fish and wildlife populations, carbon sequestration, protection of people and property from storm waves, recreational opportunities and others).

However, intangible benefits are difficult to monetize so they are frequently omitted (as is also the case in studies based on other terms). Many culturally related benefits, including spiritual, traditional or non-monetary cultural values associated with places, iconic species or other environmental features, as well as "existence values" such as biodiversity or clean water have rarely or ever been valued with economic methods (Frank and Schlenker 2016) and only a few, such as recreation and eutrophication reduction have been extensively valued monetarily. Thus policy makers intending to improve environmental status in the Baltic Sea (Sagebiel et al. 2016) were unable to include such factors and other studies are likely to encounter the same problem.

Despite its fundamental importance, biodiversity is an ecosystem feature that is challenging to monetize, because its intangible aspects (existence values, cultural and iconic significance of species) are difficult to price and because economic valuations of ecosystem services will not always favor biodiversity conservation (Adams 2014). Consequently, ecosystems cannot be sustainably managed exclusively using economic valuation: social, political and ecological values must also be included. As Frank and Schlenker (2016) concluded, "economic growth is a crucial ingredient for preservation, but does not guarantee it."

Despite these problems, economic valuations command attention because money is so fundamental to human societies and because the magnitude of ES values is impressive.

\section{ESTIMATING ECONOMIC VALUE OF ECOSYSTEM SERVICES}

Costanza et al's (1997) pioneering estimate of the minimum average annual value of global ES as \$33 trillion (in 1995 \$US) - nearly twice world Gross

21 In practice, the aggregated value of $\mathrm{ES}$ is of most interest, since the value of natural capital stocks themselves is derived from the value of the flows of services they provide. 
National Product (GNP) at that time-underlined the crucial importance of such benefits and the key role they should play in decision-making (Hancock 2010) on land and in marine ecosystems (Chan and Ruckelshaus 2010). Ocean-based ES represented 63\% ( $\$ 18$ trillion/yr) of that estimate.

Costanza et al. (2014) used updated data on habitat losses and unit values of ES related to each habitat to provide an updated global estimate of $\$ 125$ trillion/ yr (updated areas and unit values) to $\$ 145$ trillion/ yr (updated unit values only) (values in 2007 \$U.S.), with marine ES comprising $40 \%$ and $42 \%$, respectively, of those flow values. Those results did not include any of the intangible benefits and existence values so important to human culture and well-being, so the global value of ES is likely even higher than reported. Despite the impressive valuations, Costanza et al. (2014) emphasized that monetary expression of ecoservices should not be taken to imply privatization or commodification of what should best be considered and managed as public goods or common pool resources.

Because most valuation studies, including Costanza et al. (2014) do not assess the full range of ecosystem services, TEEB (2010) stressed that valuation is most useful for assessing the consequences of changes resulting from alternative management options, rather than estimating the system's total value. In that regard, Costanza et al.'s (2014) estimated annual losses of ES value from 1997 to 2011 ranged from $\$ 4.3$ trillion/yr using 1997 unit values to 20.2 trillion/yr using 2011 unit values, with marine systems showed the sharpest losses ( $\$ 10.9$ trillion/yr), resulting mainly from decreases in coral reef area and the substantially larger unit value for coral reef habitat used in 2011.

Whereas global value of ES is important as a wakeup call, alerting us to the enormous subsidies that human society receives from nature, regional ES valuations affect societies more directly. They are also more complicated, owing to geographic, as well as cultural and temporal (Hein et al. 2016) differences in the availability and perceived importance of various ES and their amenability to economic valuation. For those reasons, valuation studies must be tailored to the specific study region and will therefore differ substantially among regions in their composition, goals and results. Nevertheless, Schuster and Doerr's (2012) guidance on the evaluation process, including general concepts, methods for stakeholder engagement, socioecologic goal setting, metrics, study design, methods for valuation and relevant case studies has widespread utility.

Particularly illustrative of the process and its significance are economic valuation studies of the ES provided by oyster reefs in the U.S., including wave attenuation, shoreline stabilization and erosion reduction, habitat provision for commercial and recreational fish and shellfish, improvement of water clarity and removal of nitrogen. Economic comparison of the costs and benefits of restoring lost oyster beds is typically the primary goal. Taking all ES into account, Grabowski et al. (2012) estimated that restored and protected oyster reefs provide value ranging from $\$ 10,325$ to $\$ 99,421$ per hectare, depending on where the restored reef is located and the suite of ES that it provides. Given data cited by Grabowski et al. (2012) that 85 percent of the world's oyster reefs have been destroyed, restoring even a portion of them could yield substantial socioecological benefits.

Adding to the difficulty of regional economic valuation is the lack of a common method for classifying and assessing ecosystem services (Sagebiel et al. 2016). Those authors reviewed all economic valuation studies available for the Baltic Sea and found that only recreation and reduction of eutrophication had been economically evaluated, and even those studies were not mutually consistent methodologically. They concluded that without a coherent methodological framework, economic evaluation studies would only be of limited use to Baltic Sea policy makers, a caution that is probably broadly applicable.

Current shortcomings probably constrain the usefulness of economic ES valuations to managers. For example, Marre et al. (2016) stated that most decision makers in Australia knew about economic valuation and considered it useful or necessary in decision making, but rarely used it. As methods and knowledge improve, economic valuations of ES may become easier to carry out and use, but merely being aware of the high values determined elsewhere is likely to influence management decisions toward sustainability. 


\section{MANAGING NATURAL CAPITAL AND ECOSYSTEM SERVICES}

Effective management requires good knowledge of the system that is best gained through assessment and planning.

- Assessment uses measurements to gauge a system's present condition in relation to explicit targets or reference points (Samhouri et al. 2012). Initial assessment defines the scope of the system to be studied, specifies clear goals and measurable targets, identifies indicators, locates appropriate data and creates models and software that relate those inputs to system performance. The Ocean Health Index (Halpern et al. 2012, 2015) exemplifies such a process.

- Planning outlines the objectives, processes, degree of inclusiveness, timeline, budget and other practical and political aspects of how the system's status could be maintained or improved at maximal productivity and sustainability, as locally defined.

- Management builds on assessment and planning, as well as continued cycles of monitoring and evaluation, to take strategic and tactical actions designed to maintain or restore system status while attempting to meet the needs of all stakeholders.

Marine and coastal areas have traditionally been assessed and managed for a single objective, the best example being seafood production. Beginning in the early 1900s with observational studies of catches, year classes, body condition and other indicators, fisheries science has developed increasingly effective assessment techniques, population models and management strategies. Where carefully applied, e.g. North Pacific Fishery Management Council, a model process for stock assessment review, fisheries can thrive. According to Hilborn (2016) effective management has improved the status of stocks in many parts of the world, nearly eliminating overfishing in the US, Atlantic fisheries of the EU, New Zealand, Australia, Iceland, Norway and Canada, with important progress also evident in Peru, Argentina and Chile, though management still remains inadequate in much of the world.

To develop more predictable, sustainable harvests, progressive fisheries management is beginning to expand its longstanding focus on maximizing current production to also consider cumulative effects on other fisheries and non-fisheries stocks, tradeoffs across various management regimes and human uses and impacts of management decisions on human systems. For example, in the U.S. such considerations, termed Ecosystem-Based Fisheries Management, undergird the mission of NOAA Fisheries.

Although evaluation of several ES simultaneously, such as tourism and biodiversity, has also occurred (e.g., Secretariat of the Convention on Biological Diversity 2015), the trend has been toward increasingly comprehensive efforts that include as many ecosystem services and benefits as possible. Comprehensive assessments thus measure the physical, biological and social attributes of the defined study area, evaluate the status of the current array of specific ecosystem services that the system provides and illustrate changes in those services likely to result from specified changes in conditions or use. Assessment results along with a similarly inclusive plan enable integrated management to occur.

Efforts to manage natural capital confront a key philosophical choice between achieving 'weak sustainability' and 'strong sustainability (World Ocean Review 2015).' Weak sustainability only requires the sum total of a society's capital stocks to be held constant, such that destruction of natural capital stocks could be replaced by real or human capital (e.g. a destroyed lake or beach could be replaced by a swimming pool, or the aesthetic benefits of a rain forest or coral reef could be replaced by a virtual electronic media experience). In contrast, strong sustainability aims to conserve all stocks of natural capital whether or not they might be substitutable by human means. Strong sustainability of natural capital maximizes the potential for naturebased solutions to social and ecological problems while not obviating the potential for human ingenuity. 


\section{BOX 3. Qualitative Assessments}

Quantitative assessments are most useful for guiding management, but qualitative (narrative) assessments can be a good way to begin the process. For example, at the broadest scale, the first stage of the UN World Ocean Assessment (UNWOA1 2015) provides detailed narrative assessments of nearly every aspect of the current status of the human-ocean system. Its 53 chapters discuss major ecosystem services, hydrologic, atmospheric and geological processes, nutrient cycling and plankton production, food production (seaweeds, fisheries, aquaculture), industrial activities (shipping, ports, cables, pipelines, offshore oil and gas, renewable energy, desalinization, genetic resources), tourism and recreation, marine debris and pollution, geographic patterns of biodiversity, scientific research, species of special importance (marine mammals, sharks and elasmobranchs, seabirds, tuna and billfishes, marine reptiles), ecosystems and habitats of special importance (cold water corals, tropical and sub-tropical coral reefs, estuaries and deltas, hydrothermal vents and seeps, ice habitats, kelp forests, seagrass meadows, mangroves, salt marshes, Sargasso Sea, seamount communities) along with overall assessments of the value of the oceans to people and human impact on the oceans. WOA1 does not provide the level of detail needed to assess ES in a particular area, but provides a comprehensive discussion of human-ocean interactions at the global level. Moreover, attention to its summaries of capacity building needs in relation to human activities affecting the marine environment (Ruwa et al. 2015a) and in relation to the status of species and habitats (Ruwa et al. 2015b) can increase the value of assessments, planning and management at any scale. WOA plans to complete a second stage following review of lessons learned during its first stage.

\section{PUTTING IT ALL TOGETHER: CONCEPTUAL FRAMEWORKS FOR INCORPORATING QUANTITATIVE ECOSYSTEM ASSESSMENT INTO MANAGEMENT}

By the 1990s, pressures, environmental deterioration, natural capital, ecosystem services and humanwell-being were broadly discussed, but a common framework for analyzing their interactions was lacking. That changed in 1993 when the Drivers-PressureState-Impact-Response (DPSIR) framework appeared.

\section{DPSIR}

DPSIR (Fig. 2) was developed by the Organization of Economic Cooperation and Development (OECD, 1993) and the European Environment Agency (EEA, 1995) as a logically organized framework to describe the flow of causes and effects through a system, including human feedback. It was recommended by the UN sponsored Assessment of Assessments (UNEP and IOC-UNESCO 2009), which began the Regular Process that produced the first World Ocean Assessment (UNWOA 2015). It continues to be widely used, especially in coastal socio-ecological systems within the EU (Patricio et al. 2016, Sirak et al. 2014), sometimes with modifications or in concert with other methods.

Drivers (often called 'Driving Forces') are needs, contexts and forces acting in the background, such as population growth, patterns of consumption, and economic or political influences that operate at all scales $^{22}$ and influence human behavior and activities. Such behaviors and activities cause Pressures ${ }^{23}$ within the study system. Pressures change the system's State (often called 'status'), causing Impacts, which in turn stimulate Responses. All involve both natural and human features of the system, but analysis focuses mainly on impacts that affect humans and responses

22 Since DPSIR can be used at any scale, Drivers for a smaller system may include regional or local phenomena, such as political mandates, economic circumstances or others in addition to those of global significance.

23 "Pressures" are the forces applied to an organism, habitats or other components of the ecosystem. Stresses caused by those pressures affect ecosystem functions at all levels. Because pressures create stress, they are sometimes called "stressors." For continuity with the DPSIR model we recommend using 'pressures.' 
by humans that mitigate or adapt to those changes. Pressures acting within a system may originate elsewhere (e.g. invasive species) and may be too large or distant to be remediable from within the system itself (e.g. ocean temperature or $\mathrm{pH}$ ).

'Response' has special importance for two reasons: it is the only arena where humans can improve overall system function, utility and sustainability; and it

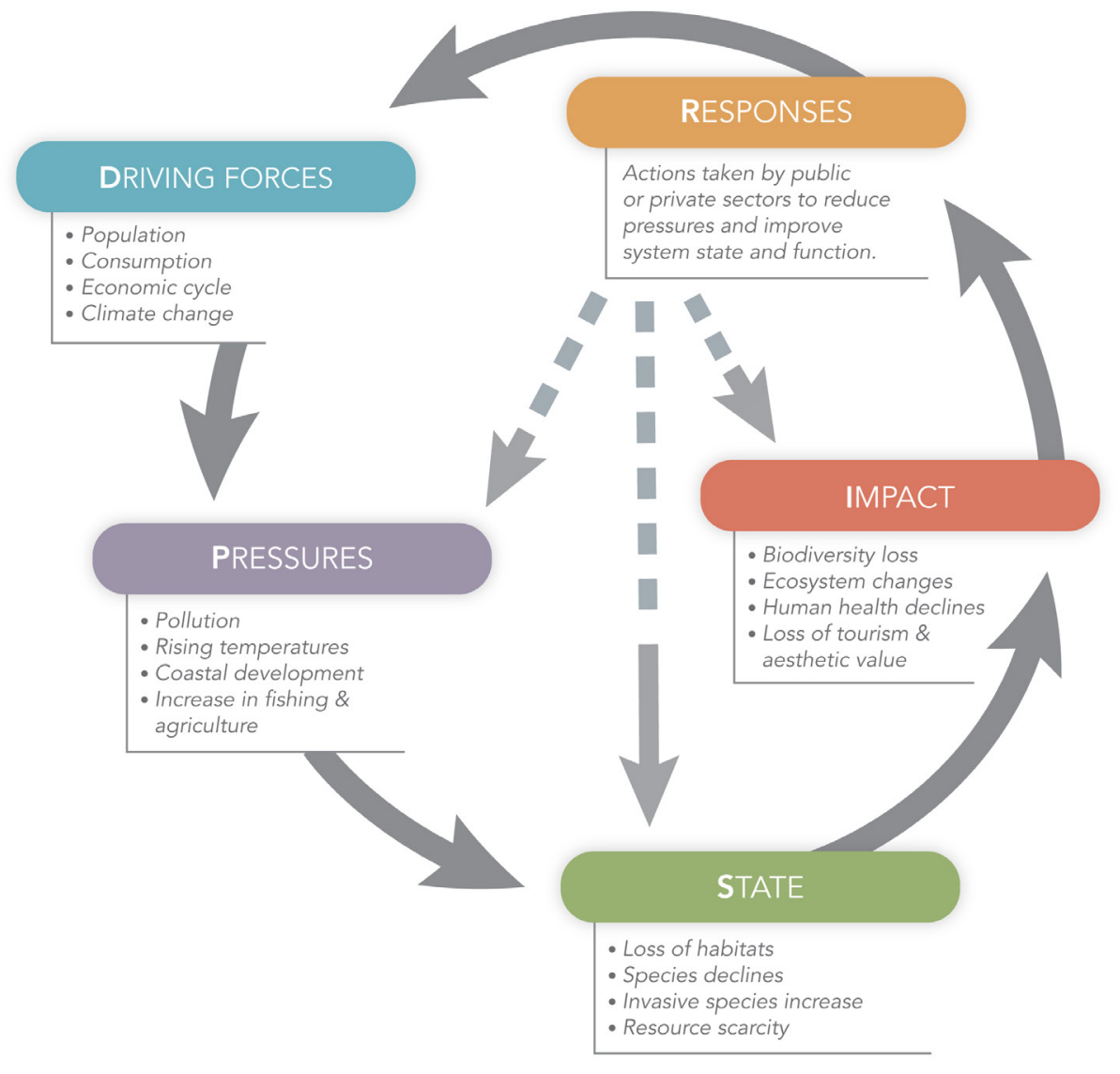

Figure 2. The DPSIR framework, diagram adapted from many sources. therefore describes the domain of management. Response is closely related to another term used to describe ecosystems, 'Resilience,' which connotes the overall system's ability to withstand shock or change and still maintain or recover its structure and function. Resilience combines the tolerances and recuperative abilities of species and habitats with demonstrated and potential restorative actions by humans. DPSIR and most of the assessment and management literature reserve the term 'Response' to mean purposeful actions taken by humans to mitigate or adapt to pressures, as opposed to the mainly physiological or (longer term) genetic adaptations ${ }^{24}$ displayed by other forms of life or changes in state of abiotic components of the environment. ${ }^{25}$

DPSIR's terminology has evolved to make it more suitable for complex socio-ecological systems such as the human-ocean system. For example, Elliott et al. (2014) suggested that Drivers actually stimulate human Activities (A) resulting in Pressures that cause positive or negative changes in the State of natural systems and Impacts on the human system. In that conception, Impacts are specific to the human portion of the system. Those authors also noted Cooper's (2013) suggested replacement of 'Impact' with 'Impacts on human Welfare'-- I(W), such that 'DPSIR became 'DAPSI(W)R'. A further transformation to DAPSI(W)

24 The opportunity for hybrid 'natural-human' resilience should not be discounted, since the feasibility of improving the resilience of tropical coral reefs to bleaching by transplantation of naturally tolerant specimens or species has already been demonstrated and the potential exists for increasing resilience with selective breeding of hosts or symbionts as well as genetic technology (van Otten et al. 2015). Hybrid responses to sea level rise by combining jetties, seawalls and other infrastructure with plantings of mangroves or seagrasses ('graygreen' adaptation, NSTC 2015) have also been demonstrated.

25 The human capacity to mount specific responses is heavily influenced by the broader context of social resilience that prevails within each society, including how well the government functions to create and enforce policies that benefit its citizens. As noted by UNEP (2010),"To achieve their environmental commitments and goals, States need strong legislative, political and judicial systems." Key factors include how governments are selected, monitored, and replaced; their capacity to make and carry out sound policies; and the respect of citizens and the state for the institutions that govern economic and social interactions among them. Such factors as how inclusively and freely citizens participate in selecting their government, freedom of expression and association and a free press enable society to vocalize issues and help engage government to respond to public concerns including ocean and environmental priorities. Political stability, absence of violence and terrorism, quality of regulations enacted, public confidence in the rule of law, contracts, property rights, police and courts; and control of corruption also strengthen the web of social resilience, enhancing society's ability to meet challenges with timely and appropriate responses. 
$\mathrm{R}(\mathrm{M})$ (Fig. 3) recognizes that EU managers prefer 'Measures' as their term for 'Responses.'

Kelble et al.s (2013) substitution of 'Ecosystem Services' for 'Impact' yielded an EBM-DPSER

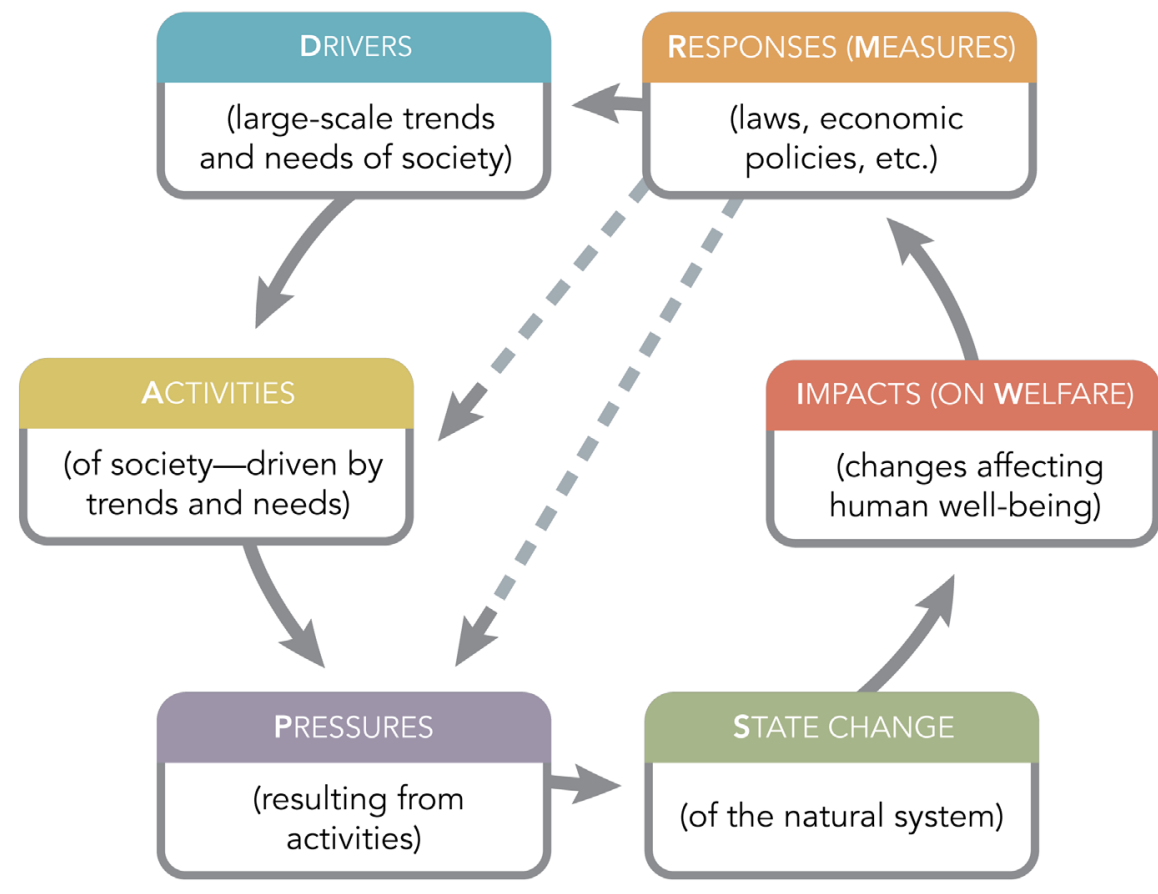

Figure 3. DAPSI $(W) R(M)$ diagram, adapted from Borja et al. (2016b).

\section{IEA AND EEA}

DPSIR provides the logical framework to illustrate how humans change ecosystems and respond to those changes, but it does not outline a method for developing those responses. Two such frameworks have been developed for EBM (MSP).

NOAA's Integrated Ecosystem Assessment (IEA) (Levin et al. 2008) (Fig. 4) and the European Environment Agency Policy Cycle (EEA 2011) (Fig. 5) both organize EBM into a logical sequence of steps for creating management plans and outcomes that are an important portion of the Responses shown in DPSIR. Both ask what knowledge, assessment, indicators, data and monitoring are needed, include numerous stakeholders and reflect the need for iterative adaptive management. Illustrations of the two processes differ slightly, but carry essentially the same meaning.

framework that emphasized how human response can introduce positive change into the system as well as negative pressures. Their diagram emphasizes the key importance of human 'Responses' as the sole locus for system improvement as well as the mutual feedbacks and synergies that exist between each of the framework's components.

However it is configured-and Patricio et al. (2016) chart its evolution into 25 derived frameworks-the general DPSIR framework is a useful guide to the web of feedbacks between large scale forces acting on people and nature and the human responses available to reduce or eliminate the negative impacts of the activities they stimulate.

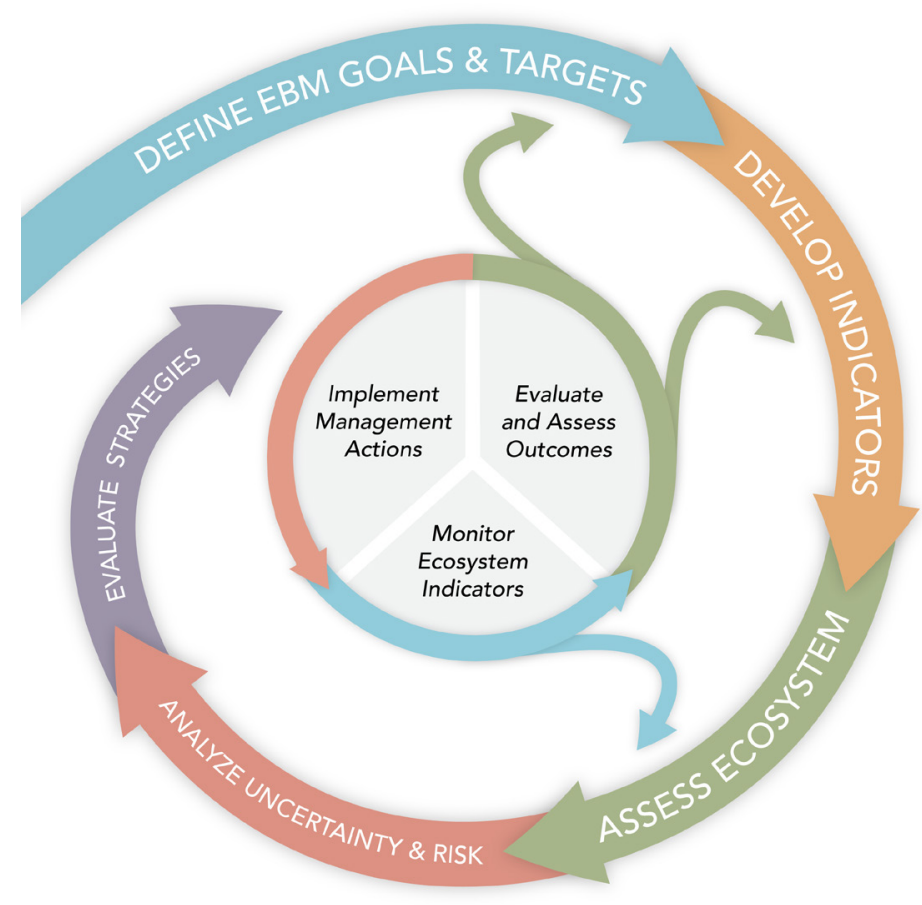

Figure 4. NOAA Integrated Ecosystem Assessment (IEA) process adapted from Levin et al. (2008). 


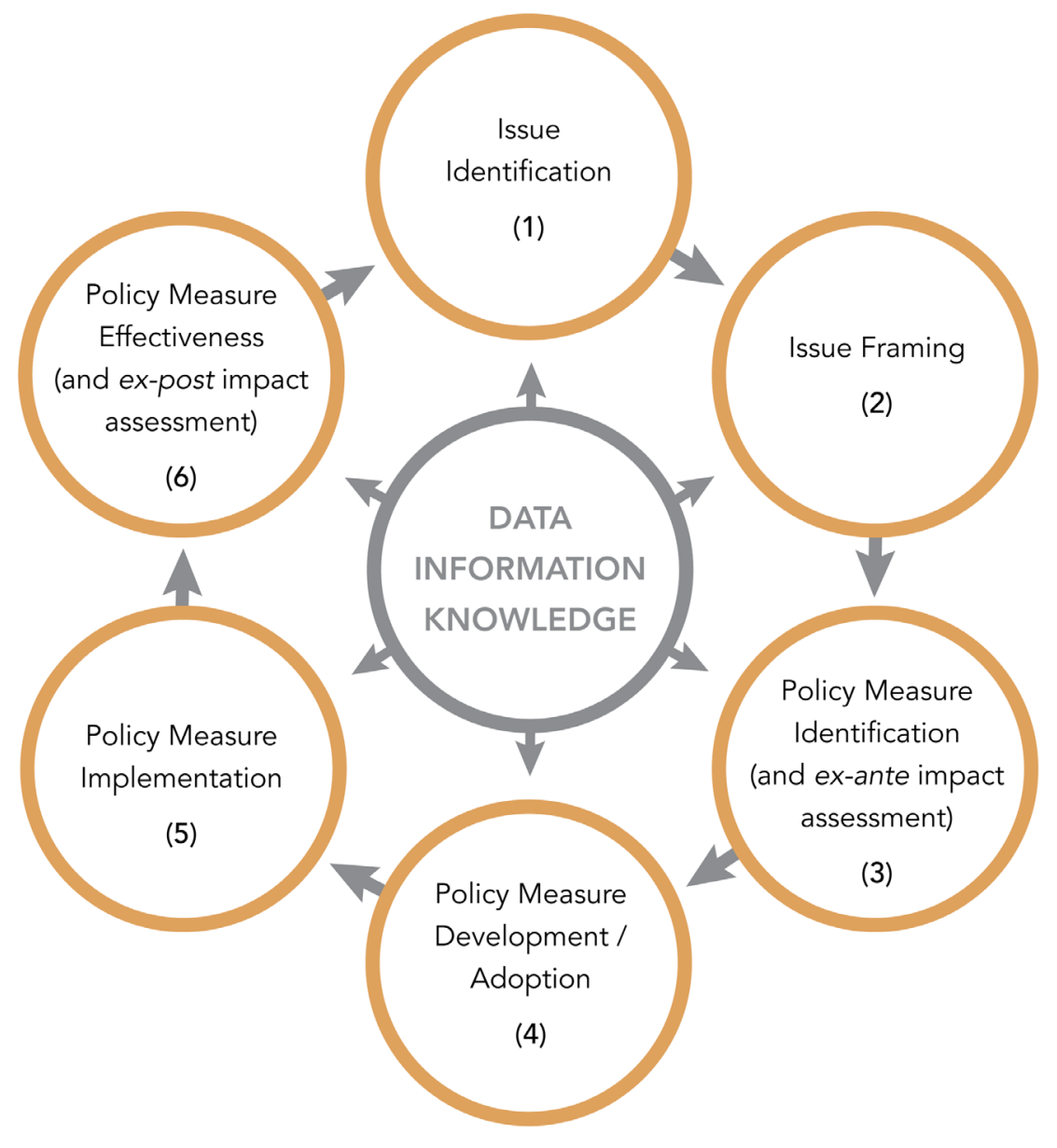

Figure 5. Main stages in the European Environment Agenda Policy Cycle, adapted from EEA (2011).
4. Overall ecosystem assessment (US). Integrate results from the risk analysis of each indicator into assessment of the overall status of the ecosystem relative to its historical status and prescribed targets.

\section{Evaluate strategies (US) - Policy} Measure Identification, Development and Adoption (EU). Evaluate the potential of different management strategies to influence ecosystem status. Re-evaluate periodically as new ecosystem issues emerge. Identify crucial knowledge and data gaps that will guide future research and data acquisition.

\section{Manage, monitor and reevaluate} (US) - Policy measure effectiveness and ex post assessment (EU): Take appropriate management actions, evaluate their success by monitoring indicators and make adjustments as necessary.

These policy stages steps are fundamentally important to any EBM framework. Detailed practical guidance for best practices to achieve them is available in Tallis et al. (2010) and Open Standards for the Practice of Conservation (Conservation Measures Partnership 2013). Fock and Frank (2016) discuss additional conceptual and philosophical considerations regarding the language, logic and mechanics of marine ecosystem assessments.

Challenging the goal of accomplishing these processes is the "paradox of environmental assessment" (Borja et al. 2016a), namely the mismatch between requirements for increased monitoring and the reality of constrained or decreased budgets, a situation that can only be remedied through development of more cost-efficient monitoring systems and/or substantial budget reallocations.

3. Risk analysis (US). Analyze qualitatively and quantitatively the susceptibility of each indicator to natural or human threats and its ability to return to its previous state after being perturbed. 


\section{DECISION SUPPORT TOOLS}

Marine spatial planning requires consideration of the interactions between many spatial, social, economic and biophysical variables and the ways they could change a system's structure, function and delivery of ecosystem services. Recognizing the complexity of the task, non-profit, government, intergovernmental and academic institutions worldwide have developed a large array of decision support tools for conservation practitioners and managers. They are designed to help users through difficult steps of decision making processes and assist in analyses while hopefully saving time, energy and resources. Such tools range from general frameworks for management processes (e.g. CMP 2013), to mathematical models and programs for conducting complex socioeconomic and ecological analyses (e.g. Rude et al., 2016). Their variety reflects different perspectives and purposes among their developers, improvements in technological capabilities over time and geographic, biophysical and sociopolitical diversity of systems to be measured. Available tools differ in suitability for different purposes and have different strengths and weaknesses (Chan and Ruckleshaus 2010, Center for Ocean Solutions 2011, van der Belt et al. 2016), including ease of use, cost (e.g. training time, fee for use), incorporation of social values, spatial representation, ability to portray dynamic changes over time and economic evaluation of services.

The sheer volume of decision support tools can be daunting and create confusion among decision makers and conservation managers seeking to focus and standardize their approaches, so there have been several efforts towards consolidating and/or synthesizing suites of tools for different purposes. One marine spatial planning decision guide (Coleman et al. 2011) evaluated 9 software tools that included visualization, spatial analysis, or modeling capabilities. The authors created the guide as an output of workshops with the Pacific Marine Analysis and Research Association, the Center for Ocean Solutions, and tool developers, where they fully evaluated the function and features of each tool in order to assist practitioners in selecting appropriate tools for their needs as well as their technical capacities. Overall the tools were deemed highly valuable but the authors suggested improvements such as representation of uncertainty in model and map outputs as well as supporting multi-objective planning and stakeholder participation (Coleman et al. 2011). The EcosystemBased Management Tools Network, coordinated by NatureServe and OpenChannels.org assist users in finding, sharing and contributing information about planning and management decision support tools and projects.

A recent systematic review of tools for planning and management of freshwater, terrestrial and marine ecosystems (Papacostas and Farmer, in prep) evaluated over 160 tools and divided them into four categories (Box 4): process tools (86) that provide a guide or framework for conservation, policy, management and/or spatial planning; interactive web-based tools (12) that can readily be used by less technical audiences for information gathering and conservation planning; programs and modeling tools (28) that use sophisticated mathematical models, programs or software for making predictions and evaluating alternative scenarios and/or management strategies; and index tools (7) which are composite statistics designed to aggregate multiple socioeconomic and/or ecological indicators that are useful for determining baselines and assessing changes in a system.

Despite the utility of the various tools for their intended purposes, several major deficiencies were identified in the review. Most significantly, no tool has been yet developed to fully describe marine biodiversity at a habitat scale that is comparable to what is available on land (e.g. Pimm et al. 2014). Potentially as a consequence, there is also a lack of effective tools for natural and ecosystem service mapping and accounting in marine systems. Other needs identified were tools for cultural assessments, tools for detailed financial analyses of conservation efforts, and tools for social network and whole systems analysis (Papacostas and Farmer, in prep).

A tool that fully accounts for a coupled humannatural system is not yet on the horizon, owing to the difficulties of modeling these complex and dynamic processes at multiple scales (Villa et al. 2016) and particularly since globalization has led to more indirect, as well as spatially distant couplings between human activities and ecosystems. Until such dynamics are fully understood, the gradual advances made in modeling these dynamics will need to guide current management efforts (e.g. An 2012, Boumans et al., 


\section{BOX 4. Categories of decision support tools for Marine Spatial Planning, with examples (Papacostas et al. in preparation)}

\begin{tabular}{|c|c|c|}
\hline CATEGORY & DESCRIPTION OF CATEGORY & EXAMPLE TOOLS \\
\hline Process Tools & $\begin{array}{l}\text { A guide or framework for one or } \\
\text { more stages of conservation, policy, } \\
\text { management and/or spatial planning (e.g. } \\
\text { planning, implementation, monitoring). }\end{array}$ & $\begin{array}{l}\text { The Open Standards for the } \\
\text { Practice of Conservation } \\
\text { (Conservation Measures } \\
\text { Partnership 2013) } \\
\text { High Conservation Values } \\
\text { Approach (HCV Resource } \\
\text { Network 2013) }\end{array}$ \\
\hline $\begin{array}{l}\text { Interactive } \\
\text { Web-based } \\
\text { Tools }\end{array}$ & $\begin{array}{l}\text { Online tools, readily accessible by } \\
\text { non-technical audiences for gathering } \\
\text { information, conducting analyses, and/or } \\
\text { conservation planning. }\end{array}$ & $\begin{array}{l}\text { Global Fishing Activity Tracking } \\
\text { Tool (Oceana, Skytruth and } \\
\text { Google 2016) } \\
\text { Mapping Ocean Wealth Tool } \\
\text { (The Nature Conservancy 2016) }\end{array}$ \\
\hline $\begin{array}{l}\text { Programs and } \\
\text { Modeling Tools }\end{array}$ & $\begin{array}{l}\text { Mathematical models, programs or } \\
\text { software that can be used to predict } \\
\text { optimal management strategies; designed } \\
\text { for assessing complex ecological or } \\
\text { socioeconomic relationships, and } \\
\text { conducting scenario analyses and/or } \\
\text { management simulations. }\end{array}$ & $\begin{array}{l}\text { Data-Limited Methods Toolkit } \\
\text { (Carruthers et al. 2016) } \\
\text { Coupled Terrestrial-Marine } \\
\text { Model for Sediment Runoff } \\
\text { Model (Rude et al. 2016) }\end{array}$ \\
\hline Index Tools & $\begin{array}{l}\text { Composite statistics based on aggregated } \\
\text { socioeconomic or ecological indicators } \\
\text { used for assessments and detecting } \\
\text { change in socioecological systems. }\end{array}$ & $\begin{array}{l}\text { Ocean Health Index (Halpern et } \\
\text { al. 2012) } \\
\text { Protected Area Suitability Index } \\
\text { (The et al. 2012) }\end{array}$ \\
\hline
\end{tabular}

2015, Villa et al., 2014). Beyond development of new tools however, ensuring that currently existing tools are accessible to key stakeholders, as well increasing the interoperability of different tools for similar purposes, are two much-needed efforts. Increased communication and collaboration among tool developers, practitioners and other stakeholders will be crucial in continuing to increase the utility of tools in decision making processes. 


\section{EVALUATING SUCCESS}

EBM-MSP processes incorporate many sectors and objectives. Methods often exist for evaluating their individual success, for example status of fisheries stocks or water quality, but quantitative methods for simultaneous evaluation of overall success have not been available until recently. Borja et al. (2016b) reviewed and compared five methods available for integrated assessment of large marine regions; the Ecosystem Health Assessment Tool; a method for the Marine Strategy Framework Directive in the Bay of Biscay; the Ocean Health Index (OHI); the Marine Biodiversity Assessment Tool, and the Nested Environmental status Assessment Tool (NEAT), paying particular attention to use of the 'ecosystem approach, employment and weighting of multiple components in the assessment, reference points, use of a range of values to capture the status, and means for expressing uncertainty.

Here we summarize the example with which we are most familiar, the Ocean Health Index (OHI). OHI was developed as a comprehensive framework to assess human-ocean ecosystems and evaluate how successfully and sustainably humans are obtaining the range of benefits that the ocean can deliver. It has been applied at scales including global (Halpern et al. 2012, 2015a), LME (Halpern et al. 2016), national (Blasiak et al. 2016, Selig et al. 2015, Tsemel et al. 2014) and subnational (Elfes et al. 2014, Halpern et al. 2014)

Benefits assessed include most tangible (food, natural products, clean water, jobs, revenue etc.) and intangible (sense of place) things that people expect from a healthy ocean. While the global assessment uses globally available open-access databases to provide a coarse estimate of health for national and territorial Exclusive Economic Zones, the OHI's framework can be tailored to incorporate regional goals, values, conditions and data (Daigle et al. 2016, Lowndes et al. 2015, Halpern et al. 2015b, Selig et al. 2015, Elfes et al. 2014), thereby enabling independent assessments to be done at national or sub-national scales, as has been completed or is ongoing in China, Colombia, Ecuador, Israel, and the Baltic Sea (e.g. Tsemel et al. 2014; see also Table 1 in Lowndes et al 2015 and www. ohi-science.org/projects; and Blasiak et al. 2016).

In all cases raw data are transformed to a unit-less 0 to 1 scale then combined in various ways to produce composite scores that are expressed on a scale of 0 to 100 , where 100 indicates that the goal-specific target values have been met.

Interactions between objectives present a challenge to multi-factorial assessment. Because quantitative assessment of the interactions between benefits is not yet possible, the OHI framework incorporates a semi-quantitative (categorical) approach to tradeoffs between goals. Thus, for example, the benefit provided by fisheries creates pressures on biodiversity, some habitats and sense of place if not carried out sustainably. The inadequacy of current science to evaluate such interactions more accurately has been identified as one of EBM's major gaps (Leslie and McLeod 2007).

At its current stage of development $\mathrm{OHI}$ is useful in a number of ways. It defines 'ocean health' for the first time, tying that definition to terms used in EBM: "a healthy ocean sustainably delivers a range of benefits to people now and in the future.' It illustrates the kinds of information (targets, indicators and data) that need to be defined and collected. It can provide a quantitative initial baseline measure of conditions and, when repeated, a useful approximation of how well management actions achieved their overall goals. Additionally, OHI allows users to test 'what if' scenarios and investigate potential effects of proposed management actions on overall scores and scores for individual goals. $\mathrm{OHI}$ assessments are conducted using freely available software tools that enable researchers to build directly off the work of past assessments (Lowndes et al 2015)

In all cases scores are only estimates for actual conditions that must be ground-truthed with data collected in a monitoring program. Since OHI assessments may include elements important to ocean health that are not captured in MSP, and vice versa, determining whether $\mathrm{OHI}$ is the right tool to evaluate MSP efforts and how to interpret results requires explicit expectations and intentions.

Given the Ocean Health Index's definition and the assumption that its scores are a reasonable estimate of coastal and marine conditions, score improvement should in time help boost other indicators of human well-being. Conversely, enhancement of fair, just and effective governance that enables societies to take 
actions to mitigate socio-ecologic pressures should improve ocean conditions and Ocean Health Index scores. Good correlation between current scores for the OHI and the Human Development Index already exists (Halpern et al. 2012) and correlation with other measures, including the Sustainable Development Goals, may be expected in future.

\section{EXAMPLES OF EBM-MSP AT VARIOUS SCALES}

Broad and integrative goals along with challenges discussed previously, including differential values, costs and benefits among stakeholders, guarantee that EBM-MSP processes will frequently be lengthy and difficult. Nevertheless, progress is slowly being made. Below we highlight examples at different scales. All are works in progress, but as emphasized earlier, successful EBM never ends. Additional examples of marine EBM are introduced by Link and Browman (2017).

\section{OCEAN SCALE: HIGH SEAS}

No system yet exists for implementing EBM on the High Seas, the $60 \%$ of the ocean outside of the Exclusive Economic Zones ${ }^{26}$ (EEZs) of coastal countries and their territories (World Ocean Review 2015). This area, also called 'international waters' or 'areas beyond national jurisdiction (ABNJ) is not owned by any country and can only be governed and regulated by international agreements, among which UNCLOS, is the keystone treaty.

Though UNCLOS and its supporting agreements (see Fig. 10, where UN treaties are shown outlined in orange) address important topics such as free passage, pollution and fisheries, they do not incorporate the integrative principles of EBM and its development at High Seas scales will not come quickly.
The strengths and weaknesses of current ocean governance, key issues needing to be addressed and recommendations for improvement are provided by Council on Foreign Relations (2013); Ardron et al. (2013); and Global Ocean Commission (2016).

In summary, UNCLOS, which was concluded in 1982 and entered into force in 1994, is more than 30 years old and does not address emerging challenges such as transnational crime and pollution, overfishing in the high seas and melting of the Arctic. Although 166 countries and the European Union have signed and ratified it, the world's leading naval country, the U.S., has signed, but not ratified it. Moreover, UNCLOS's mechanisms for surveillance and enforcement are weak. Progress toward ocean improvement is difficult to assess, because no single institution has the responsibility to monitor and collect data on all oceanrelated issues at national, regional, and global scales.

Regional Seas Conventions and Action Plans have been created, as well as Regional Fisheries Management Organizations, but national systems of governance among the member UNCLOS countries are not synchronized.

Recommended actions (Global Ocean Commission 2016) include:

- Create a high seas regeneration zone free from industrial fishing

- Establish binding international safety standards, liability provisions and response preparedness for offshore oil and gas operations

- Keep plastics out of the ocean by eliminating land-based and sea-based inputs

26 The EEZ concept was adopted as part of the U.N. Convention on the Law of the Sea (UNCLOS) in 1982. That convention defines a country's territorial waters as a band extending 12 nautical miles $(22.2 \mathrm{~km})$ off the coast from some baseline, usually the low-water mark, within which it retains exclusive sovereignty over the water, subsoil, seabed and their resources as well as the airspace above. A country may also claim a contiguous zone a further 12 nautical miles seaward of the coast, within which it may enforce military, immigration, sanitation and other rights. The exclusive economic zone (EEZ) extends still further seaward, but not beyond 200 nautical miles (370.4 $\mathrm{km}$ ) from the coast. Within the EEZ, the coastal state has sovereign rights to explore, exploit, conserve and manage living and non-living natural resources of the seabed and waters, as well as to produce energy from the water, currents and winds. It can also establish and use artificial islands or other structures for economic or marine scientific purposes or to preserve the marine environment. However, within one country's EEZ, other states still maintain the traditional high seas freedoms, such as freedom of navigation and overflight and the freedom to conduct military exercises. 
- Eliminate illegal, unregulated and unreported (IUU) fishing by assigning mandatory IMO numbers to all ships, banning transshipment of IUU catches at sea, implementing an international fishing treaty, and deflagging and denying port entry to IUU fishing vessels

- $\quad$ Reduce overfishing by ending harmful high seas subsidies

- Strengthen governance by creating an UNCLOS implementation agreement on high seas marine biodiversity, creating a UN special representative for oceans and other measures

High Seas (Fig 6) degradation is frequently lamented and many of its aspects are reviewed by the UN World Ocean Assessment (UNWOA1 2015), but the only quantitative assessment to date was done by the Ocean Health Index (OHI 2014), which assessed their

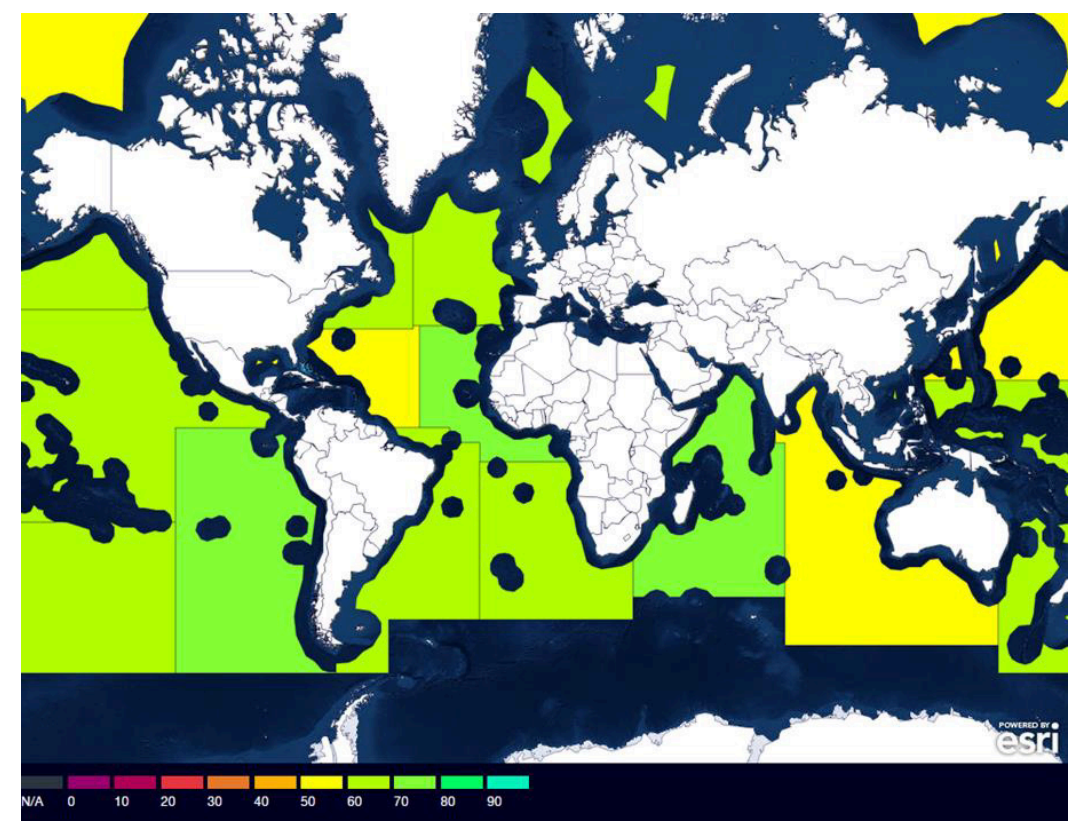

Figure 7. Ocean Health Index scores for High Seas regions. Colored blocks correspond to FAO statistical areas in Figure 6. White areas are land. Black areas are waters within national jurisdiction (EEZs and territorial waters). Also colored black are waters

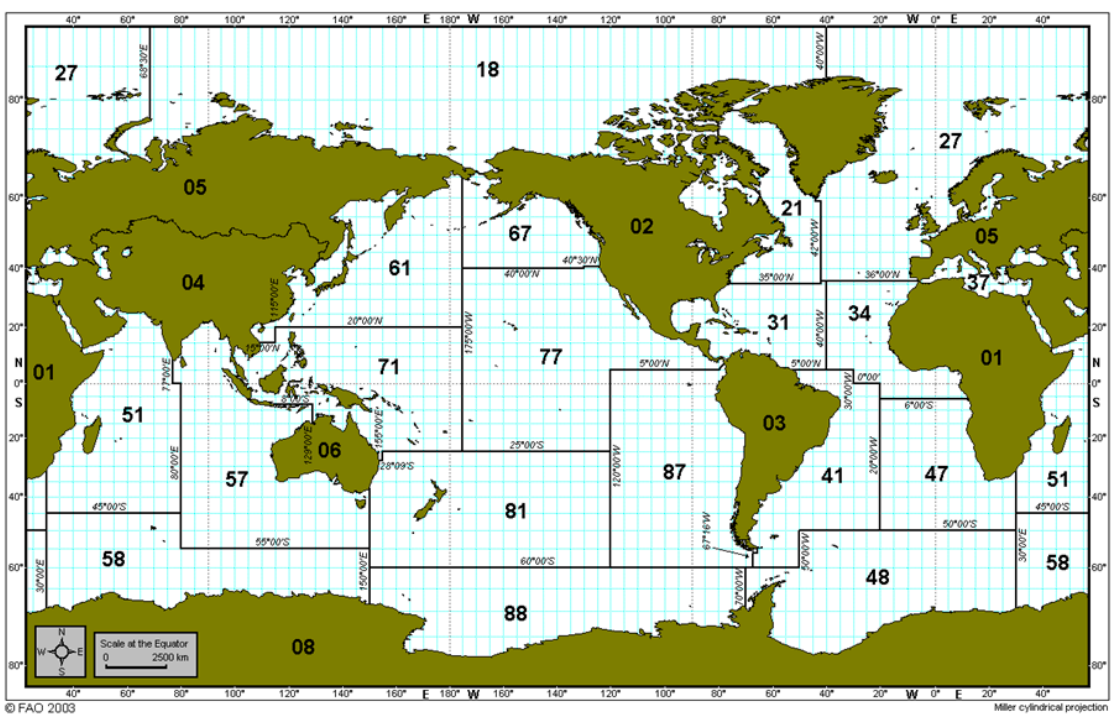
of the Southern Ocean surrounding Antarctica, which were analyzed separately and not included here.

The overall score (0-100) for the High Seas was 67 . Scores for the three goals evaluated were: Food Provision (Fisheries) scored 45; Sense of Place (Iconic Species) scored 75 and Biodiversity (Species) scored 80. Fig. 7 maps overall OHI scores for the high seas areas shown in Fig. 6.

Figure 6. Statistical areas used by the UN Food and Agriculture Organization (FAO). Nineteen (19) of the areas contain marine waters and all but one of them, Number 37, the Mediterranean Sea, contain High Seas areas. The Ocean Health Index analyzes areas 58, 88 and 48 with its Antarctic area; and the other 15 areas as its High Seas areas.

27 Other goals normally assessed, such as Mariculture, Natural (Non-Food) Products, Opportunities for Artisanal Fishing and Coastal Protection do not occur in the High Seas and cannot be reflected. Two other goals, Tourism \& Recreation and Livelihoods \& Economies occur in passing when cruise ships or merchant ships transit the High Seas, but their benefits only accrue where trips originate and visit. So those two goals are not evaluated for the open ocean itself, but are accounted for in the coastal countries or territories where the activities take place. The High Seas also provide other important general benefits, such as climate regulation and oxygen production by plant plankton, but OHI does not assess them. 


\section{OTHER OCEAN BIOMES}

Blasiak et al. (2016) call for identification of other important and vulnerable ocean biomes where assessment and management could provide significant benefits for conservation and human well-being. For example, UNESCO (2016) proposed extending the 1972 World Heritage Convention to include sites of outstanding universal value in areas beyond national jurisdiction $(\mathrm{ABNJ})$ and detailed possible processes for doing so, but mechanisms for management, including enforcement and periodic assessment, would need to be constructed.. The five sites initially proposed for protection are:

- The Costa Rica Thermal Dome, a highly productive wind- and current-driven upwelling system off the Pacific coast of Central America that supports spawning, migration and feeding of many endangered and commercially important species.

- The White Shark Café, midway between the North American mainland and Hawaii and the only known offshore aggregation of north Pacific white sharks.

- The Sargasso Sea, a unique and complex pelagic ecosystem organized around the floating Sargassum spp. seaweeds and supporting many endemic species.

- The Lost City Hydrothermal Field, a unique deep water (700-800 m) ecosystem on the mid-Atlantic ridge dominated by $60 \mathrm{~m}$ high carbonate pillars and unlike any other known ecosystem on earth.

- The Atlantis Bank, a sunken fossil island at depths of 700 to $4,000 \mathrm{~m}$ located within subtropical waters of the Indian Ocean, with old headlands, precipitous cliffs, stacks, beaches, lagoons and a very diverse deep-sea fauna featuring large corals, anemones and armchairsized sponges.

\section{MULTINATIONAL: THE EUROPEAN UNION MARINE STRATEGY FRAMEWORK DIRECTIVE}

The European Union (EU) Marine Strategy Framework Directive (MSFD 2010) creates a process by which its 28 member states will manage their human-ocean systems to achieve 'good environmental status' (GES) by 2020, with a first evaluation report to be published by 2019 . GES was not well defined, quantitatively described or easily understandable when originally promulgated, but Borja et al. (2016a) describe continuing efforts to address those shortcomings.

Marine waters have GES when they are ecologically diverse, clean, healthy, productive and support the resources upon which marine-related economic and social activities depend. MFSD calls for adaptive management, as states are required to review and update their strategies every 6 years.

Because EU states vary substantially in their political, social, economic and ecological conditions, MSFD does not attempt to establish a single path toward GES. Developing and administering the many separate plans required probably entails duplication of effort and other inefficiencies, but is the only practical approach.

Also in progress are assessments of Europe's four regional seas, North-East Atlantic, Baltic Sea, Black Sea and Mediterranean Sea, each of which is a complex multi-national entity, but It is not yet clear how their methods and results will be integrated with those done by the EU member states. MSFD contains 11 descriptors for GES (Box 5) along with indicators for what should be measured in assessing them. However, except for fish populations (Descriptor 3) and contamination levels (Descriptors 8 and 9) targets or reference points are not quantitatively specified, nor is it stated whether they could vary among the member states (although states may eliminate any indicators not relevant to their waters). Also not specified is any shared mechanism by which indicators could be combined to produce integrated assessments of GES status and pressures (Fock and Kraus 2016). 


\section{BOX 5. Descriptors for EU Marine Strategy Framework Directive (MSFD)}

Descriptor 1: Biological diversity (species and habitats) is maintained.

Descriptor 2: Non-indigenous species introduced by human activities are at levels that do not adversely alter the ecosystem.

Descriptor 3: Populations of all commercially exploited fish and shellfish are within safe biological limits, exhibiting a population age and size distribution that is indicative of a healthy stock.

Descriptor 4: All elements of the marine food webs, to the extent that they are known, occur at normal abundance and diversity and levels capable of ensuring the long-term abundance of the species and the retention of their full reproductive capacity.

Descriptor 5: Human-induced eutrophication is minimized, especially adverse effects thereof, such as losses in biodiversity, ecosystem degradation, harmful algal blooms and oxygen deficiency in bottom waters.

Descriptor 6: Sea-floor integrity is at a level that ensures that the structure and functions of the ecosystems are safeguarded and benthic ecosystems, in particular, are not adversely affected.

Descriptor 7: Permanent alteration of hydrographical conditions does not adversely affect marine ecosystems. 2.9.2010

Descriptor 8: Concentrations of contaminants are at levels not giving rise to pollution effects.

Descriptor 9: Contaminants in fish and other seafood for human consumption do not exceed levels established by Community legislation or other relevant standards.
Descriptor 10: Properties and quantities of marine litter do not cause harm to the coastal and marine environment.

Descriptor 11: Introduction of energy, including underwater noise, is at levels that do not adversely affect the marine environment.

MSFD requires states to take an ecosystem approach to achieving GES. While human use of the ocean is implicit in all of its 11 descriptors, there are no descriptors focused specifically on human benefits such as tourism, recreation, livelihoods or cultural value.

Since the regions to be managed are geographically specified, the process is by definition marine spatial planning, even though that term is not used. MSFD does not specify any particular management instruments that a state should use (e.g. marine protected areas, zoning or other regulations), but allows each to chart its own course toward GES. Nevertheless, some commonalities will emerge because MSFD is nested within a number of other high-level management plans (Fig. 10), some of which identify specific and quantitative goals, for instance that by 2020 ten percent of coastal and marine areas, especially those important for biodiversity and ecosystem services, are conserved as effectively protected areas, $\underline{\mathrm{CBD} \text { Target 11). }}$.

Aggregation of indicators into an integrated assessment within and among different regions may be facilitated using a new software program, NEAT (Nested Environmental status Assessment Tool) that expresses multiple indicators over differing temporal and spatial scales on a common scale ranging from 0 (worst possible status) to 1 (best possible status), with GES defined by a default value of 0.6 , options for setting other status boundaries (high-good $=0.8$; moderate-poor $=0.4$; poor-bad $=0.2$ ) and use of weighted averaging and linear interpolation to span the entire scale (Borja et al. 2016a).

Multinational: Seascapes: 'Seascapes' are initiatives which implement the principles of EBM in large-scale marine systems either at multinational 
or sub-national scale. To date they have not involved assessments, ES valuation or formal implementation of DPSIR, IEA or EEA over an entire Seascape area, but are instead constellations of projects at various scales coordinated by partnerships among a variety of public and private groups all working toward conserving nature, natural benefits and human wellbeing. The approach has been applied multinationally in the Eastern Tropical Pacific (Costa Rica, Panama, Colombia, Ecuador), Sulu-Sulawesi Sea (Philippines, Malaysia, Indonesia) and Pacific Oceanscape (22 island nations) and subnationally in Bird's Head (Indonesia) and Abrolhos (Brazil). Examples of each are profiled below.

Seascapes must meet three key criteria: Scale, Scope, and Commitment.

- Scale: The scale may range from subnational to multinational, but must be large enough to incorporate one or more networks of MPAs. Establishing and managing a network of marine protected areas (MPAs) is central to achieving desired ecological and socio-economic outcomes. The network must be sufficiently large to ensure cultural, political, economic and ecological connectivity. Outcomes must include protection of priority marine habitats, ecosystems, safeguarding threatened and overexploited species, and providing benefits to people-especially local communities (Atkinson et al. 2011; see also Westlund et al. 2017). Beyond just establishing successful MPAs, securing a a Seascape's benefits also requires working on fisheries reform, climate change, legal frameworks, capacity building, developing sustainable financing, building public commitment and identifying 'champions' to continue those efforts for many years.

- Scope: The scope must address 9 essential elements. The first three are necessary enabling conditions: 1) A legal framework which facilitates marine management, 2) Institutional and stakeholder capacity to manage the marine environment, 3) Social and political support for marine management. Next are three critical components of effective management: 4) Private sector solutions for marine management challenges, 5) Integrated ecosystem-based marine management strategies, 6) Long term financing for marine management including harnessing market mechanisms. The final three are outcomes which the Seascape approach aims to provide and enhance at scale: 7) Priority marine habitats and ecosystems, 8) Threatened and overexploited species, and 9) Benefits derived by people, especially local communities.

- Commitment: Creating a Seascape requires an overarching vision that is shared by a committed coalition of governmental, NGO (local and international), university, private sector and community partners; a coherent (but dynamic) plan to achieve it; and a multidecadal time scale to implement it. Willingess to use a variety of tools at a variety of scales is needed. A flexible approach is also needed to mobilize and collaborate with many partner organizations. More than 150 partners have helped implement the Seascape approach to date. Building such coalitions mobilizes more resources, creates teams built of complementary strengths, strengthens local organisations and helps everyone work toward an agreed common mission.

Achieving these broad social, ecological and economic goals across such large and diverse areas does not happen quickly. The examples below highlight important successes, but more time and evaluative work will be needed to conclusively demonstrate how well Seascapes are achieving their desired socioeconomic impacts.

\section{The Eastern Tropical Seascape (ETPS): A multinational Seascape (Fig. 8)}

ETPS encompasses 2,100,000 $\mathrm{km}^{2}$ and spans the Pacific waters, coasts and islands of Costa Rica, Panama, Colombia and Ecuador. Its key marine and coastal ecosystems include Cocos, Coiba, Gorgona, Malpelo and the Galapagos Islands, four of which are marine UNESCO World Heritage Sites, as well as more than 20 Marine Protected Areas totalling $166,030 \mathrm{~km}^{2}$. ETPS is often called the 'Serengeti of the Seas', because its vast pelagic area, seamounts, productive coastal waters, 
coral and rocky reefs, estuaries, gulfs, and mangroves host such abundant marine wildlife, including sharks, rays, marine mammals, turtle nesting beaches, and one of the highest rates of regional marine endemism in the world (Miloslavich et al, 2011). Its pelagic waters are a major migration route for many large marine animals people lived within $10 \mathrm{~km}$ of the coast. ETPS's valuable fisheries are under imminent threat of being depleted by overfishing and the use of inappropriate fishing gear (Edgar et al., 2011). Marine tourism is well developed in some areas and many coastal communities depend on marine resources.

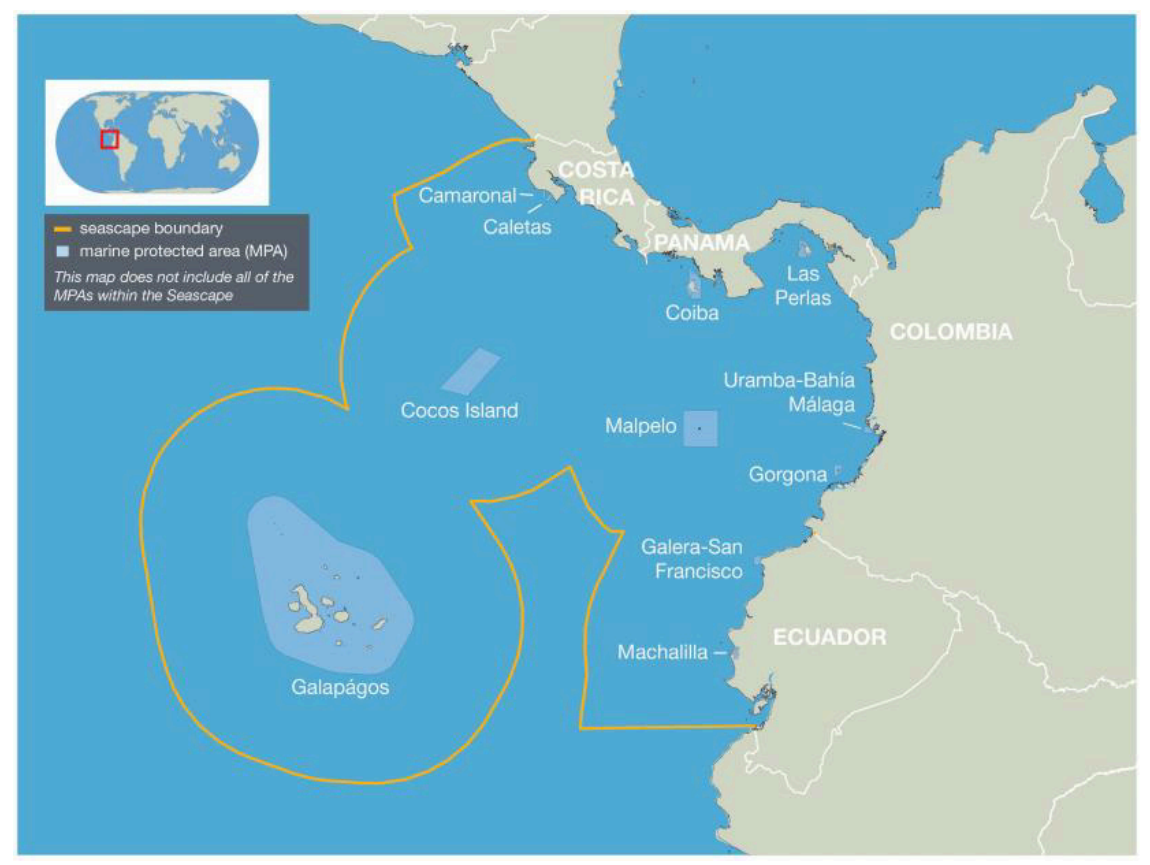

Figure 8. Map Source: Conservation International (Hearn et al. 2010). As of 2010, more than 5.1 million

Integration of ETPS is led by Conservation International, which develops and coordinates projects involving more than 100 partner organizations and agencies. Key to ETPS success has been the transition from conserving marine habitats and wildlife for their own sake to a more integrated goal of conservation that helps coastal villages gain sustainable benefits. Examples of successful ETPS projects at different scales are shown below.

\section{- EcoGourmet and the Bahia Solano (Colombia) Community Fishery.} EcoGourmet was founded in 2009 as collaboration between Conservation International-Colombia and Fondo Acción to help associations of smallscale fishers reach their objectives to achieve more sustainable livelihoods by fishing more responsibly. Working with EcoGourmet, associations strengthen their technical and administrative capacity, can gain fairer agreements with suppliers and restaurants, and educate consumers to make purchasing decisions that are more accountable and conscious. By offering locally sourced, sustainably caught fish, participating restaurants can serve higher quality product at higher prices while reducing negative impacts on marine ecosystems and increasing profits for local fishers.

The success of this strategy is

IThe ETPS program began in 2005 following the signing in 2004 of the San Jose Declaration by governments of the four countries to create the Eastern Tropical Pacific Marine Corridor (CMAR). The agreement aims to safeguard connectivity and migration between the countries' marine protected areas, protect biodiversity, and foster sustainable fisheries and tourism. Building on the unique context and opportunity provided by CMAR, ETPS was founded to help the governments achieve those goals, and it has continued as a dynamic collaboration between public, private and non-profit entities working together to conserve key marine and coastal ecosystems and the human communities that depend on them.
demonstratedbyfishersintheremoteColombian village of Bahia Solano. Their cooperative, Red de Frío (Cold Chain Network), has participated in EcoGourmet since 2012. At first, fishers had to be convinced of the need to use sustainable and selective fishing gear. They had to install a cold storage room in one of the wettest and hottest areas on the planet, including obtaining legal tenure for the land where it was sited and establishing a system to ensure the supply of ice to fishermen at sea. They had to create an accounting system, budget and system for tax compliance. All members of the cooperative agreed to fish only in allowed areas, use ecofriendly methods, only capture individuals that are sexually mature and well above minimum 
size and not capture threatened species. A monitoring system to guarantee compliance was put in place.

The result is that the cooperative delivers locally-caught, sustainable, quality-controlled, cold-stored fish to Bogota, where the Colombian Gourmet restaurant chain, Wok, sells it less than 48 hours after it was caught. Wok pays significantly better prices (up to $\$ 3.5$ more per kilo) directly to the fishers in exchange for obtaining such high quality of fish for their customers. At the restaurants, placemats containing important information about sustainable fishing practices were seen by nearly 600,000 customers, and several hundred attended responsible consumption workshops. The number of customers who reported keeping their environmental commitment in mind when it came to selecting fish products rose from $6 \%$ at the project's start to $21 \%$. Such commitment makes the project increasingly self-sustaining.

Thanks to participation in this EcoGourmet program, Red de Frio's participation in the market has increased by $13 \%$ and the quality of life for its fishers has increased. Without the program, the cooperative would have to sell 83 more tons of fish to meet their current level of earnings. Equally important, the conservation measures undertaken help insure a healthy future both for Bahia Solano's fish stocks and the people whose livelihoods depend on them. Similar projects are being planned for other locations in the ETPS.

\section{- Camaronal Wildlife Refuge, Costa Rica.}

This small $\left(163 \mathrm{~km}^{2}\right)$ refuge was created in 1994 and expanded in 2009 to protect marine ecosystems, mangroves, and particularly the four species of endangered sea turtles (Green, Olive Ridley, Leatherback and Hawksbill) that nest there. Visitors have long come to watch wildlife, surf, fish and camp, but so have poachers who steal eggs from turtle nests. During the past decade, CI-Costa Rica has worked with site park rangers, the Costa Rican Ministry of Environment, Coast Guard, local police and volunteers to increase protection of nests through increased beach surveillance at night (when turtles lay their eggs) and enforcement with fines or imprisonment. A system for encouraging and training volunteers for beach patrol was created. Although 259 nests were poached in 2016, this was still a 40\% decrease from the previous year. Subsistence fishing is also being controlled through a registry that monitors species, quantity and sizes of fish caught, origin of fishermen and gear used. Ecotourism is being promoted by helping micro-enterprises created by local community leaders to improve their workplans for best practices, train tour guides and help them increase their fluency in English and learn more about marine biology and coastal ecosystem ecology. Currently, all tours to see nesting of sea turtles in the refuge require the participation of one local tour guide to assure their compliance to regulations. Also, volunteer programs developed with local micro-enterprises are now able to strengthen and expand sea turtle conservation efforts to nearby nesting beaches, within and outside MPAs.

\section{Offshore protection for ETPS waters}

- Malpelo Flora and Fauna Sanctuary (Colombia). One of the first offshore reserves in the ETPS, Malpelo Flora and Fauna Sanctuary (MFFS) is located about $500 \mathrm{~km}$ off the coast of Colombia. In 2005 its area was expanded 13-fold to its current extent of 8,575 $\mathrm{km}^{2}$, and a proposal was submitted to designate it as a marine World Heritage site. Colombian authorities agreed that if the site received such designation, they would regulate the growing dive tourism industry and deploy Navy patrol vessels to combat illegal fishing. Additionally, public and private contributions were obtained to create the $\$ 5$ million Malpelo Trust Fund as a sustainable financing mechanism to help underwrite core management costs, including enforcement. UNESCO designated MFFS as a World Heritage site in 2006. It is now one of the largest no-fishing areas in the Eastern Tropical Pacific, providing a critical habitat for internationally threatened marine 
species, including large populations of silky, hammerhead and whale sharks; giant grouper; billfish; and tuna. Steep walls and beautiful deepwater caves and tunnels add to its renown as one of the world's top diving sites. Along with marine World Heritage sites in each of the other ETPS Seascape nations, MFFS helps form the Eastern Tropical Pacific Marine Corridor that supports migrations of marine mammals, birds, turtles and fish, which was created largely as an ETPS initiative. Regular management effectiveness evaluation using the World Bank's 'MPA Scorecard' (Staub and Hatziolos, 2004) has been ongoing at MFFS and all ETPS MPAs since 2011.

- Cocos Seamounts Marine Management Area (Costa Rica). Cocos Island is a $24 \mathrm{~km}^{2}$ seamount island located $550 \mathrm{~km}$ offshore from the coast of Costa Rica. A national park established in 1978 to protect its tropical rainforest and high species endemism was expanded $20 \mathrm{~km}$ (12 nautical mi) offshore in 2001 to create a $1997 \mathrm{~km}^{2}$ marine area to protect its rich coral reefs and its marine biodiversity. In 1997 UNESCO designated it a World Heritage Site. Research and discussions during the following decade revealed that additional protection was needed to safeguard the marine resources of the park and its surrounding waters, especially a group of underwater seamounts $35 \mathrm{~km}$ south of Cocos Island. Guided by that work, Costa Rican president Laura Chinchilla Miranda signed legislation in 2011 to create a new marine protected area: Seamounts Marine Management Area (SMMA) (Área Marina de Manejo Montes Submarinos) that will surround Cocos Island National Park, and protect another nearly $10,000 \mathrm{~km}^{2}$, including the seamounts. Currents striking the steep-sided underwater mountains convey deep nutrient-rich water toward the surface, nourishing plankton production and providing food for sharks, turtles, whales, tuna and other important species. SMMA has two no-take zones, one surrounding the seamounts and the other adjacent to the park's northern boundary. The remaining $6,000 \mathrm{~km}^{2}$ or so is zoned for sustainable use and permits longline fishing for catching yellowfin tuna, but with highly restrictive regulations including, among others, rules specifying type of fishing lines and hooks and requiring attachment of identification tags to all fishing equipment. All boats must be equipped with vessel monitoring systems (VMS) and undergo specific fishing inspections at port. A radar system was also installed recently on Cocos Island to monitor boats within SMMA and illegal activities within the National Park. Government, environmental authorities and the Coast Guard are assessing mechanisms to improve vessel compliance with zones and regulations.

- Galapagos Marine Reserve expansion (Ecuador). In March 2016, Ecuador's president, Rafael Correa, issued a decree that expanded the no-take zone of the Galapagos Marine Reserve northward to include Darwin and Wolf Islands. The newly protected area covers $38,800 \mathrm{~km}^{2}$-almost the size of Switzerlandand protects what is said to be the world's largest concentration of sharks (Salinas de León 2016). The area will only be accessible for scientific use and tourism, but no resource extraction-including fish-will be allowed. The new protection will help curb illegal fishing for groupers, sharks and sea cucumbers and will also support benefits from tourism, as a recent analysis calculated the present (lifetime) value of a shark for tourism in the Galapagos to be $\$ 5.4$ million, compared to about $\$ 200$ for a shark that is caught and sold (Lynham et al. 2015). Following president Correa's decree, in September 2016 the presidents of Ecuador, Colombia and Costa Rica agreed to work together to further strengthen marine protection in their offshore waters, particularly in the Pacific Marine Corridor that is so important to migrating sharks, turtles, whales and other important marine life.

\section{The Pacific Oceanscape}

The Pacific Oceanscape, the largest Seascape initiative to date, was endorsed in 2010 by all Pacific Island Forum leaders as a framework for action among 23 island nations and territories that together control 10\% of Earth's total ocean area. The Pacific 
Oceanscape is intended to foster stewardship of the oceans and human well-being by addressing issues of mutual concern, including overfishing, sea level rise and other consequences of climate change, habitat destruction, and is grounded in the cultures and customs of Pacific Island people. This is a multidecadal effort for Pacific states that have redefined themselves by complementing their international personae as "Small Island States" with recognition of being the largest group of "Large Ocean Developing Nations" on the planet. In its first five years of effort the Pacific Oceanscape has united the region in common ocean policy and helped pioneer a new scale of ocean conservation in the rapid expansion of large scale MPAs. The recently established Office of the Pacific Ocean Commissioner and Pacific Ocean Alliance provide real hope to address ocean issues at scale in active collaboration. With the framework for ocean action agreed and in place there is a high expectation that real traction in EBM will build both within the jurisdictions of each island state and across the region.

\section{Bird's Head, Indonesia: a subnational Seascape}

Bird's Head Seascape's (BHS) coast and waters span $225,000 \mathrm{~km}^{2}$ in West Papua, Indonesia, containing diverse coral reefs, extensive mangrove bays, turtle nesting beaches, marine lakes and the highest recorded marine biodiversity for an area of its size in the world (Veron et al, 2009; Allen and Erdmann, 2012). The area is a national and global priority for marine conservation (Huffard et al, 2012). As of 2010, more than 1 million people lived within $10 \mathrm{~km}$ of the coast, with a population density of 20.1 per $\mathrm{km} 2$. Many live in remote, culturally distinct areas with high rates of poverty and weak central governance (Tallis et al. 2010). There is a strong tradition of marine tenure rights, since many people rely on fisheries for food security.

The vision for a BHS initiative began in 2004 with discussions between Conservation International, The Nature Conservancy and WWF-Indonesia aimed at developing a shared strategy to protect the Seascape's biodiversity in a manner that also sustains fisheries, empowers communities, and ensures the growth of sustainable local livelihoods. Over time the partnership expanded into a coalition of more than 20 local NGOs, universities, and the regency, provincial and national governments coordinated by a BHS secretariat in the provincial capital.

Innovative outreach and education programs helped the coalition build strong, multi-disciplinary social and political understanding and support for conservation and EBM, resulting in a carefully designed network of 15 EBM-based MPAs (five pre-existing MPAs and ten new) that cover more than $36,000 \mathrm{~km}^{2}$, about $16 \%$ of the Seascape. Each MPA completely protects at least $20-30 \%$ of all critical habitats in No-Take-Zones, with the majority of the remaining MPA areas restricted for sustainable traditional fishing practices by local communities.

Empowering and training local communities and governments to professionally manage MPA resources was a key strategy. All the new MPAs were designed through a bottom-up, community-driven process and their management teams were recruited directly from local communities. In 2013, the local community MPA teams were officially integrated into an innovative comanagement arrangement with the local government. Regular management effectiveness evaluations are done using the World Bank's 'MPA Scorecard' (Staub \& Hatziolos, 2004; Glew et al. 2015).

BHS is part of the broader Coral Triangle Initiative, a multilateral agreement and partnership for ecosystembased management of coastal and marine resources begun in 2007 to protect coral reefs, fisheries and food security in Indonesia, Malaysia, Papua New Guinea, Philippines, Solomon Islands and Timor Lese in the Coral Triangle, a large-scale marine ecosystem at the confluence of the Indian Ocean and the Western Pacific.

\section{MULTINATIONAL: LARGE MARINE ECOSYSTEMS (LME)}

The US National Oceanic and Atmospheric Administration (NOAA) identified the system of large marine ecosystems (LMEs) to facilitate EBM within broad areas of the coastal ocean that are ecologically linked by currents or other factors. There are 66 LMEs, 64 of which are populated, which include coastal areas from river basins and estuaries to the seaward boundaries of continental shelves and outer margins of major coastal currents as well as enclosed or semi-enclosed seas. Each LME is characterized by 
distinct bathymetry, hydrography, productivity and trophic structure, but all provide ES essential to their bordering countries, contributing 95\% of the global fishery catch and an estimated US $\$ 28$ trillion annually to the global economy (IOC-UNESCO and UNEP 2016). However, population increases, migration to the coasts and consequent pressures from human activities are affecting their ability to provide such benefits. Consequently, the UN Global Environment Facility (GEF) commissioned an assessment (IOCUNESCO and UNEP 2016) of the 49 transboundary LMEs, i.e. those that cross the boundaries of two or more nation states, which evaluated them based on indicators in six categories: socio-economics, governance, productivity, fish and fisheries, and pollution and ecosystem health, taking into account the probability of adverse consequences for people and the environment resulting from decline in LME health status.

For each LME, IOC-UNESCO and UNEP (2016) identified current trends, main drivers, most impactful issues and ecosystem services most at risk while also identifying where human dependence on LME ecosystem services is highest and where humans are most vulnerable to changes in LME condition. The study evaluated the status of governance and arrangements between nations for LME management, but did not provide examples of ongoing LME management initiatives.

A good example of the LME approach is the Caribbean Large Marine Ecosystem Project (CLME+), which was launched in January of 2016 and unites the Caribbean Large Marine Ecosystem and the Brazil Shelf Large Marine Ecosystem, covering an area of about 4.4 million $\mathrm{km}^{2}$. A highly ocean dependent geography, CLME+ is a partnership of 25 countries in South America, Central America, and the Caribbean Islands region, also including dependent territories from France, the Netherlands, the United Kingdom and the United States of America. The area is characterized not only by its natural richness of diversity in habitats and species, but is also unique in its great cultural and demographic diversity. Within the CLME+ are countries with populations ranging from a few hundred million to just a few thousand inhabitants, some of predominantly Afro-Caribbean and Native-Caribbean background and others of Euro-Caribbean compositions. At least four main languages are spoken (Spanish, English,
French, and Portuguese) in addition to the many local creole tongues. Co-financed between the member countries and the GEF, the project seeks to improve management of reef, pelagic, and continental-shelf ecosystems. A preliminary Transboundary Diagnostic Assessment (TDA) was conducted prior to the launch of the project, which identified unsustainable fishing practices, habitat degradation, and pollution as the three main drivers negatively affecting the sustainable delivery of ocean goods and services. In response to the TDA, the CLME+ Project Coordinating Unit developed a Strategic Action Programme, which includes policy, legal, governance, and conservation management interventions. The specific objectives include: 1) achieving the sustainable management of shared living marine resources (LMR); 2) improving the shared knowledge base for sustainable use and management of transboundary LMR; 3) implementing legal, policy and institutional reforms to achieve sustainable transboundary management of LMR; and 4) developing an institutional and procedural approach for monitoring, evaluation, and reporting. A main focus of the project is to improve information collection, flows, and transfers. To support that goal, the project is creating a multidisciplinary information management system, aimed at supporting decisionmaking at national and regional scales.

National Scale: Overview (Fig. 9). Mori, Andrews and Taei (in preparation) reviewed online resources, including government websites (legislation, policies and national strategic plans) and multiagency/ NGOs programmes for all coastal countries that possess an EEZ to see which ones had approved national plans or marine management policy that covered their "whole domain" (including islands, the Territorial Sea, the Exclusive Economic Zone, the seabed, as well as terrestrial and watershed areas with significant connections to marine resources). Large marine protected areas and territorial islands were not reviewed. As of 2016, only $10 \%$ of countries are applying a "whole domain" marine management approach in their marine jurisdiction, with another $7 \%$ in progress of doing so, the two totalling about $30 \%$ of ocean area under national jurisdiction (Fig. 9). The Northern European region leads in this effort, with whole domain management nationally in force in Germany, Netherland, Norway, UK, Scotland, Belgium and Germany as well as Latvia, Lithuania, 
Netherlands, Sweden and Poland. Other locations found to be applying whole domain management or making progress toward doing so were Portugal, Canada and the USA (partial), Russia (partial), South Africa, Angola, Namibia, Seychelles, China (partial), Indonesia (partial), Seychelles, Australia, New Caledonia, Cook Islands and Palau.

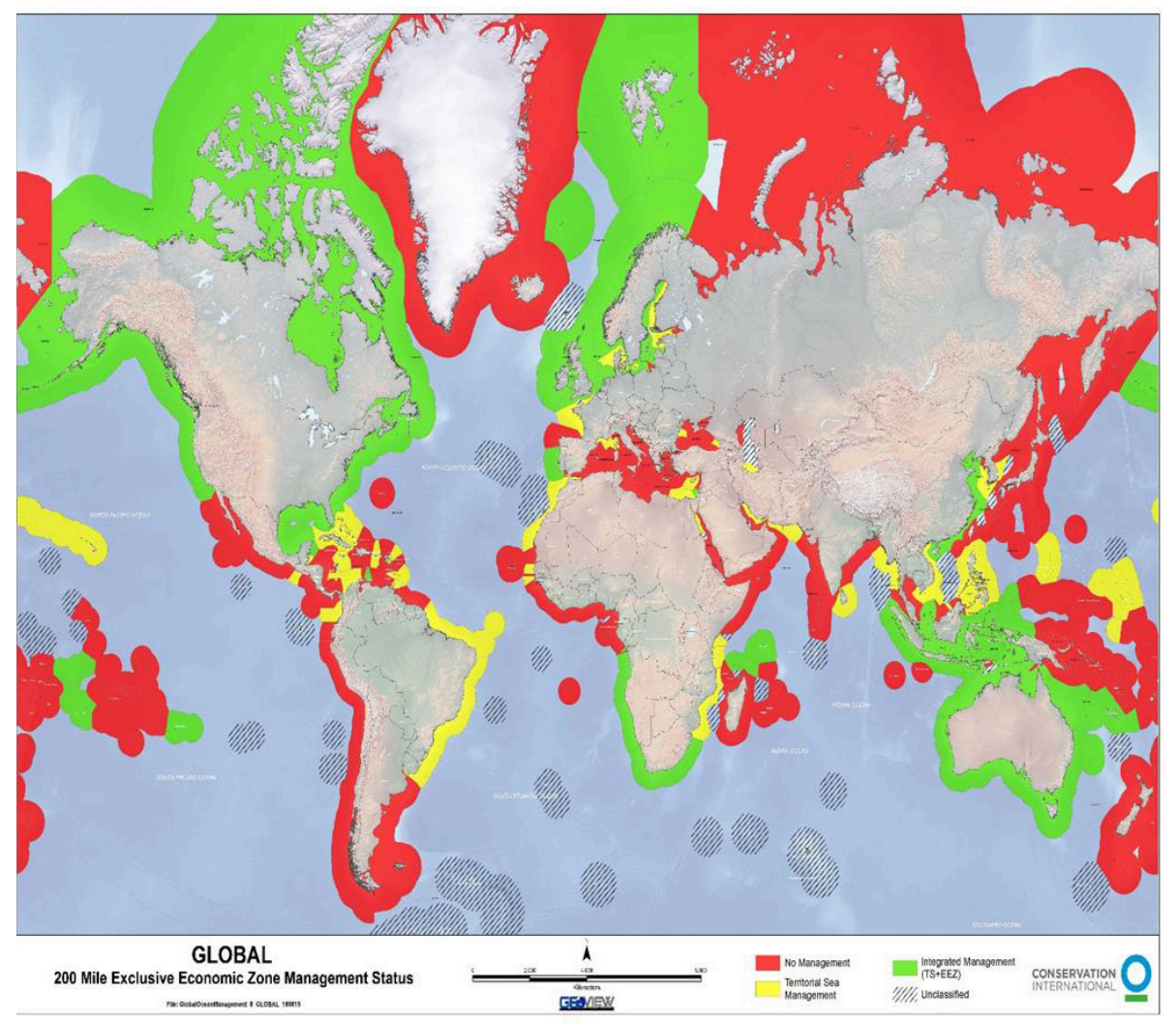

Figure 9. Spatial representation of the global status of integrated marine management (EBM) at national scale. Green represents a "whole domain" integrated marine management policy approach; Yellow represents areas where management only includes territorial waters; and Red represents no approach for integrated management. Map courtesy of Mori, Andrews and Taei, Conservation International (in preparation).

and warning system for the ocean-society-economy system. The preliminary $\mathrm{OHI}$ assessment results will identify priority thematic and spatial areas, as well as develop a more detailed assessment of the trends for those areas. As part of this initiative to manage integral socio-ecological systems, SOA is: 1) identifying key characteristics/indicators in each ocean area and setting reference conditions (targets); 2) researching the system interactions of the identified key indicators; 3) developing models and software for a monitoring and warning system on the carrying capacity of ocean and coastal habitats; 4) and piloting these systems in five regions: Bo Sea Changxingdao, Dongying, Ningbo city, Wenzhou, and Huizhou city. The implementation of this strategy is resulting in improvements to the National Marine Data and Information Service to ensure adequate data availability and standardization across the pilot regions.

Colombia: This South American nation's efforts to systematically use EBM as an integrated ocean mechanism are reflected in the creation of the Colombian Oceans Commission (CCO), an intersectorial body whose role is to assess, consult, plan and coordinate the national government's initiatives in regards to national ocean and coastal zone policy and their associated themes,

\section{National scale: examples from three countries.}

China: China's State Oceanic Administration (SOA) is responsible for implementing international marinerelated agreements such as the United Nation's Law of the Sea (UNCLOS). It is in charge of monitoring, evaluating, protecting, and managing the ocean and coastal environment, as well as passing and enforcing laws and regulations, developing standards, creating and implementing plans, and ensuring the sustainable exploitation of marine resources. Because SOA manages across sectors (including fisheries, coastal and ocean habitats, economic development, climate change) it has proposed using the Ocean Health Index as the core evaluation tool to build a monitoring such as science, technology, economy, environment, and sustainable development. The CCO spearheaded the development of a National Ocean Indicators framework, which contains 113 indicators from subjects ranging from ecology, sociology, and economy, and is aimed at centralizing all ocean-related information into a single platform. In combining all these elements together, the $\mathrm{CCO}$ is able to coordinate the sustainable management of ocean and coastal resources across sectors and institutions.

In October of 2012, the CCO announced its intentions to independently develop a national level Ocean Health Index assessment to fulfill its mandate to advise the government on the adoption, design, and 
implementation of mechanisms for the "management, study, and conservation of ocean and coastal areas and their associated resources." For this, CCO has created and trained technical working groups at sub-national scales to standardize methods for data gathering and analysis across all national jurisdictions. The nation has also established a wide range of short- and longterm ocean-management- related targets, the first group of which are bound to 2018 (coinciding with the end of the current presidential administration) and the second group set to 2025 (a 10-year horizon from when the targets were first set). In establishing a systematic approach for gathering and analyzing information at various scales of management, Colombia is able to design and implement strategies to articulate sectoral policies on the use and exploitation of ocean and coastal areas and their resources. This approach not only fosters a more strategic allocation of resources, but also enhances ocean culture and awareness, and contributes to the recognition of the oceans as a sustainable resource for the socioeconomic development of the nation.

New Caledonia: Management of marine habitats and resources started several decades ago in NewCaledonia (NC) with the first MPA created in the 1970 s as a no-take zone. However, that simply provided full protection to a very beautiful and quite pristine reef, but did not specify how to manage the system as a whole. For the following 40 years, NC expanded an MPA network throughout the territory's extensive lagoon and reef system with the creation of 30 MPAs. Yet it was only in the early 2000s as the territory considered being acknowledged as a World Heritage Site for its biodiversity, ecological processes, and natural beauty that ecological units began to be defined and EBM became more widely implemented. At the time, a panel of marine experts from various backgrounds and fields of expertise was reunited to identify areas of ecological importance. A total of six areas were submitted as "Lagoons of NewCaledonia: Reef diversity and associated ecosystems" and acknowledge by UNESCO as a World Heritage Site in series in 2008. The whole reef ecosystem including not only reef habitats, but also mangroves, sea grass bed, islets and beach, was considered as an integrated system that needed to be understood and managed as a whole. Several management plans were developed for each of these sites, which included input from 20 indigenous tribes, and priority areas were identified based on ecological importance, cultural importance, uses, and threats. In 2014, NC created the Coral Sea Natural Park, a management area of 1.293 million $\mathrm{km}^{2}$ that encompass the entire EEZ (at the time the largest MPA in the world), a huge commitment to the Pacific Oceanscape (see above) and the global efforts to preserve large portions of the oceans. The Park integrates a great variety of ecosystems from reef and islands to pelagic systems, seamounts and deep sea coral ecosystems. To support management efforts, key habitats, high biodiversity/biomass areas, endangered and iconic species, connectivity between sites as well as Ecologically and Biologically Significant Areas (EBSAs) or Important Birds Areas (IBAs) were considered and juxtaposed with human activities and uses. The Park's management committee incorporated within the management plan objectives focusing on whole ecosystem protection as well as responsible uses with reduced impacts on species and habitats. Furthermore, connectivity is a core component included in several objectives as it encourages managers and conservation practitioners to understand the big picture and the existing links between different ecosystems. For such large MPAs, EBM implies considering a great variety of scales as well as developing an innovative governance mechanism between managers across the site boundaries, both in-country with Provincial authorities and at the regional level with neighboring countries. ${ }^{28}$

Sub-national scale: As of 2013, UNESCO estimated that more than 40 countries will have established between 60-70 marine spatial plans at the national (EEZ), subnational (territorial seas), or province or state level over the next decade (Ehler 2014). The process of marine spatial planning, although originally developed and implemented in high-income countries such as Western Europe, North America, and Australia, is now rapidly developing across mid- and lower income nations such as Indonesia, Vietnam, South Africa and island countries of the Carribbean and Coral Triangle. Several case-studies are summarized below. Many more plans are developing or underway globally. 
Early EBM adoption in Norway. Norway was one of the earliest adopters of an integrated ecosystem-based management approach aligned with international guidelines set in the EU Marine Strategy Framework Directive. The first integrated management plan was developed for the Barents-Sea-Lofoten region, bordered by Norway and Russia, which still possessed a relatively intact ecosystem with diverse habitats and comparatively clean water, but faced the potential for rising pressures and pollution associated with increased oil and gas exploration and production, fishing (especially benthic trawling), shipping and aquaculture, as well as climate change (Buhl-Mortensen et al. 2016, Olsen et al. 2016). The Norwegian Barents Sea Management Plan (MSMP) was developed between 2002-2006 led by a steering committee chaired by the Norwegian Ministry of Environment, with updates in 2009 and 2011, and focused on space conflict among oil and gas development, marine transport, nature conservation as well as value creation across marine sectors. Both the process of developing a plan and the plan itself have since been used as models for management plans for all Norwegian Sea areas, all of which aim to promote economic development through sustainable use.

MSP in Scotland. In an effort to a develop marine spatial planning at the national scale for Scotland, as designated by the Marine (Scotland) Act of 2010 and UK Marine and Coastal Access, 2009, the Shetland Island Marine Spatial Plan (SMSP) was implemented as part of a pilot project across four regions: Firth of Clyde, the Sound of Mull, Berwickshire Coast and Shetland Islands in order to develop and test the most effective marine management approach for sustainable development of Scotland's coastal and marine environments.

The SMSP mapped key environmental, socio-economic and cultural elements and activities and highlighted ecosystems services, including a sub-plan that focused primarily on aquaculture usage and capacity. The SMSP was most constructive in establishing a Marine Atlas and policy framework to guide decision-making and national-planning of marine developments, especially at initial stages, and promoting international and regional collaboration. The SMSP first began in 2006 under the Scottish Sustainable Marine Environment Initiative guided by Marine Scotland, a directorate of the Scottish government, and a national and local steering group, and released its fourth edition in 2015 (Kelly et al. 2012, Shucksmith et al. 2014).

MSP for wind energy siting in Massachusetts. Massachusetts was the first state in the U.S. to pass a law requiring MSP for ocean management. White, Halpern and Kappel (2012) studied the economic relationships between offshore windfarm sites selected by the state, fisheries (flounder and lobster) and the whale watching industry. Compared to conventional single-sector planning, MSP could prevent $>\$ 1$ million in losses to fisheries and whale watching while generating $>\$ 10$ billion in extra value to the wind energy sector.

\section{CONCLUSION: GAINING SAFE HARBOR}

The large number of management-related processes and their many names, synonyms and acronyms; the multitude of goals and obligations expressed in treaties and other initiatives; and the variety of decision-support tools in use creates a complex and frequently confusing seascape for marine managers, policy makers and others trying to chart a course toward healthier oceans for coastlines, countries and the world.

Equally confounding is the sheer number of entities responsible for marine management. Global Ocean Commission (2014) illustrates the relationships among 51 supra-national institutions, programs and organizations operating within the framework of the United Nations whose purviews include ocean policy. Countless other entities share that charge at national and sub-national levels. For example, in the U.S. at least 20 federal agencies implement over 140 federal ocean-related statutes (Crowder et al. 2006). Boyes and Elliott's (2016) map (Fig. 10) of environmental protection dramatically illustrates the complicated seascape confronting marine managers in the EU, including 200 directives, regulations and many other forms of legislation that have direct repercussions for marine environmental policy and management.

For those piloting activities in such complex seascapes, legal-political features are not obstacles to avoid, but bases to be touched. That is, actions taken must be consistent with the aims of all relevant initiatives and obligations. Thanks to the 50 years of sequential deliberations summarized earlier, as well as further 
deliberations within the marine conservation and management communities, higher level initiatives increasingly share goals and are cross-referential, so that coherence with one may confer coherence with a number of others. At the same time, changes at the national (e.g. Brexit) (Boyes and Elliott 2016) or international level may add further complexity to the seascape such that it will likely always remain more complicated than anyone wishes.

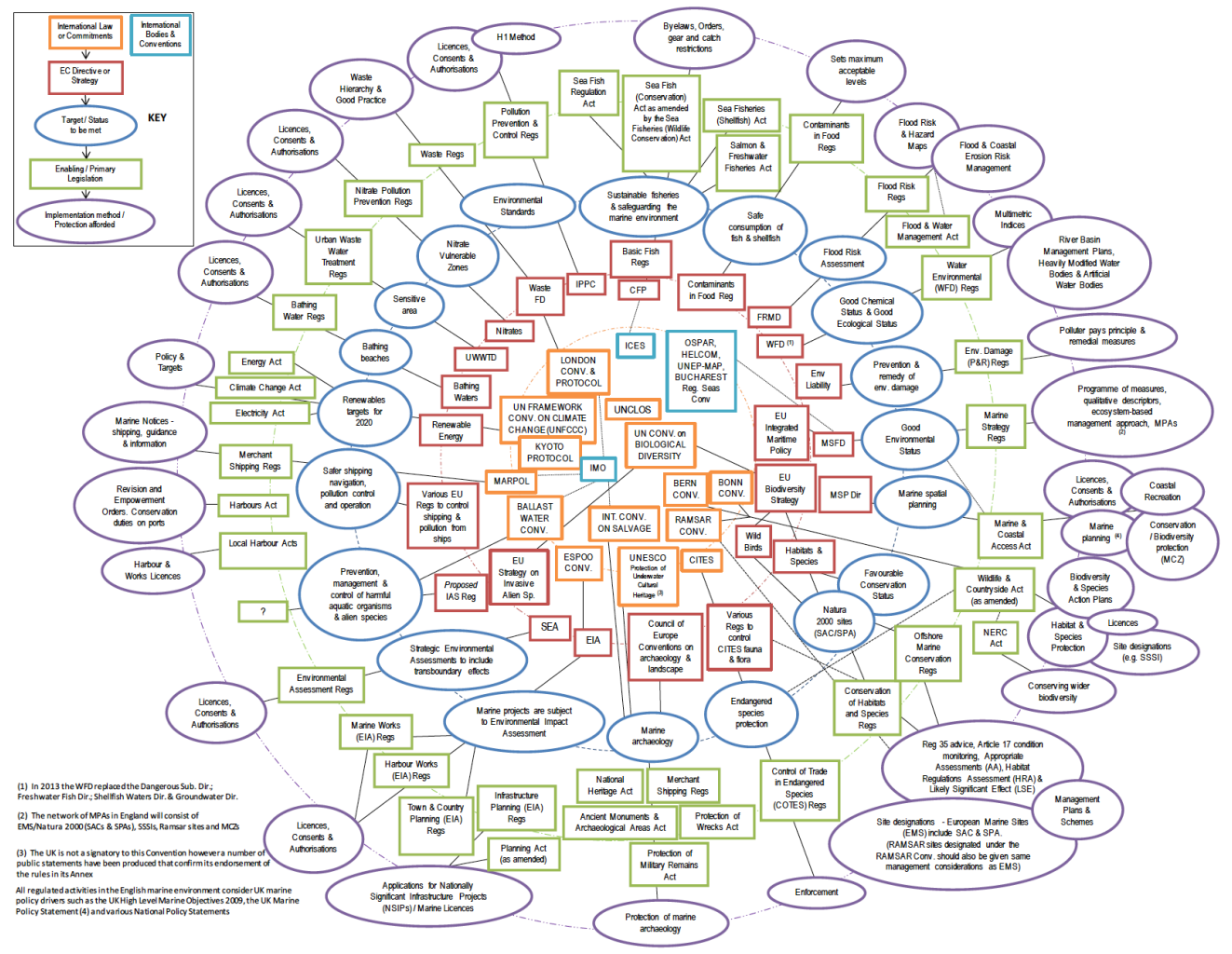

goals and values ensure that management aims and methods will vary. Territorial disputes in some marine regions complicate potential management efforts. Nevertheless, numerous examples of planning and management efforts exist at all scales and a steady stream of new ones appears in the literature on a nearly weekly basis. International, national and sub-national initiatives are undertaking marine management at a steadily growing rate and with increased focus on shared goals (e.g. the UN Sustainable Development Goals) and shared understanding of the need for an ecosystembased approach and adaptive management. Marine management is still a work in progress and the state of the world's oceans leaves no doubt that achieving healthy oceans will require a generation or more. Regardless, the fact that the Operating Manual for our spaceship, Planet Earth, now has a pretty good draft for its Oceans chapter, with more and more regions using it, is good cause for celebration.

Figure 10. International, European and UK legislation giving protection to the marine environment. Marine environmental legislation horrendogram showing Regulations made through the European Communities Act 1972 to implement an EU directive versus a UK Primary Act of

Parliament. Source: Fig. 1 in Boyes and Elliott (2016), used with permission of Elsevier.

However, just as a ship's captain safely navigates by paying close attention to specific navigational markers rather than memorizing every feature of submarine topography, ocean health can usually be pursued successfully by paying close attention to the key concepts and guidelines (Box 6), consulting additional sources for further detail, advice and examples (Box 7) when desired or needed.

The need for planning and management is sensed nearly everywhere, though jurisdictions vary in their readiness and capacity to carry out such work. Different geographic, ecologic, political, social and economic circumstances, as well as different cultural

\section{BOX 6. Key navigational markers for the} journey toward ocean health.

- $\quad$ Specify the geographic area to be managed using an ecosystem-based approach

- Describe the overall goals for management using marine spatial planning

- Assess current status of the ecological, sociopolitical and economic aspects of the selected socio-ecological system 
- Explain why the assessment is being done

- Describe what the assessment aims to achieve

- Specify the importance (weights) of the various aims

- Select targets (reference points) for those aims

- Select aim-specific indicators able to detect current status and sensitive to change

- Gather data relevant to the selected indicators

- Analyze data to describe current status

- Analyze changes in status from previous assessments (if any) and progress toward goals

- Forecast, if possible, likely changes in future conditions given hypothetical specified actions

- Hindcast, where appropriate, past and present conditions had specified actions not been taken

- Use assessment results to guide plans and management actions to improve overall system structure and function

- Create strategic plan to improve overall system health or selected aspects thereof

- Plan and organize strategic activities in best ways to achieve overarching goals

- Select and implement processes and other tactical actions needed to achieve strategic goals

- Use decision support tools appropriate to tasks and circumstances selected for action
- Repeat assessment to determine whether strategy, plans and tactics moved system toward goals

- Review and update strategic goals, plans and tactics based on results of assessments and new information or conditions

\section{BOX 7. LEARN MORE ABOUT EBM, MSP AND DECISION SUPPORT TOOLS: Training, Professional Development and Educational Resources}

There are a variety of ways for current and future EBM and MSP practitioners to broaden their knowledge base and connect with other practitioners for the sharing of best practices. For those seeking a formal degree, a number of universities offer graduate and postgraduate marine policy and management degree programs that explicitly incorporate EBM and MSP theory and training and/or elements useful to EBM and MSP practitioners (e.g., GIS skills, conflict resolution training). The University of St. Andrews in Scotland offers a one-year master's program dedicated to marine EBM. Other universities primarily in Europe and North America - offer graduate degree programs - primarily at the master's degree level - dedicated to MSP or with strong MSP elements.

For current practitioners wishing to increase their understanding of the theory and practice of MSP without completing a formal degree, a number of professional training short courses exist. Some, such as the Marine Planning Advancement Training course and Blue Planning in Practice training course, provide opportunities to join other practitioners from other regions and planning processes - online or in person - on predetermined dates. Other courses are generally held for groups from a single planning process. Relatively few short courses for EBM currently exist. 
Informal resources to help professionals stay current and develop in their practice and learn from and share their own knowledge with others on an on-going basis also exist. Some free and widely-utilized educational and networking resources for EBM and MSP practitioners include:

- EBM Tools Network: Co-hosts a webinar series on EBM and MSP tools and case studies (as well as other current topics in marine conservation and management). Also hosts a discussion listserve that enables people to reach out to over 4,500 other marine and coastal managers and conservationists worldwide to ask questions and share information about tools and methods that can be used to improve marine conservation and management. [Sign up for webinar announcements and the discussion listserve.]

- MEAM (Marine Ecosystems and Management) newsletter: Global on-line newsletter for ocean planning and EBM which provides news, analysis, and perspectives from experts and practitioners around the world on a monthly basis. [Sign up here.]

\section{- OpenChannels.org: Fully-searchable,} global on-line knowledge hub on ocean planning and EBM which provides updates on latest news, publications, grant opportunities, job opportunities, and more. Recordings of past webinars co-hosted with the EBM Tools Network, the top literature lists for EBM and MSP, and the on-line guide to evaluating MSP plans will be of particular interest to EBM and MSP practitioners.

\section{A COSMIC POSTSCRIPT}

From a distance the world looks blue and green, and the snow-capped mountains white.

From a distance the ocean meets the stream, and the eagle takes to flight.

From a distance, there is harmony,

and it echoes through the land.

It's the voice of hope, it's the voice of peace,

it's the voice of every man...

it's the voice of every man...

From a Distance, Verses 1 and 2, Words and music by uulie Gold, 1987

Based on data from the National Aeronautics and Space Administration's (NASA) Hubble Telescope, the universe is estimated to contain at least 125 billion galaxies, each with billions of stars. Our Milky Way galaxy alone contains 10 to 100 billion stars. An estimated $30 \%$ of stars have planets, suggesting the existence of between 3 billion to 30 billion planets just in the Milky Way. Though many of those planets or their moons are potential homes for oceans and life, we only know one place where both exist: Earth.

That may soon change. Evidence suggests that other oceans exist relatively nearby, causing us to wonder whether simple life exists in the oceans under the icecovered surfaces of Europa, one of Jupiter's 62 known moons, or Enceladus, one of Saturn's 62 moons.

Deeper in space there is every likelihood that life-including intelligent life-- exists on other planets sharing Earth's good fortune to occupy a zone neither too close nor too far from their central star, where water exists in all three of its phases, vapor, liquid and ice, and with sufficient mass that gravity prevents vapor from escaping into space. If so, they probably have oceans too.

Agencies and scientists engaged in space exploration here on Earth recognize the likelihood and urgent practical implications of life's existence elsewhere. By sterilizing spacecraft prior to planetary exploration and 
quarantining samples returned to Earth ${ }^{29}$, they protect any alien biodiversity as well as our own, procedures that would be appreciated by any intelligent beings out there, who are probably as curious about life on remote worlds as we are.

Immediate practical and ethical reasons move us to take good care of Earth's oceans and the remarkable array of life forms it supports, including us. Doing so not only extends our ethical network to include respect for the integrity of the planet we call home, but also honors those elsewhere in the universe who might one day spot our remarkable 'blue marble' and perhaps be able to marvel at the life that evolved here and how well we acted as its steward.

\section{ACKNOWLEDGEMENTS}

We thank Beau and Heather Wrigley, The Pacific Life Foundation, Dan Sten Olsson, CEO of Stena AB, Jayne and Hans Huffschmid, and the Gordon and Betty Moore Foundation for making this work possible through support given to the Ocean Health Index, the National Center for Ecological Analysis and Synthesis, and Conservation International.

We thank Daniel Hales, Jennifer Rock, Eva Schemmel and Greg Stone for ideas, suggestions and critique during preparation of this work. We are grateful to Megan Nowak for graphic design of the manuscript and a number of figures.

\section{HOW TO CITE THIS ARTICLE}

Suggested citation: Katona, S.K., J. Polsenberg, J.S.S. Lowndes et al. 2017. Navigating the seascape of ocean management: waypoints on the voyage toward sustainable use. OpenChannels: Forum for Ocean Planning and Management. 44 pp. Available at: $\underline{\text { https:// }}$ www.openchannels.org/literature/16817.

\section{LICENSE INFORMATION}

This work is licensed under a Creative Commons Attribution-NonCommercial- $\quad$ ShareAlike 4.0 International license. 


\section{REFERENCES}

Aeschylus. 400 B.C. The Oresteia. A Trilogy Consisting of the tragedies: Agamemnon, The Libation Bearers, The Eumenides. A Translation by Ian Johnston. http://abs.kafkas.edu.tr/upload/225/The Orestia.pdf

Adams, M.W. 2014. The value of valuing nature. Science 346(6209):549-551. 31 October, 2014.

Agardy, T. 2005. Global marine conservation policy versus site-level implementation: the mismatch of scale and its implications. Marine Ecology Progress Series 300:242-258.

Allen, G.R. and M.V. Erdmann, 2012. Reef fishes of the East Indies. Perth, Australia: University of Hawai'i Press, Volumes I-III. Tropical Reef Research. http://dx.doi.org/

Altman, I., R. Boumans, J. Roman and L. Kaufman. 2012. Multi-scale Integrated Model of Ecosystem Services (MIMES) for the Massachusetts Ocean (v 1.0). Technical Document. September 2012. http://www.seaplan.org/ wp-content/uploads/210.02.12-MIMES-tr1.pdf

An, L. 2012. Modeling human decisions in coupled human and natural systems: Review of agent-based models. Ecol. Modell. 229: 25-36. doi:10.1016/j.ecolmodel.2011.07.010

Anderson, J.L, C.M. Anderson CM, J. Chu et al. 2015. The Fishery Performance Indicators: A management tool for triple bottom line outcomes. PLoS ONE 10(5):e0122809. doi:10.1371/journal.pone.0122809

Ardron, J. 2010. Marine planning: tragedy of the acronyms. Marine Ecosystems and Management 4(2). October November 2010. Online. http://depts.washington.edu/meam/MEAM15.pdf

Ardron, J., E. Druel, K. Gjerde, K. Houghton, J. Rochette and S. Unger. 2013. Advancing Governance of the High Seas. Institute for Advanced Sustainability Studies (IASS), Potsdam and Institute for Sustainable Development and International Relations (IDDRI), Paris. IASS Policy Brief 1/2013. http://www.un.org/depts/los/ biodiversityworkinggroup/documents/iass-iddri2013.pdf

Atkins, J.P., Burdon, D., Elliott, M., Gregory, A.J., 2011. Management of the marine environment: integrating ecosystem services and societal benefits with the DPSIR framework in a systems approach. Mar. Pollut. Bull. 62 (2): 215-226.

Atkinson S., N. Esters N., G. Farmer., K. Lawrence and F. McGilvray. 2011 The Seascapes Guidebook: How to Select, Develop and Implement Seascapes. Conservation International, Arlington, Virginia, USA. 60 pp. www. conservation.org/marine/seascapesguidebook

Bagstad, K.j., D.J. Semmens, S. Waage and R. Winthrop. 2013. A comparative assessment of decision-support tools for ecosystem services quantification and valuation. Ecosystem Services 5: E27-E39. http://unstats.un.org/unsd/envaccounting/seeaRev/meeting2013/EG13-BG-10.pdf

Barbier, E. 2014. Economics: Account for depreciation of natural capital. Nature 515:32-33. 06 November 2014. doi:10.1038/515032a

Beaumont, N.J., M.C. Austen, J.P. Atkins, D. Burdon, S. Degraer, T.P. Dentinho, S. Derous, P. Holm, T. Horton, E. van Ierland, A.H. Marboe, D.J. Starkey, M. Townsend and T. Zarzycki. 2007. Identification, definition and quantification of goods and services provided by marine biodiversity: implications for the ecosystem approach. Marine Pollution Bulletin 54:253-65. 
Blasiak, R., E. Pacheco, K. Furuya, C.D. Golden, A.R. Jauharee, Y. Natori, H. Saito, H. Sinan, T. Tanaka, N. Yagi and E. Yiu. 2016. Local and regional experiences with assessing and fostering ocean health. Marine Policy 71: 54-59. September 2016. doi:10.1016/j.marpol.2016.05.011

Blau, J. and L. Green. 2015. Assessing the impact of a new approach to ocean management: Evidence to date from five ocean plans Marine Policy 56:1-8. http://www.sciencedirect.com/science/article/pii/S0308597X15000299

Bolding, K. E. 1966. The economics of the coming spaceship earth. Presented at the Sixth Resources for the Future Forum on Environmental Quality in a Growing Economy, Washington, D.C. , March 8,1966. Available online http://www.eoearth.org/view/article/156525/

Borja A., E.M, P.V.R. Snelgrove, M.C. Austen, T. Berg, S. Cochrane, J. Carstensen, R. Danovaro, S. Greenstreet, A-S. Heiskanen, C.P. Lynam, M. Mea, A. Newton, J. Patrício, L. Uusitalo, M.C. Uyarra and C. Wilson. 2016a. Bridging the gap between policy and science in assessing the health status of marine ecosystems. Front. Mar. Sci. 3:175. doi: $10.3389 /$ fmars.2016.00175

Borja, A., M. Elliott, J.H. Andersen, T. Berg, J. Carstensen, B.S. Halpern, A.-S. Heiskanen, S. Korpinen, J.S. Stewart Lowndes, G. Martin and N. Rodriguez-Ezpeleta. 2016b. Overview of integrative assessment of marine systems: the ecosystem approach in practice. Front. Mar. Sci., 01 March 2016 | http://dx.doi.org/10.3389/fmars.2016.00020

Boumans, R., J. Roman, I. Altman and L. Kaufman. 2015. The Multiscale Integrated Model of Ecosystem Services (MIMES): Simulating the interactions of coupled human and natural systems. Ecosyst. Serv. 12, 30-41. doi:10.1016/j.ecoser.2015.01.004

Boyes, S.J. and M. Elliott. 2014. Marine legislation - the ultimate 'horrendogram': International Law, European Directives \& National Implementation. Marine Pollution Bulletin, 86:39-47.

Boyes, S.J. and M. Elliot. 2016. Brexit: The marine governance horrendogram just got more horrendous! Marine Pollution Bulletin 111 (2016) 41-44.

Braat, L.C. and R. de Groot. 2012. The ecosystem services agenda: bridging the worlds of natural science and economics, conservation and development, and public and private policy. Ecosystem Services 1(1):4-15. doi:10.1016/j.ecoser.2012.07.011

Brondizio, E.S. and F.-M. Le Tourneau. 2016. Environmental governance for all. Science 352(6291):1272-1273. 10 June 2016.

Buhl-Mortensen, L. I Gasparsoro, T.V. Fernández et al. 2016. Maritime ecosystem-basesd management in practice: Lessons learned from the application of a generic spatial planning framework in Europe. Marine Policy 75: 174186. DOI: 10.1016/j.marpol.2016.01.024

Burgass, M.J., B.S. Halpern, E. Nicholson and E.J. Milner-Gulland. 2017. Navigating uncertainty in environmental composite indicators. Ecological Indicators 75: 268-278.

Burke, L., K. Reytar, M. Spalding and A. Perry. 2011. Reefs At Risk Revisited. World Resources Institute, Washington. 130 p. http://www.wri.org/publication/reefs-risk-revisited

Carruthers, T., A. Hordyk, D. Butterworth, D. Campbell, H. Geromonth, W. Harford, R. Hillary, Q. Huynh, L. Kell, T. Kitakado and S. Sagarese. 2016. Data-Limited Methods Toolkit (DLMtool) [WWW Document]. NRDC. URL http://www.datalimitedtoolkit.org (accessed 4.10.16). 
Carson, R. 1962. Silent Spring. Boston: Houghton Mifflin; Cambridge, Mass.; Riverside Press.

Center for Ocean Solutions. 2011. Decision Guide: Selecting Decision Support Tools for Marine Spatial Planning. The Woods Institute for the Environment, Stanford University, California. http://themaritimealliance.org/pdf/ cos msp guide selecting tools.pdf

Chan, Kai M.S. and M. Ruckelshaus. 2010. Characterizing changes in marine ecosystem services. F1000 Biology Reports 2010, 2:54 (doi:10.3410/B2-54) available at http://f1000.com/reports/biology/content/2/54

Chapin, F.S. III, M. Sommerkorn, M.D. Robards and K. Hillmer-Pegram. 2016. Ecosystem stewardship: A resilience framework for arctic conservation. Global Environmental Change 34: 207-212. http://dx.doi.org/10.1016/j. gloenvcha.2015.07.003

Cheng, Q., J.C.H. Chiang and D. Zhang 2013. Atlantic Meridional Overturning Circulation (AMOC) in CMIP5 Models:

RCP and historical simulations. J. Climate 26:7187-7197. DOI: 10.1175/JCLI-D-12-00496.1 http://journals. ametsoc.org/doi/pdf/10.1175/JCLI-D-12-00496.1

Christensen, V. and C.J.Walters. 2004. Ecopath with Ecosim: methods, capabilities and limitations. Ecol Modell 2004, 172:109-39.

Coleman, H., M. Foley, E. Prahler, M. Armsby and G. Shillinger. 2011. Decision Guide: Selecting Decision Support tools for Marine Spatial Planning. Center for Ocean Solutions, Stanford, California USA.

Colgan, C. S. 2016. Measurement of the ocean economy from national income accounts to the sustainable blue economy,"

Journal Of Ocean and Coastal Economics 2, Article 12. DOI: http://dx.doi.org/10.15351/2373-8456.1061

Conservation Measures Partnership. 2013. Open Standards for the Practice of Conservation. Version 3.0 / April 2013. www.conservationmeasures.org

Costanza, R. ,R. d'Arge, R. de Groot, S. Farber, M. Grasso, B. Hannon, K. Limburg, S. Naeem, R. V. O'Neill, J. Paruelo, R.G. Raskin, P. Sutton and M. van den Belt. 1987. The value of the world's ecosystem services and natural capital. 1987. Nature 387:253-260. 15 May 1987.

Council on Foreign Relations. 2013. The Global Oceans Regime. Issue Brief. Last updated June 19, 2013. http:// www.cfr.org/oceans/global-oceans-regime/p21035

Crowder, L.G., G. Osherenko, O. R. Young, S. Airamé, E. A. Norse, N. Baron, J. C. Day, F. Douvere, C. N. Ehler, B. S. Halpern, S. J. Langdon,. L. McLeod, J. C. Ogden, R. E. Peach,A. A. Rosenberg and J. A. Wilson. 2006. Resolving mismatches in U.S. ocean governance. Science 313: 617-618. 4 August 2006. https://woods.stanford.edu/sites/ default/files/documents/NYC-Salon-Crowder-Policy-Brief-20111004.pdf

Daigle, R.M., W. Haider, S. Fernández-Lozada, K. Irwin, P. Archambault and I.M. Côté. 2016. Public perception of ocean-derived benefits in Canada. Marine Policy 74: 77-84.

Daily, G.C., S. Alexander, P.R. Ehrlich, L. Goulder, J. Lubchenco, P.A. Matson, H.A. Mooney, S. Postel, S. H. Schneider, D. Tilman and G.M. Woodwell. 1997. Ecosystem services: benefits supplied to human societies by natural ecosystems. Issues in Ecology 1(2): 1-18. https://cfpub.epa.gov/watertrain/pdf/issue2.pdf 
Daily, G.C. 1997a. Introduction: What are ecosystem services? Pages 1-10 in G. Daily, editor. Nature's Services: Societal Dependence on Natural Ecosystems. Island Press, Washington, D.C.

Dennison W.C,, T.R. Lookingbill, T.J. Carruthers, J.M. Hawkey and S.L. Carter. 2007. An eye-opening approach to developing and communicating integrated environmental assessments. Front Ecol Environ 5:30714.

Dickinson, M., M. Rutherford and T. Gunton. 2010. Principles for Integrated Marine Planning: A Review of International Experience. Environments Journal Volume 37(3). https://www.researchgate.net/ publication/265620914 Principles for Integrated Marine Planning A Review of International Experience

Douvere, F., F. Maes, A. VanHulle and J. Schrijvers. 2007. The role of marine spatial planning in sea use management: The Belgian case. Marine Policy 31:182-191. http://www.unesco-ioc-marinesp.be/uploads/ documentenbank/4196c93f0934d5d1decb5b1cdbf9bf87.pdf

EBM Tools Network, 2011. EBM Tools Database [WWW Document]. Creat. Commons Attrib. Non-Comercial Licens. v3. URL https://ebmtoolsdatabase.org (accessed 10.5.16).

Edgar, G.E., S.A. Banks, S. Bessudo, J. Cortés, H.M. Guzmán, S. Henderson, C. Martinez, F. Rivera, G. Soler, D. Ruiz and F.A. Zapata. 2011. Variation in reef fish and invertebrate communities with level of protection from fishing across the Eastern Tropical Pacific seascape. Global Ecology and Biogeography 20 (5):730-743. 10.1111/j.14668238.2010.00642.x

EEA. 2011. Europe's Environment: An Assessment of Assessments. European Environment Agency. http://www. eea.europa.eu/publications/europes-environment-aoa/download

Ehler C. 2014. A guide to evaluating marine spatial plans. Intergovernmental Oceanographic Commission Manual and Guides no. 70, ICAM Dossier no. 8. Paris: UNESCO http://unesdoc.unesco.org/images/0022/002277/227779e. pdf

Ehler, C. and F. Douvere. 2009. Marine Spatial Planning: a step-by-step approach toward ecosystem-based management. Intergovernmental Oceanographic Commission and Man and the Biosphere Programme. IOC Manual and Guides No. 53, ICAM Dossier No. 6. Paris: UNESCO.

http://www.unesco-ioc-marinesp.be/uploads/documentenbank/d87c0c421da4593fd93bbee1898e1d51.pdf

Ehler, C. and F. Douvere. 2007. Visions for a Sea Change. Report of the First International Workshop on Marine Spatial Planning. Intergovernmental Oceanographic Commission and Man and the Biosphere Programme. IOC Manual and Guides, 46: ICAM Dossier, 3. Paris: UNESCO, 2007. http://www.unesco-ioc-marinesp.be/uploads/ documentenbank/322a25f624fcb940dc70d0b3b510de24.pdf

Elfes, C.T., C. Longo, B.S. Halpern, D. Hardy, C. Scarborough, B.D. Best, T. Pinheiro, G. Dutra. 2014. A regionalscale ocean health index for Brazil. 2014. PLoS ONE 9(4): e92589. doi:10.1371/ journal.pone.0092589

Elliott, M. 2014 Integrated marine science and management: wading through the morass. Marine Pollution Bulletin $84: 1-4$

Ellis, G. and W. Flannery. 2016. Marine spatial planning: Cui bono? Pp. 122-128 in Flannery et al. (2016) op.cit.

Engler, C. 2015. Beyond rhetoric: navigating the conceptual tangle towards effective implementation of the ecosystem approach to oceans management. Environmental Reviews. NRC Research Press. Environmental Review 23(3):288-320. 
Fairgrieve, R. 2016. Maritime spatial planning - “ad utilitatem omnium.” Pp. 140-143 in: Flannery et al. (2016) op.cit.

Farmer, A., L. Mee, O. Langmead, P. Cooper, A. Kannen, P. Kershaw and V. Cherrier. 2012. The Ecosystem Approach in Marine Management. EU FP7 KNOWSEAS Project. ISBN 0-9529089-5-6. http://www. msfd.eu/knowseas/library/PB2.pdf

Fernández-Macho, J., P. González and J. Virto. 2015. An index to assess maritime importance in the European Atlantic economy. Marine Policy 64 (2016) 72-81. http://dx.doi.org/10.1016/j.marpol.2015.11.011

Flannery, W. et al. 2016. Exploring the winners and losers of marine environmental governance.

Planning Theory \& Practice 17(1): 121-151.

http://dx.doi.org/10.1080/14649357.2015.1131482

Fock, H.O. and G. Kraus. 2016. From metaphors to formalism: a heuristic approach to holistic assessments of ecosystem health. PLoS ONE 11(8):e0159481. doi:10.1371/journal.pone.0159481

Foley M.M., B.S. Halpern, F. Micheli, M.H. Armsby, M.R. Caldwell, C.M. Crain, E. Prahler, N. Rohr, D. Sivas, M.W. Beck, M.H. Carr, L.B. Crowder, J.E. Duffy, S.D. Hacker, K.L. McLeod, S.R. Palumbi, C.H. Peterson, H.M. Regan, M.H. Ruckelshaus, P.A. Sandifer and R.S.

Foley, M.M., M.H. Armsby, E.E. Prahler, M.R. Caldwell, A.L. Erickson, J.N. Kittinger, L.B. Crowder and P.S. Levin. 2013. Improving ocean management through the use of ecological principles and integrated ecosystem assessments. BioScience 63(8):619-631. doi: 10.1525/bio.2013.63.8.5

Frank, E.G. and W. Schlenker. 2016. Balancing economic and ecological goals. Science 353(6300):651-652.

Frazier M, C. Longo and B.S. Halpern. 2016. Mapping uncertainty due to missing data in the global Ocean Health Index. PLoS ONE 11(8): e0160377. doi:10.1371/journal.pone.0160377

Glew, L., G.N. Ahmadia, H.E. Fox, M.B. Mascia, P. Mohebalian, F. Pakiding, Estradivari, N.I. Hidayat, D. N. Pada, and Purwanto. 2015. State of the Bird's Head Seascape MPA Network Report, 2015. World Wildlife Fund, Conservation International, Rare, The Nature Conservancy, and Universitas Papua, Washington D.C., United States, Jakarta, Indonesia, and Manokwari, Indonesia. http://mpamystery.org/content/technical-reports/State Bird's Head Seascape MPA Network 2015 ENGLISH.pdf

Global Ocean Commission. 2014. From Decline to Recovery: A Rescue Package for the Global Ocean. Published online at June 24, 2014.

Global Ocean Commission. 2016. The Future of Our Ocean: Next steps and priorities.

Report 2016. http://www.some.ox.ac.uk/research/global-ocean-commission/.

Golden, C.D., W.H. Allison, W.W.L. Cheung, M.M. Dey, B.S. Halpern, D.J. McCaughley, M. Smith, B. Vaitla, D. Zeler and S.S. Myers. 2016. Fall in fish catch threatens human health. Nature 534:317-320. (16 June 2016).

Grabowski, J., R.D. Brumbaugh, R.F. Conrad, A.G. Keeler, J.J. Opaluch, C.H. Peterson, M.F. Piehler, S. P. Powers and A.R. Smyth.

2012. Economic valuation of ecosystem services provided by oyster reefs. BioScience 62: 900-909. 
Haines-Young, R. and M. Potschin. 2010. The links between biodiversity, ecosystem services and human wellbeing. Chap. 6 In: Raffaelli, D. and C. Frid (eds.): Ecosystem Ecology: a new synthesis. BES Ecological Reviews Series, CUP, Cambridge, UK. https://www.pik-potsdam.de/news/public-events/archiv/alter-net/formerss/2009/10.09.2009/10.9.-haines-young/literature/haines-young-potschin 2009 bes 2.pdf

Haine, T.W.N. 2016. Ocean science: vagaries of Atlantic overturning. Nature Geoscience 9: 479-480. doi:10.1038/ ngeo2748. Published online 20 June 2016.

Halpern, B.S., S. Walbridge, K.A. Selkoe et al. 2008. Global map of human impact on marine ecosystems. Science 319:948-952. 15 February 2008.

Halpern, B.S., S.E. Lester and K.L. McLeod. 2010. Placing marine protected areas onto the ecosystem-based management seascape. Proceedings of the National Academy of Sciences 107: 18312-18317.

Halpern, B.S., Longo, C., Hardy, D., McLeod, K.L., Samhouri, J.F., Katona, S.K., Kleisner, K., Lester, S.E., O'Leary, J., Ranelletti, M., Rosenberg, A.A., Scarborough, C., Selig, E.R., Best, B.D., Brumbaugh, D.R., Chapin, F.S., Crowder, L.B., Daly, K.L., Doney, S.C., Elfes, C., Fogarty, M.J., Gaines, S.D., Jacobsen, K.I., Karrer, L.B., Leslie, H.M., Neeley, E., Pauly, D., Polasky, S., Ris, B., St. Martin, K., Stone, G.S., Sumalia, U.R., Zeller, D. 2012. An index to assess the health and benefits of the global ocean. Nature 488: 615-620. DOI 10.1038/nature11397.

Halpern, B.S., C. Longo, C. Scarborough, D. Hardy, B. Best, S. C. Doney, S.K. Katona, K. L. McLeod, A.A. Rosenberg and J. F. Samhouri. 2014. Assessing the health of the U.S. west coast with a regional-scale application of the Ocean Health Index. PLoS ONE 9(6): e98995. doi:10.1371/journal.pone.0098995

Halpern, B.S., M. Frazier, J. Potapenko, K.S. Casey, K. Koenig, C. Longo, J.S. Lowndes, R.C. Rockwood, E.R. Selig, K.A. Selkoe and S. Walbridge.2015a. Spatial and temporal changes in cumulative human impacts on the world's ocean. Nature Communications 6:7615 doi: 10.1038/ncomms8615 (2015).

Halpern, B. S., C. Longo, J.S. Stewart Lowndes, B.D. Best, M. Frazier, S.K. Katona, K.M. Kleisner, A.A. Rosenberg, C. Scarborough and E.R. Selig. 2015b. Patterns and emerging trends in global ocean health. PLoS ONE 10(3): e0117863. doi:10.1371/journal.pone.0117863.

Halpern, B., M. Frazier, B. Best, C. Longo and J. Stewart Lowndes. 2016. Ocean Health Index for the world's large marine ecosystems. Chapter 7.8 In IOC-UNESCO and UNEP (2016). Large Marine Ecosystems: Status andTrends. United Nations Environment Programme, Nairobi, pp 239-249. Available at http://www.geftwap.org/ publications/lmes-technical-report/view

Hancock, J. 2010. The case for an ecosystem service approach to decision-making. BioHorizons 3(2). DOI.10.1093/ biohorizons/hzq013.

Hand, E. 2016. New scrutiny for a slowing Atlantic conveyer. Science 352(6287):751-752.

HCV Resource Network. 2013. Common Guidance for the Identification of High Conservation Values. https:// www.hcvnetwork.org/

Hearn, A., J. Ketchum, A.P. Klimley, E. Espinoza and C. Penaherrera. 2010. Hotspots within hotspots? Hammerhead shark movements around Wolf Island, Galapagos Marine Reserve. Marine Biology:157:1899-1915.

Hein, L., C.S.A. van Koppen, E.van Ierland and J. Leidekker. 2016. Temporal scales, ecosystem dynamics, stakeholders and the valuation of ecosystems services. Ecosystem Services 21:109 - 119. DOI: 10.1016/j.ecoser.2016.07.008 
HELCOM. 2010. Ecosystem Health of the Baltic Sea 2003-2007: HELCOM Initial Holistic Assessment. Balt. Sea Environ. Proc. No. 122.

Hicks, C.C., L.B Crowder, N.A.J. Graham, J.N. Kittinger and E. Le Cornu. Social drivers forewarn of marine regime shifts. Front Ecol Environ 2016; 14(5): 252-260, doi:10.1002/fee.1284

Hilborn, R. 2016. Marine biodiversity needs more than protection. Nature 535: 224-226. 14 July 20106.

Hobday, A.J., S. M. Maxwell, J. Forgie et al. 2014. Dynamic Ocean Management: Integrating Scientific and Technological Capacity with Law, Policy, and Management. Stanford Environmental Law Journal 33(2):125-165.

Huffard C.L., J. Wilson, C. Hitipeuw, C. Rotinsulu, S. Mangubhai, M.V. Erdmann, W. Adnyana, P. Barber, J. Manuputty, M. Mongdong, G. Purba, K. Rhodes and H. Toha (2012). Ecosystem based management in the Bird's Head Seascape Indonesia: turning science into action. BHS Ecosystem Based Management Program: Conservation International, The Nature Conservancy, and World Wide Fund for Nature Indonesia. Bali, Indonesia. 40 pp. https:// www.conservationgateway.org/Files/Pages/ecosystem-based-managemen.aspx

Huxley, T.H. 1883. Inaugural Address. Fisheries Exhibition. London. Available at http://aleph0.clarku.edu/huxley/ $\underline{\text { SM5/fish.html }}$

IOC-UNESCO and UNEP. 2016. Large Marine Ecosystems: Status and Trends, Summary for Policy Makers. United Nations Environment Programme (UNEP), Nairobi.

Katsanevakisa, S., V. Stelzenmüller, A. South et al. 2011. Ecosystem-based marine spatial management: Review of concepts, policies, tools, and critical issues. Ocean \& Coastal Management 54(11):807-820.

doi:10.1016/j.ocecoaman.2011.09.002

Kelble C.R., D.K. Loomis, S. Lovelace, W.K. Nuttle, P.B. Ortner, P. Fletcher et al. 2013. The EBM-DPSER conceptual model: integrating ecosystem services into the DPSIR framework. PLoS ONE 8(8): e70766. doi:10.1371/journal. pone.0070766

Kittinger, J. N., J. E. Cinner, S. Aswani and A. T. White. 2015. Back to the future: integrating customary practices and institutions into co-management of small-scale fisheries. Pp. 135-161 in: J. N. Kittinger, L. McClenachan, K. B. Gedan and L. K. Blight (eds.). Marine historical ecology in conservation: applying the past to manage for the future. University of California Press, Berkeley.

Knol, M. and S. Jentoft. 2016. Marine spatial planning: "it is better to be on the train than being hit by it." Pp. $143-$ 146 in: Flannery et al. (2016) op. cit.

Koehn, J.Z., D.R. Reineman and J.N. Kittinger. 2013. Progress and promise in spatial human dimensions research for ecosystem-based ocean planning. Marine Policy 42 (2013) 31-38. https://www.researchgate.net/ publication/257163075 Progress and promise in spatial human dimensions research for ecosystem-based ocean planning

Kusek, J.Z. and R. C. Rist. 2004. Ten Steps to a Results-Based Monitoring and Evaluation System. A Handbook for Development Practitioners. The World Bank. Washington, D.C.

Laffoley, D.d'A. and G. Grimsditch (eds). 2009. The management of natural coastal carbon sinks. IUCN, Gland, Switzerland. $53 \mathrm{pp}$ 
Lynham, J., C. Costello, S.D. Gaines and E. Sala. 2015. Economic valuation of marine and shark-based tourisms in the Galápagos Islands. National Geographic Pristine Seas; Washington, D.C.

Levin, P.S., M.J. Fogarty, G.C. Matlock and M. Ernst. 2008. Integrated Ecosystem Assessments. NOAA Technical Memorandum NMFS-NWFSC-92. U.S. Department of Commerce, NOAA/NMFS. 20 pp. June 2008. http://www. nwfsc.noaa.gov/assets/25/796 07302008144647 IEA TM92Final.pdf

Levin P.S., M.J. Fogarty, S.A. Murawski and D. Fluharty. 2009. Integrated ecosystem assessments: Developing the scientific basis for ecosystem-based management of the ocean. PLoS Biol 7(1): e1000014. doi:10.1371/journal. pbio. 1000014 http://www.unep.org/ieacp/ res/site/file/pdf/Integrated\%20Ecosystem\%20Assessment Oceans.pdf

Levin, P. S., C.R. Kelble, R. Shuford, C. Ainsworth, Y. deReynier, R. Dunsmore, M.J. Fogarty, K. Holsman, E. Howell, M. Monaco, S. Oakes and F. Werner. 2014. Guidance for implementation of integrated ecosystem assessments: a US perspective. - ICES Journal of Marine Science, 71:1198-1204. http://icesjms.oxfordjournals. org/content/71/5/1198.full.pdf

Link, J. S. and H.I. Browman. 2017. Operationalizing and implementing ecosystem-based management. ICES Journal of Marine Science, doi:10.1093/icesjms/fsw247.

Long, R.D., A. Charles and R.L Stephenson. 2015. Key principles of marine ecosystem-based management. Marine Policy 57: 53-60.

Looa, Y.Y. L. Billab and A. Singha. 2015. Effect of climate change on seasonal monsoon in Asia and its impact on the variability of monsoon rainfall in Southeast Asia. Goscience Frontiers: 6:817-823. http://www.sciencedirect. com/science/article/pii/S167498711400036X

Lowndes J.S.S, E.J. Pacheco, B.D. Best, C. Scarborough, C. Longo, S.K. Katona and B.S. Halpern. 2015. Best practices for assessing ocean health in multiple contexts using tailorable frameworks. PeerJ 3:e1503 https://doi. org/10.7717/peerj.1503

Lu, Y. 2016. Rate oceans' capital to help achieve SDGs. Nature 537, 1 September 2016, p.14.

Maclean , K. , M. Cuthill and H. Ross. 2013. Six attributes of social resilience. Journal of Environmental Planning and Management. DOI:10.1080/09640568.2013.763774. http://dx.doi.org/10.1080/09640568.2013.763774

Marre, J-B., O. Thebaud, S. Pascoe, S. Jennings, J. Boncoeur and L. Coglan. 2106. Is economic valuation of ecosystem services useful to decision-makers? Lessons learned from Australian coastal and marine management. Journal of Environmental Management 178:52 - 62. DOI: 10.1016/j.jenvman.2016.04.014

McLeod, K.L. and H. Leslie (eds.). 2009. Ecosystem-Based Management for the Oceans. Island Press, Washington. $392 \mathrm{pp}$.

McLeod, K. L., J. Lubchenco, S. R. Palumbi, and A. A. Rosenberg. 2005. Scientific Consensus Statement on Marine Ecosystem-Based Management. Signed by 221 academic scientists and policy experts with relevant expertise and published by the Communication Partnership for Science and the Sea at http://compassonline.org/?q=EBM.

MEA.2005. Millenium Ecosystem Assessment. 2005. Ecosystems and Human Well-being: A Framework for Assessment. Island Press. Online at http://www.unep.org/maweb/documents/document.300.aspx.pdf

Miloslavich, P., E. Klein, J.M. Díaz et al. 2011. Marine biodiversity in the Atlantic and pacific coasts of South America: knowledge and gaps. PLOS,January 31, 2011. http://journals.plos.org/plosone/article?id=10.1371/ journal.pone.0014631 
National Ocean Council. 2013. Marine Planning Handbook. Washington. July, 2013. https://www.whitehouse.gov/ sites/default/files/microsites/ostp/guidance for marine plans final 151001.pdf

Nellemann, C., E. Corcoran, C.M. Duarte, L. Valdés, C. De Young, L. Fonseca and G. Grimsditch (eds). 2009. Blue Carbon. A Rapid Response Assessment. United Nations Environment Programme, GRID-Arendal. http://www. grida.no/files/publications/blue-carbon/BlueCarbon screen.pdf.

Nilsson, M., D. Griggs and M. Visbeck. 2016. Map the interactions between Sustainable Development Goals. Nature 534:320-322 (16 June 2016).

NSTC. 2015. Ecosystem-Service Assessment: research needs for coastal green infrastructure. National Science and Technology Council. Washington, D.C. https://www.whitehouse.gov/sites/default/files/microsites/ostp/cgies research agenda final 082515.pdf

Oceana, Skytruth, Google, 2016. Global Fishing Watch. http://globalfishingwatch.org/

OECD. 2006. Applying Strategic Environmental Assessment. Good Practice Guidance for Development CoOperation. DAC Guidelines and Reference Series. Organisation For Economic Co-Operation And Development. Paris. 160 pp.

http://www.oecd.org/environment/environment-development/37353858.pdf

Österblom, H., A. Merrie, M. Metian, W. J. Boonstra, T. Blenckner, J.R. Watson, R.R. Rykaczewski, Y. Ota, J.L. Sarmiento, V. Christensen, M.Schlüter, S. Birnbaum, B.G. Gustafsson, C. Humborg, C.-M. Mörth, B. MüllerKarulis, M.T. Tomczak, M. Troell and C. Folke. 2013. Modeling social-ecological scenarios in marine systems. BioScience 63(9):735-744.

Papacostas, K.J. and G. Farmer. Decision support tools for integrated “whole domain” management. In preparation.

Patricio, J., M. Elliott, K. Mazik, K-N Papadopoulou and C.J. Smith. 2016. DPSIR—Two Decades of Trying to Develop a Unifying Framework for Marine Environmental Management? Frontiers in Marine Science 3. Article 177. Doi:10.3389/fmars.2016.00177.

Pauli, G. 2010. The Blue Economy: 10 years - 100 innovations - 100 million jobs. Paradigm Press. 336 pp. http:// www.theblueeconomy.org/

Pimm, S.L., C.N. Jenkins, R. Abell, T.M. Brooks, J.L. Gittleman, L.N. Joppa, P.H. Raven, P.H., C.M. Roberts and J.O. Sexton. 2014. The biodiversity of species and their rates of extinction, distribution, and protection. Science 344(6187), 30 May 2014. DOI: 10.1126/science.1246752

Pomeroy, R., R. Brainard, M. Moews, A. Heenan, J. Shackeroff, and N. Armada. 2013. Coral Triangle Regional Ecosystem Approach to Fisheries Management (EAFM) Guidelines. Publication. Honolulu, Hawaii: The USAID Coral Triangle Support Partnership.

Qiu, W. and P.J.S. Jones. 2013. The emerging policy landscape for marine spatial planning in Europe. Marine Policy 39 (2013) 182-190. http://dx.doi.org/10.1016/j.marpol.2012.10.010

Report of the Coast and Deep Sea Fisheries of Ireland. 1870. Dublin. Available here.

Robbins, K. (ed.). 2013. The Laws of Nature: reflections on the evolution of ecosystem management law and policy. University of Akron Press. 
Rocliffe S, Peabody S, Samoilys M, Hawkins JP (2014) Towards A Network of Locally Managed Marine Areas (LMMAs) in the Western Indian Ocean. PLoS ONE 9(7): e103000. doi:10.1371/journal.pone.0103000. http:// journals.plos.org/plosone/article?id=10.1371/journal.pone.0103000

Rosenberg A.A. and K.L. McLeod . 2005. Implementing ecosystem-based approaches to management for the conservation of ecosystem services. Mar Ecol Prog Ser 300:270-274.

Rude, J., A. Minks, B. Doheny, M. Tyner, K. Maher, C. Huffard, N.I. Hidayat and H. Grantham. 2016. Ridge to reef modelling for use within land-sea planning under data-limited conditions. Aquat. Conserv. Mar. Freshw. Ecosyst. 26, 251-264. doi:10.1002/aqc. 2548

Sagebiel, J., C. Schwartz, M. Rhozyel et al. 2016. Economic valuation of Baltic marine ecosystem services: blind spots and limited consistency. ICES Journal of Marine Science 73(4): 991 - 1003. DOI: 10.1093/icesjms/fsv264. http://icesjms.oxfordjournals.org/content/73/4/991.abstract?etoc

Salinas de León, P., D. Acuña-Marrero, E. Rastoin, A. M. Friedlander, M.K. Donovan and E. Sala. 2016. Largest global shark biomass found in the northern Galápagos Islands of Darwin and Wolf PeerJ 4:e1911 https://doi. org/10.7717/peerj.1911.

Schemmel, E., A.M. Friedlander, P. Andrade, L. Castro, K. Keakealani, C. Wiggins, B. Wilcox, Y. Yasutake and J. Kittinger. 2016. The co-development of reef fisheries monitoring methods to support local management. Ecology \& Society.

Schuster, E. and P. Doerr. 2015. A Guide for Incorporating Ecosystem Service Valuation into Coastal Restoration Projects. The Nature Conservancy, New Jersey Chapter. Delmont, NJ. http://www.nature.org/media/ oceansandcoasts/ecosystem-service-valuation-coastal-restoration.pdf

Secretariat of the Convention on Biological Diversity. 2015. Tourism supporting Biodiversity - A Manual on applying the CBD Guidelines on Biodiversity and Tourism Development. Montreal, 56 pp. https://www.cbd.int/ tourism/doc/tourism-manual-2015-en.pdf

Selig, E.R.. M. Frazier, J.K. O'Leary, S.D. Jupiter, B.S. Halpern, C. Longo, K.L. Kleisner, L. Sivo, and M. Ranelletti. 2015. Measuring indicators of ocean health for an island nation: the Ocean Health Index for Fiji. Ecosystem Services 16: 403-412. December 2015.

Sherman, K., M. Sissenwine, V. Christensen, A. Duda, G. Hempel, C. Ibe, S. Levin, D. Lluch-Belda, G. Matishov, M. O’Toole, S. Seitzinger, R. Serra, H.R. Skjoldal, Q. Tank, J. Thulin, V. Vandeweerd and K. Zwanenburg. 2005. A global movement toward an ecosystem approach to management of marine resources. Marine Ecology Progress Series 300:275-279.

Sirak, R.G., A. Newton and J.D. Icelyc. 2014. A review of the application and evolution of the DPSIR framework with an emphasis on coastal social-ecological systems. doi:10.1016/j.ocecoaman.2014.11.013

Spalding, M.D., H.E. Fox , G.R. Allen, N. Davidson, Z.A. Ferdaña, M. Finlayson, B.S. Halpern, M.A. Jorge, A. Lombana, S.A. Lourie, K.D. Martin, E. McManus, J. Molnar, C.A. Recchia and J. Robertson. 2007. Marine Ecoregions of the World: a bioregionalization of coast and shelf areas. BioScience 57: 573-583.

Staub, F. and M.E. Hatziolos. 2004. Score card to assess progress in achieving management effectiveness goals for marine protected areas. Prepared for the World Bank. Revised version, July 2004. http://francisstaub.com/MPA/ $\underline{\text { sc2 eng nocover.pdf }}$ 
Steneck. 2010. Guiding ecological principles for marine spatial planning. Marine Policy 34: 955-966. http://cmap. msi.ucsb.edu/publications/foley etal 2010 marpol

Tallis H., P.S. Levin, M. Ruckelshaus, S.E. Lester, K.L. McLeod, D.L. Fluharty and B.S. Halpern. 2010. The many faces of ecosystem-based management: making the process work today in real places. Mar Policy 34:340-348.

TEEB. 2010. The economics of ecosystems and biodiversity: mainstreaming the economics of nature: a synthesis of the approach, conclusions and recommendations of TEEB. The economics of ecosystems and biodiversity. Authored by Sukhdev, P., H. Wittmer, C. Schröter-Schlaack, C. Nesshöver, J. Bishop, P. ten Brink, H. Gundimeda, P. Kumar and B. Simmons. http://doc.teebweb.org/wp-content/uploads/Study\%20and\%20Reports/Reports/ Synthesis\%20report/TEEB\%20Synthesis\%20Report\%202010.pdf

Teh, L.C.L., L.S.L. Teh and T.J. Pitcher, T.J. 2012. A tool for site prioritisation of marine protected areas under data poor conditions. Mar. Policy 36, 1290-1300. doi:10.1016/j.marpol.2012.04.010

TNC. 2016. Mapping Ocean Wealth [WWW Document]. The Nature Conservancy. http://oceanwealth.org/ (accessed 1.23.2017).

Tsemel, A., A. Scheinin and Y. Suari. 2014. D grade for the Mediterranean-applying the ocean health index to Israel. Ecology \& Environment 5:218-222 (in Hebrew).

UN 1967. Treaty on Principles Governing the Activities of States in the Exploration and Use of Outer Space, Including the Moon and Other Celestial Bodies. 1967. Article IX, U.N. Doc. A/RES/2222/(XXI) 25 Jan 1967, TIAS No. 6347. United Nations, New York.

UN. 2012. Blue Economy Concept Paper. United Nations, Division for Sustainable Development. https:// sustainabledevelopment.un.org/content/documents/2978BEconcept.pdf

UNDP. 2000. World Energy Assessment: Energy and the challenge of sustainability. United Nations Development Programme, UN Department of Economic and Social Affairs (UNDESA) and World Economic Council. http:// www.undp.org/content/undp/en/home/librarypage/environment-energy/sustainable energy/world energy assessmentenergyandthechallengeofsustainability.html

UNEP. 2014a. Assessing Global Land Use: Balancing Consumption with Sustainable Supply. A Report of the Working Group on Land and Soils of the International Resource Panel. Bringezu, S. H. Schütz, W. Pengue, M. O 'Brien, F. Garcia, R. Sims, R. Howarth, L. Kauppi, M. Swilling and J. Herrick. http://www.unep.org/resourcepanelold/Portals/24102/PDFs//Full Report-Assessing Global Land UseEnglish (PDF).pdf

UNEP (2014b). The Importance of Mangroves to People: A Call to Action. J. van Bochove, E. Sullivan and T. Nakamura (Eds). United Nations Environment Programme World Conservation Monitoring Centre, Cambridge. 128 pp. http://www.unep-wcmc.org/resources-and-data/the-importance-of-mangroves-to-people--a-call-to$\underline{\text { action }}$

UNEP and IOC-UNESCO. 2009. An Assessment of Assessments, Findings of the Group of Experts. Start-up Phase of a Regular Process for Global Reporting and Assessment of the State of the Marine Environment including Socio-economic Aspects. ISBN 978-92-807-2976-4

UNESCO. 2016. World Heritage Sites in the High Seas: An Idea Whose Time Has Come. United Nations Educational, Scientific and Cultural Organization, Paris. http://unesdoc.unesco.org/images/0024/002454/245467e.pdf 
UNWOA. 2015. The First Global Integrated Marine Assessment (World Ocean Assessment 1). A Regular Process for Global Reporting and Assessment of the State of the Marine Environment, including Socio-economic Aspects. L. Inniss and A. Simcock (Joint Coordinators) and A.Y. Ajawin, A. C. Alcala, P. Bernal, H. P. Calumpong, P.E. Araghi, S.O. Green, P. Harris, O.K. Kamara, K. Kohata, E. Marschoff, G. Martin, B. P. Ferreira, C. Park, R.A. Payet, J. Rice, A. Rosenberg, R. Ruwa, J. T. Tuhumwire, S. Van Gaever, J. Wang and J.M. Węsławski. UN General Assembly. http://www.un.org/Depts/los/global reporting/WOA RegProcess.htm

USAID. 2013. Ecosystem Approach to Fisheries Management (EAFM) Guidelines. USAID Coral Triangle Support Partnership. Honolulu, Hawaii. http://docs.lib.noaa.gov/noaa documents/CoRIS/EAFM Guidelines.pdf

van den Belt, M., E. Granek, F. Gaill, B. Halpern, M. Thorndyke, P. Bernal. 2016. Assessment of Major Ecosystem Services from the Marine Environment (Other than Provisioning Services). UN World Ocean Assessment. Part III. Pp. 1-37. http://www.un.org/depts/los/global reporting/WOA RPROC/Chapter 03.pdf

Veron, J.E.N., L.M. Devantier, E. Turak, A.L. Green, S. Kininmonth, M. Stafford-Smith and N. Peterson. 2009. Delineating the Coral Triangle. Galaxea, Journal of Coral Reef Studies. 11: 91-100.

Villa, F., K.J. Bagstad, B. Voigt, G.W. Johnson, R. Portela, M. Honzák and D. Batker. 2014. A methodology for adaptable and robust ecosystem services assessment. PLoS ONE 9(3): e91001. doi:10.1371/journal.pone.0091001

Voosen, P. 2016. Anthropocene pinned to postwar period. Science 353(6302)852-853. 26 August 2016.

Ward, B. and R. J. Dubos. 1972. Only One Earth: The Care and Maintenance of a Small Planet. Norton, 1972225 pages

WAVES Partnership. 2016. Wealth accounting and the valuation of ecosystem services. https://www. wavespartnership.org/en.

Westlund, L., A. Charles, S. Garcia and J. Sanders (eds). 2017. Marine protected areas: Interactions with fishery livelihoods and food security. FAO Fisheries and Aquaculture Technical Paper No. 603. Rome, FAO. 158 pp.

White, C., B.S. Halpern and C. V. Kappel. 2012. Ecosystem service tradeoff analysis reveals the value of marine spatial planning for multiple ocean uses. Proceedings of the National Academy of Sciences 109: 4696-4701. http:// www.ncbi.nlm.nih.gov/pmc/articles/PMC3311352/pdf/pnas.201114215.pdf

Williams, M., J. Zalasiewicz, C. N. Waters, M. Edgeworth, C. Bennett, A.D. Barnosky, E. C. Ellis, M. 1. A. Ellis, A. Cearreta, P.K. Haff, J. A. I. do Sul, R. Leinfelder, J. R. McNeill, E. Odada, N. Oreskes, A. Revkin, D. deB Richter, W. Steffen, C. Summerhayes, J.P. Syvitski, D. Vidas, M. Wagreich, S.L. Wing, A.P. Wolfe and A. Zhisheng. 2016. The Anthropocene: a conspicuous stratigraphical signal of anthropogenic changes in production and consumption across the biosphere. Earth's Future. DOI 10.1002/2015EF000339 http://onlinelibrary.wiley.com/ doi/10.1002/2015EF000339/full

Willis, A.J. 1997. The ecosystem: an evolving concept viewed historically. Functional Ecology 11:268-271. http:// fiferrer.webs.ull.es/Bibliog/Biblio/EecosystemConcept.pdf

World Ocean Review. 2015. Sustainable Use of Our Oceans - Making Ideas Work. N. Gelpke and M. Visbeck, eds. World Ocean Review 4. http://worldoceanreview.com/wp-content/downloads/wor4/WOR4 en.pdf

Zalasiewicz, J., M. Williams, W. Steffen, and P. Crutzen. 2010. The new world of the Anthropocene. Environ. Sci. Technol. 44 (7): 2228-2231. Available online at http://pubs.acs.org/doi/pdfplus/10.1021/es903118j. 